\title{
Bisphenol A alters the function and expression of BK channels in vascular smooth muscle through membrane and nuclear signals
}

Shinichi Asano

West Virginia University

Follow this and additional works at: https://researchrepository.wvu.edu/etd

\section{Recommended Citation}

Asano, Shinichi, "Bisphenol A alters the function and expression of BK channels in vascular smooth muscle through membrane and nuclear signals" (2012). Graduate Theses, Dissertations, and Problem Reports. 3580.

https://researchrepository.wvu.edu/etd/3580

This Dissertation is protected by copyright and/or related rights. It has been brought to you by the The Research Repository @ WVU with permission from the rights-holder(s). You are free to use this Dissertation in any way that is permitted by the copyright and related rights legislation that applies to your use. For other uses you must obtain permission from the rights-holder(s) directly, unless additional rights are indicated by a Creative Commons license in the record and/ or on the work itself. This Dissertation has been accepted for inclusion in WVU Graduate Theses, Dissertations, and Problem Reports collection by an authorized administrator of The Research Repository @ WVU.

For more information, please contact researchrepository@mail.wvu.edu. 


\title{
Bisphenol A alters the function and expression of BK channels in vascular smooth muscle through membrane and nuclear signals
}

\author{
By Shinichi Asano
}

A thesis submitted to the

School of Medicine at West Virginia University in partial fulfillment of the requirements for the degree of

Doctor of Philosophy

In Exercise Physiology

Committee:

Gregory M. Dick, Ph.D., Chair
Stephen E. Alway, Ph.D.
John M. Hollander, Ph.D.
Han-Gang Yu, Ph.D.
I Mark Olfert, Ph. D.

Division of Exercise Physiology
Morgantown, West Virginia 2012

Keywords: endocrine disruptor, large conductance $\mathrm{Ca}^{2+} /$ voltage-sensitive potassium channel, penitrem $A$, cardiovascular disease 


\section{ABSTRACT}

Bisphenol A (BPA) exposure has recently become a public health concern, and the safety of the utilization of BPA has attracted the attention of the scientific community, politicians, and the general population. Although BPA is banned from baby products in a few countries because infants and young children are particularly susceptible to endocrine disruption, recent studies have consistently indicated the association between urinary BPA concentration and cardiovascular diseases in adults. Therefore, adult exposure to this xenoestrogen is becoming a healthcare issue that cannot be ignored. We selected large conductance $\mathrm{Ca}^{2+} /$ voltage sensitive potassium (BK) channels as one of the target proteins for BPA effects because the function and expression of BK channels are regulated by estrogen. Additionally, BK channels play an important role in vascular function and changes in BK expression are associated with disease. We hypothesized that BPA would differently affect BK channel function and expression via separate non-genomic and genomic mechanisms. The goals of our studies were 1) to characterize a novel, membrane-permeable, and economical antagonist called penitrem A to facilitate the study of BK channels, 2) to determine the mechanisms by which BPA increases BK channel activity and, 3) to determine the mechanisms by which BPA reduces vascular BK channel expression.

Current from patches of HEK 293 cells transfected with $h$ Slo $\alpha$ or $\alpha+\beta 1$ were blocked $>95 \%$ by penitrem A $\left(\mathrm{IC}_{50} 6.4\right.$ vs. $\left.64.4 \mathrm{nM} ; p<0.05\right)$. Further, penitrem A inhibited BK channels in inside-out and cell-attached patches, 
whereas iberiotoxin could not. Inhibitory effects of penitrem A on whole-cell $\mathrm{K}^{+}$ currents were equivalent to iberiotoxin in canine coronary smooth muscle cells. Penitrem $\mathrm{A}$ enhanced sensitivity to $\mathrm{K}^{+}$-induced contraction in canine coronary arteries by $23 \pm 5 \%(p<0.05)$ and increased the blood pressure response to phenylephrine in anesthetized mice by $36 \pm 11 \%(p<0.05)$.

In cultured canine coronary artery smooth muscle cells (CASMC), acute BPA $(10 \mu \mathrm{M})$ exposure increased BK channel currents $179 \pm 8 \%(p<0.05)$. Inside out recordings from native canine CASMCs showed that acute BPA increased BK channel open probability $\left(P_{\circ}\right)$ from $0.11 \pm 0.03$ to $0.47 \pm 0.09$ at $+40 \mathrm{mV}(p<0.05)$. HEK cells transfected with BK $\alpha$ subunits alone were insensitive to acute BPA (currents at $+100 \mathrm{mV}$ were $101 \pm 13 \%$ of control) while acute BPA increased BK channel currents by $53 \pm 12 \%(p<0.05)$ when cells were transfected with $\alpha$ and $\beta 1$ subunits. Similarly, single channel recordings indicated $N P_{\text {o }}$ was $123 \pm 20 \%$ of control in the BK a subunits alone with BPA, however, acute BPA increased NPo $201 \pm 41 \%$ in patches from cells expressing BK $\alpha$ and $\beta 1$ subunits. Thus, BK $\beta 1$ subunits facilitated BPA-induced BK channel activation and the effects of BPA were non-genomic, as these effects were observed in cell-free patches.

In contrast to the acute effects of BPA on BK channel activity, 48-72 hrs of BPA $(10 \mu \mathrm{M})$ exposure decreased BK channel expression in A7r5 cells and cultured rat aorta. Western blot data indicated that BK $\alpha$ subunit protein content was $33 \pm 8 \%$ of control in BPA-treated aorta $(p<0.05)$. Patch clamp recording showed that whole cell current densities at $+100 \mathrm{mV}$ were $57 \pm 7 \%$ lower in aortic 
SMC treated with $10 \mu \mathrm{M}$ BPA $(p<0.05)$ while whole cell current densities from aortic SMC treated with BPA + ICI $182780(100 \mathrm{nM}$; an estrogen receptor blocker) were not different (101 $\pm 14 \%$ of control). Penitrem A-sensitive current densities at $100 \mathrm{mV}$ were $53.9 \pm 14.8,12.0 \pm 3.0$, and $48.4 \pm 10.1 \mathrm{pA} / \mathrm{pF}$ in DMSO, BPA and BPA $+I C I 182780$, respectively $(p<0.05)$. Thus, chronic BPA exposure decreased BK channel expression by estrogen receptor mediated signaling.

Our data indicate: 1) penitrem $A$ is an economical alternative to iberiotoxin for BK channel analysis; 2) acute BPA exposure activates BK channel activity and BK $\beta 1$ subunits play a role in BPA induced BK channel activation; 3) chronic BPA exposure decreases vascular BK channel expression via estrogen receptordependent mechanisms. Although acute BPA exposure activates the BK channel through a non-genomic mechanism that could be beneficial for heart due to coronary dilation, longer BPA exposure decreases the number of functional BK channels through a genomic mechanism that could be detrimental to the heart. Thus, the overall effect of BPA exposure on vascular function may be harmful due to disruption of BK channel-mediated vascular regulation. Taken together, these results indicated BPA induced altered BK channel function and expression may be one of the mechanisms for the association between BPA exposure levels and cardiovascular diseases seen in epidemiological studies. 


\section{TABLE OF CONTENTS}

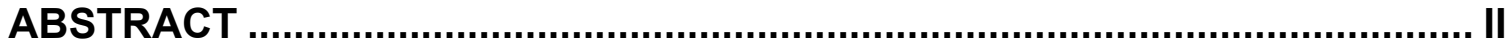

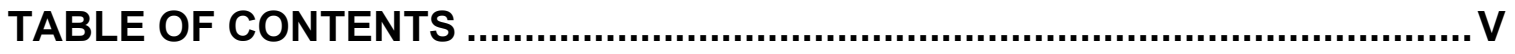

LIST OF TABLES ........................................................................................

LIST OF FIGURES …................................................................................. VII

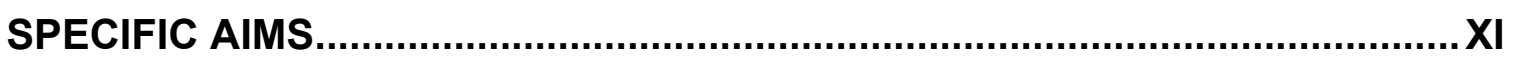

REFERENCES

CHAPTER 1 BACKGROUND AND SIGNIFICANCE ..................................... 1

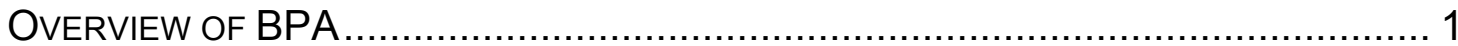

BPA exposure and health concerns ..................................................... 1

Toxicodynamics / toxicokinetics of BPA ….......................................... 3

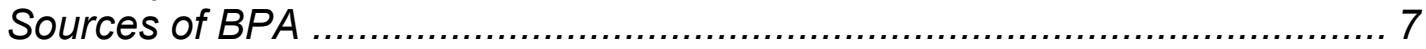

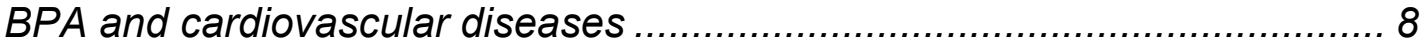

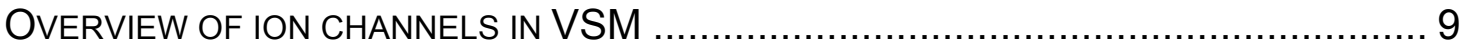

Ion channel and toxicological compounds .............................................. 9

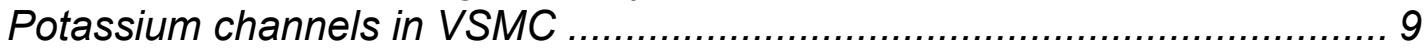

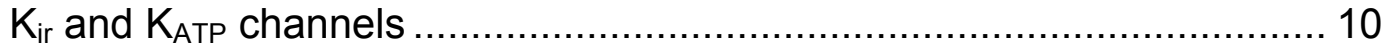

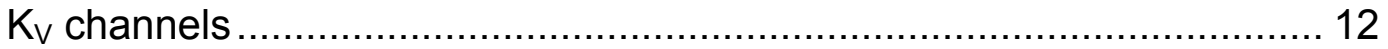

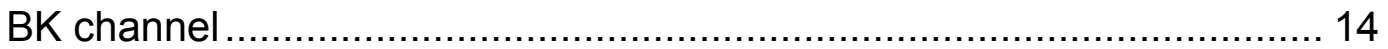

BK CHANNEL AND VASCULAR PATHOLOGIES ................................................ 20

Aging, hypertensive and diabetic vascular BK channels ......................... 20

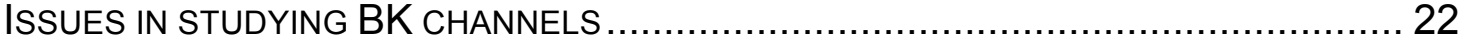

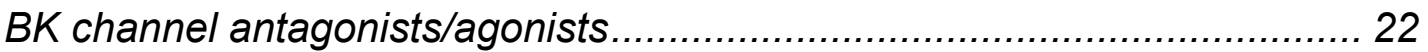

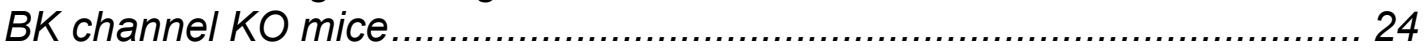

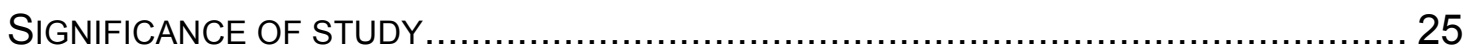

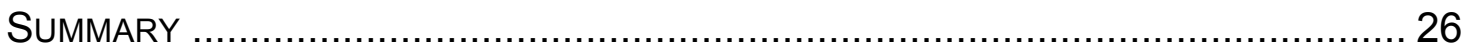

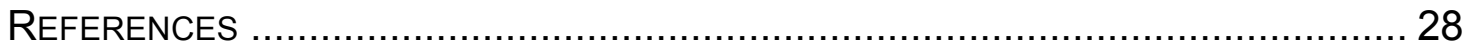

CHAPTER 2 PENITREM A AS A TOOL TO UNDERSTAND THE ROLE OF BK

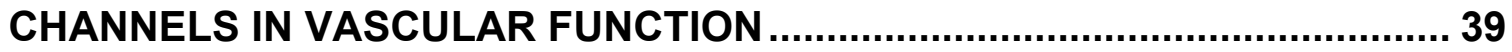

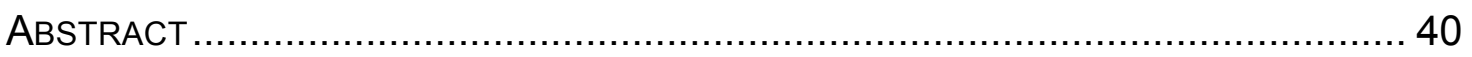

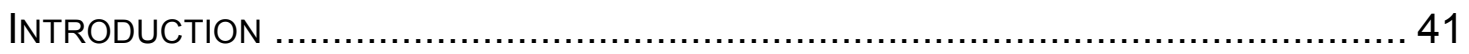

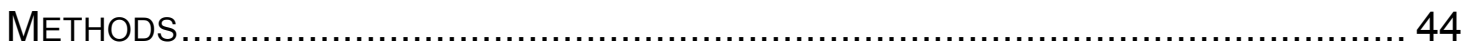

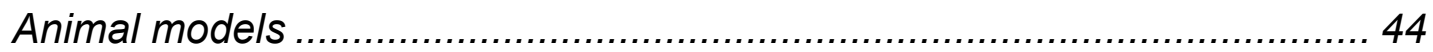

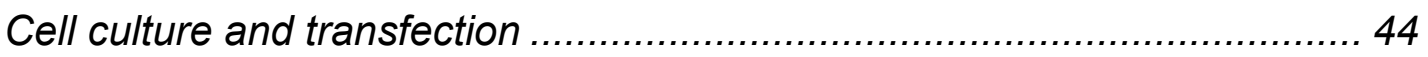

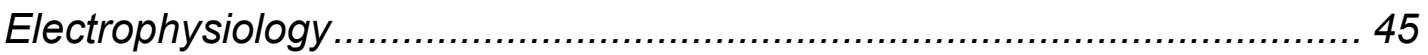

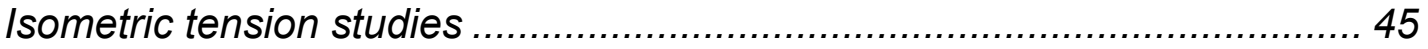

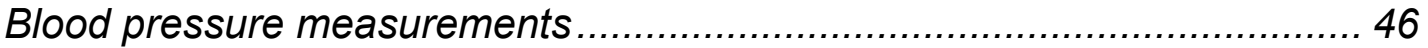

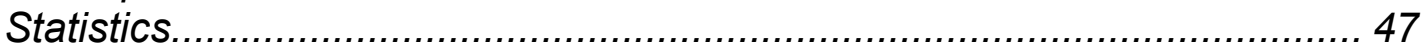

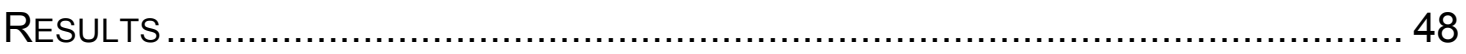

Penitrem A inhibits BK channels in a concentration-dependent manner:

influence of the $\beta 1$ subunit............................................................. 48

Penitrem A, but not iberiotoxin, inhibits BK channels in inside-out patches. 49 
Specificity of penitrem A: block of BK, but not $K_{V}$ or $K_{A T P}$ channels. .......... 50

Penitrem A augments smooth muscle contractility in vitro and in vivo. ....... 51

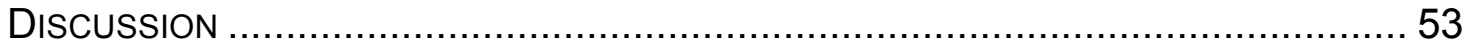

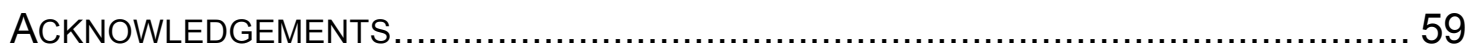

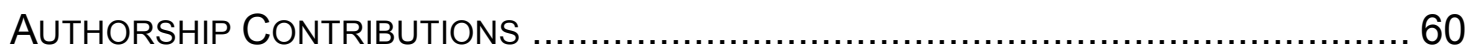

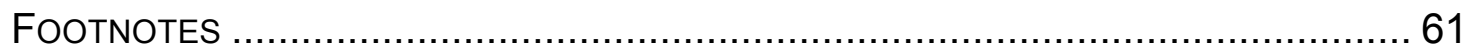

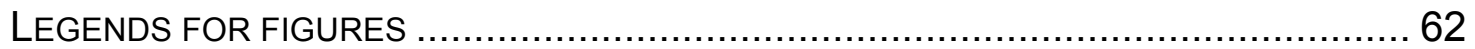

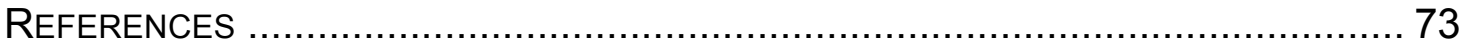

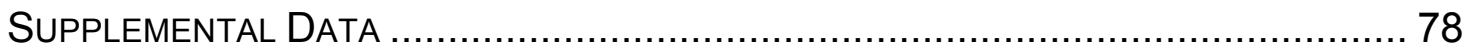

CHAPTER 3 BISPHENOL A ACTIVATES MAXI-K CHANNELS IN CORONARY

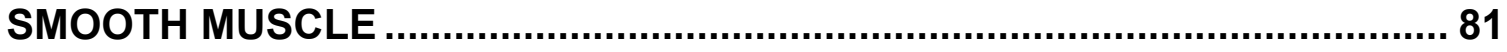

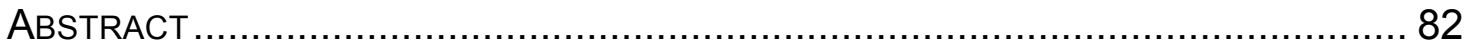

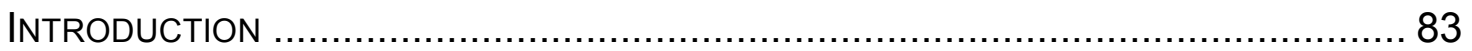

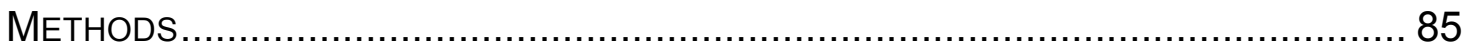

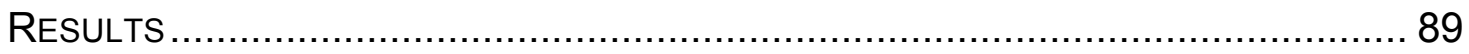

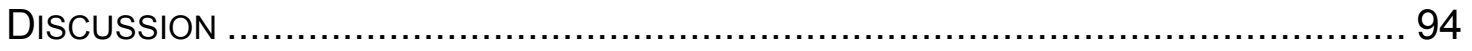

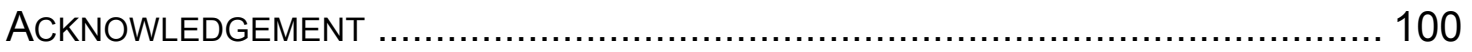

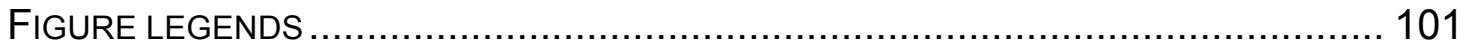

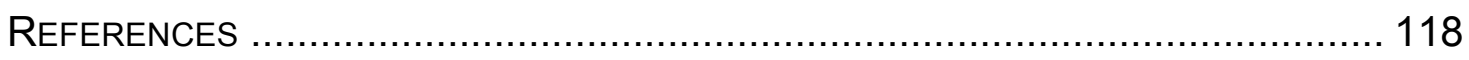

CHAPTER 4 BISPHENOL A DECREASES BK CHANNEL EXPRESSION IN RAT AORTIC SMOOTH MUSCLE VIA ESTROGEN RECEPTOR MEDIATED

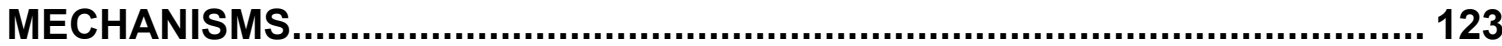

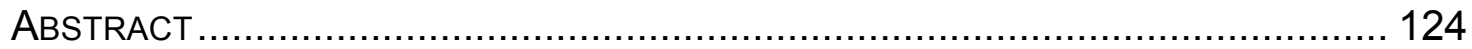

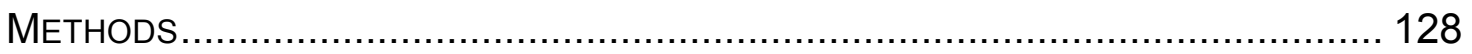

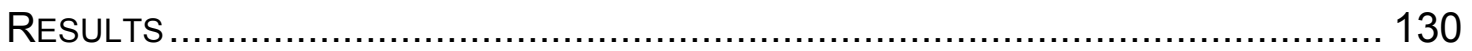

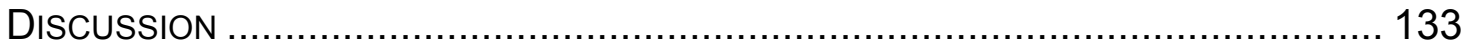

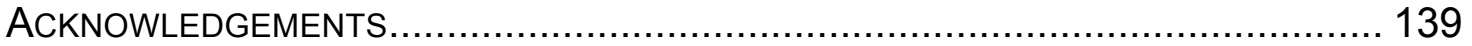

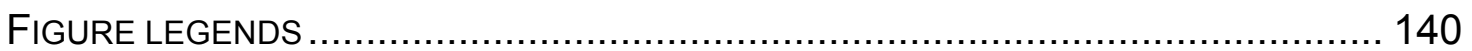

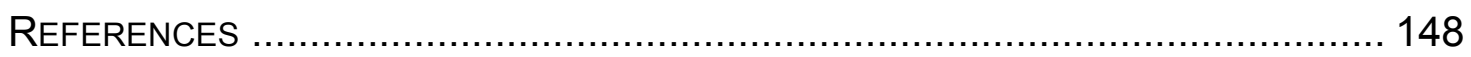

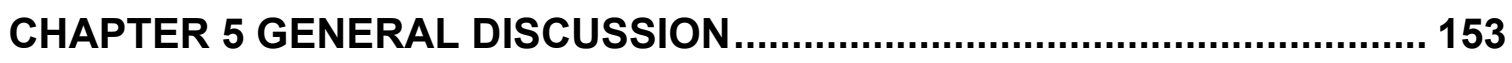

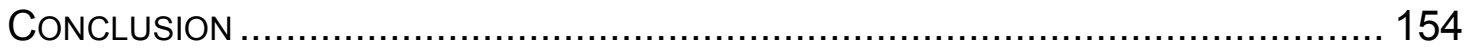

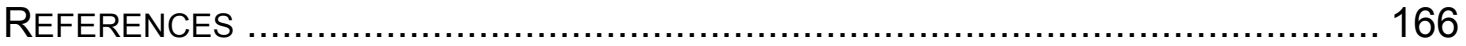




\section{LIST OF TABLES}

Table 21 Characteristics of BK channel blockers .......................................... 77

Table $31 \beta 1$ subunit determines the response of Maxi-K channels to $10 \mu \mathrm{M}$ BPA 105

Table 41 Primers used for the RT-PCR analysis 142

Table 51 Studies measured urinary BPA 163 


\section{LIST OF FIGURES}

Figure 11 Chemical structures of E2 and xenoestrogens and related

compounds.

Figure 12 Chemical reactions to release BPA from polycarbonate products...... 6

Figure 13 Molecular structure of BK channel $\alpha$ subunit and $\beta 1$ subunit. .......... 17

Figure 14 Dual regulation by $\mathrm{Ca}^{2+}$ and voltage on $\mathrm{BK}$ activity....................... 18

Figure 15 The function of BK channel in vascular smooth muscle cells........... 19

Figure 21 Presence of the $\beta 1$ subunit decreases the sensitivity of BK channels to

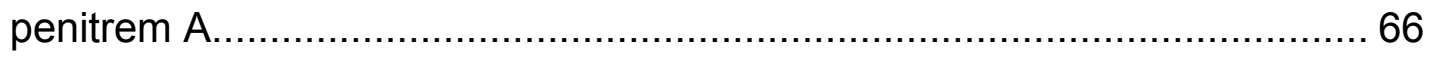

Figure 22 Irreversible block of BK channels by penitrem A ........................... 67

Figure 23 Penitrem A blocks BK channels in inside-out and cell-attached

patches

Figure 24 Iberiotoxin and penitrem A block the same current in canine coronary smooth muscle cells. 69

Figure 25 Penitrem $\mathrm{A}$ has no effect on $\mathrm{K}_{\mathrm{V}} 1.5$ or $\mathrm{K}_{\mathrm{ATP}}$ channels. 70

Figure 26 Penitrem A selectively inhibits BK channel to alter vascular contraction from in vitro vascular functional experiments. 71

Figure 27 Block of BK channels by penitrem A augments phenylephrine-induced blood pressure responses in mice

Figure 28 Supplemental Figure1 Penitrem $\mathrm{A}$ on $\mathrm{K}^{+}$currents in a variety of vascular smooth muscle cells 79 
Figure 29 Supplemental Figure2 Penitrem $\mathrm{A}$ on $\mathrm{K}^{+}$currents in a variety of vascular smooth muscle cells 80

Figure 31 BPA increases Maxi-K current in smooth muscle cells cultured from the canine coronary artery. 106

Figure 32 BPA increases Maxi-K channel $\mathrm{NP}_{\mathrm{o}}$ in smooth muscle cells freshly isolated from the canine coronary artery 107

Figure 33 Maxi-K $\beta 1$ subunit confers sensitivity to $10 \mu \mathrm{M}$ BPA. 108

Figure 34 BPA $(10 \mu \mathrm{M})$ increases $\mathrm{NP}_{\circ}$ of Maxi-K channels containing the $\beta 1$ subunit 109

Figure 35 The activation of Maxi-K channels by BPA is concentration-dependent and reversible. 110

Figure $36 \mathrm{BPA}$, at a concentration of $100 \mu \mathrm{M}$, increases Maxi-K current in human coronary artery smooth muscle cells 111

Figure 37 Supplemental Figure 1. Cells cultured from the canine LAD coronary artery revealed typical smooth muscle morphology and expressed smooth muscle phenotypic markers 116

Figure 38 Supplemental Figure 2. Smooth muscle cells plated for patch clamp experiments continue to express phenotypic markers

Figure 41 Cultured rat aorta and A7r5 cells express estrogen receptors 144

Figure 42 BPA reduces BK channel expression 145 
Figure 43 BPA decreases functional BK channel expression in cultured rat aorta 146

Figure 44 ER antagonist (ICl 182,780) abrogates effect of BPA on BK channel expression 147

Figure 51 Non-genomic effect of BPA on vascular BK channel..................... 157

Figure 52 Genomic effect of BPA on vascular BK channel.......................... 159 


\section{SPECIFIC AIMS}

Scientific and technological advances provide a variety of chemicals for tremendous benefit; however, concerns have been raised regarding environmental exposure to xenoestrogens that disrupt endocrine function. Recent data suggest that the effect of estrogen on cardiovascular physiology is far more complicated than previously envisioned. Because we do not fully understand the function of estrogen in cardiovascular health and disease, it is difficult to predict the effects of xenoestrogens and endocrine disruptors on cardiovascular physiology. One estrogenic endocrine disruptor, bisphenol A (BPA), holds enormous financial and practical importance for plastic manufacturers, but issues surrounding its safety create concern. A recent epidemiological study associated urinary BPA levels with cardiovascular diseases including angina, atherosclerosis, and myocardial infarction(Lang et al., 2008). Mechanistic data regarding effects of BPA on the cardiovascular system are scarce; therefore, we do not yet understand how BPA could be linked to coronary heart conditions. BPA acts on nuclear estrogen receptors (ER) to mediate genomic effects, while non-genomic effects of BPA appear to originate at the cell membrane. Membrane targets for BPA remain unclear, but include the G protein-coupled estrogen receptor (GPER30; (Thomas \& Dong, 2006)) and ion channels (Choi et al., 2007). Importantly, there are no data available regarding the effect of BPA on the function and expression of ion channels in vascular smooth muscle cells (VSMC), a cell type involved intimately in angina, atherosclerosis, and myocardial infarction. 
Large conductance $\mathrm{Ca}^{2+} /$ voltage-sensitive $\mathrm{K}^{+}(\mathrm{BK})$ channel is an excellent model for studying non-genomic effects of BPA, because its activity is estrogensensitive (Valverde et al., 1999; Dick \& Sanders, 2001). The BK channel is also an excellent model for studying genomic actions of BPA, because the underlying gene, KCNMA1, is regulated by estrogen (Kundu et al., 2007). BK channels are highly expressed in VSMC, possess the regulatory $\beta 1$ subunit (Tanaka et al., 1997), and regulate coronary vascular tone (Ledoux et al., 2006; Borbouse et al., 2009). Our long-range goal is to identify molecular mechanisms by which estrogenic chemicals affect vascular function. Our objective in this application is to determine mechanisms by which BPA modulates BK channel expression and function. The central hypothesis is that BPA alters BK channel expression and function through separate genomic and non-genomic mechanisms. The rationale is that receptors for BPA exist at both the cell membrane and in the nucleus. To test the central hypothesis and achieve the objective, we propose 2 specific aims:

\section{Determine the non-genomic mechanism by which BPA increases BK} channel activity in VSMC. The working hypothesis is that BPA increases BK channel activity by binding to an extracellular site on the channel that is comprised, at least in part, of the regulatory $\beta 1$ subunit. Patch clamp studies will be performed on VSMC using a derivative of BPA that we have synthesized. BPA-monosulfate (BPA-MS) is permanently charged, membrane-impermeable, and will be used to determine on which side of the membrane the binding site 
resides. The role of the $\beta 1$ subunit will be determined using cloned BK channels composed of $\alpha$ or $\alpha+\beta 1$ subunits.

\section{Determine the genomic mechanism by which BPA decreases BK channel} expression in VSMC. The working hypothesis is that BPA reduces BK channel expression by activating nuclear ER. Western blots will be used to determine the expression level of BK channels in VSMC treated with BPA. The pure ER antagonist Fulvestrant (ICI 182,780) and BPA-MS will be used to determine the involvement of nuclear and membrane ER in BPA-induced reductions of BK channel protein expression.

We expect, at the completion of this project, to define mechanisms by which BPA increases BK channel activity and reduces BK channel expression in VSMC. Knowing the mechanisms of action of BPA on VSMC will aid interpretation of correlative studies regarding BPA exposure and human health. The proposed work is innovative because it addresses both genomic and non-genomic effects of BPA related to ion channels, VSMC, and cardiovascular disease. 


\section{REFERENCES}

Borbouse L, Dick GM, Asano S, Bender SB, Dincer UD, Payne GA, Neeb ZP, Bratz IN, Sturek M \& Tune JD. (2009). Impaired function of coronary $\mathrm{BK}(\mathrm{Ca})$ channels in metabolic syndrome. Am J Physiol Heart Circ Physiol 297, H1629-1637.

Choi IS, Cho JH, Park EJ, Park JW, Kim SH, Lee MG, Choi BJ \& Jang IS. (2007). Multiple effects of bisphenol A, an endocrine disrupter, on GABA(A) receptors in acutely dissociated rat CA3 pyramidal neurons. Neurosci Res 59, 8-17.

Dick GM \& Sanders KM. (2001). (Xeno)estrogen sensitivity of smooth muscle BK channels conferred by the regulatory beta1 subunit: a study of beta1 knockout mice. J Biol Chem 276, 44835-44840.

Kundu P, Alioua A, Stefani E \& Toro L. (2007). Regulation of mouse Slo gene expression: multiple promoters, transcription start sites, and genomic action of estrogen. J Biol Chem 282, 27478-27492.

Lang IA, Galloway TS, Scarlett A, Henley WE, Depledge M, Wallace RB \& Melzer D. (2008). Association of urinary bisphenol A concentration with medical disorders and laboratory abnormalities in adults. JAMA 300, 1303-1310.

Ledoux J, Werner ME, Brayden JE \& Nelson MT. (2006). Calcium-activated potassium channels and the regulation of vascular tone. Physiology (Bethesda) 21, 69-78.

Tanaka Y, Meera P, Song M, Knaus HG \& Toro L. (1997). Molecular constituents of maxi $\mathrm{KCa}$ channels in human coronary smooth muscle: predominant alpha + beta subunit complexes. J Physiol 502 ( Pt 3), 545-557.

Thomas P \& Dong J. (2006). Binding and activation of the seven-transmembrane estrogen receptor GPR30 by environmental estrogens: a potential novel mechanism of endocrine disruption. J Steroid Biochem Mol Biol 102, 175179.

Valverde MA, Rojas P, Amigo J, Cosmelli D, Orio P, Bahamonde MI, Mann GE, Vergara C \& Latorre R. (1999). Acute activation of Maxi-K channels (hSlo) by estradiol binding to the beta subunit. Science 285, 1929-1931. 


\section{CHAPTER 1 Background and significance \\ Overview of BPA}

\section{BPA exposure and health concerns}

BPA is used to manufacture products including polycarbonate plastic, the resin inside of cans, dental sealants, and as a non-polymer additive to other plastics. Since BPA is a versatile material, over 6 billion pounds are produced each year, and over 100 tons are disposed of on the earth (Vandenberg et al., 2009). BPA, which possesses estrogen mimetic properties, has recently become the subject of much interest and attention. BPA is public health concern due to exposure in the environment, and a possible association with several pathological conditions. According to the National Health and Nutrition Examination Survey (NHANES) conducted during 1988-1994, BPA was detected in over $95 \%$ of population (Calafat et al., 2005). Newer data collected during 2003-2004 also supports the initial finding of widespread human BPA exposure (Calafat et al., 2008). Notably, the geometric mean of BPA exposure from 20032004 NHANES $(2.6 \mu \mathrm{g} / \mathrm{L})$ was twice as large as the one from 1988-1994 (1.33 $\mu \mathrm{g} / \mathrm{L})$. These data may suggest that BPA exposure is continuously increasing over the years.

Currently, the U.S. Food and Drug Administration (FDA) and the U.S. Environmental Protection Agency (EPA) state the reference dose; a daily exposure to the human population that is likely to be without an appreciable risk of deleterious effect during a lifetime, of BPA is $50 \mathrm{\mu g} \mathrm{kg}^{-1} \mathrm{day}^{-1}$. Importantly, there is continuing controversy whether this current acceptable daily intake level 
is an appropriate estimate for the safe level. A number of recent studies are suggesting the possible low dose effect of BPA, which may involve totally newly mechanisms that alter cellular functions. Furthermore, many studies have detected BPA in urine, blood and tissue; however, the levels of BPA exposure are controversial. BPA has been shown to accumulate in adipose tissue (Nunez et al., 2001; Fernandez et al., 2007) so that the local BPA concentration in tissue could be higher than the values reported in total blood BPA concentration. Furthermore, cumulative BPA exposure levels may play a role in BPA associated pathologies. Additionally, this reference dose was calculated based on a toxicological experiment to determine the lowest observed adverse effect level (LOAEL) in the 1980's. Thus, there is a desperate need for updated data regarding BPA's toxicological aspects.

Although there is no clear consensus of adverse health effects from BPA, the large body of evidence suggested that BPA possesses endocrine disrupting activities in a tissue specific manner. Specifically, BPA may be associated with altered fetal/neonatal development (Vandenberg et al., 2007), reproductive function (Savabieasfahani et al., 2006), metabolic homeostasis (Hugo et al., 2008) and carcinogenesis (Wetherill et al., 2002; Wetherill et al., 2005). Thus, the U.S. Food and Drug Administration (FDA) and National Toxicology Program (NTP) at the National Institute of Health state that they have "some concerns regarding the potential effect of BPA on the brain, behavior, and the prostate gland in fetuses, infants and young children (http://www.fda.gov/newsevents/publichealthfocus/ucm064437.htm). 


\section{Toxicodynamics / toxicokinetics of BPA}

BPA is a lipophilic molecule that contains 2 phenol rings, which resembles other toxic chemicals such as diethylstilbestrol (DES) and

dichlorodiphenyltrichloroethane (DDT) (Fig. 1-1). These compounds were banned due to their endocrine disrupting properties and have been associated with an increased risk of tumor development (Vandenberg et al., 2009). Similarly, one of the well-known chemical properties of BPA is an estrogenic property that interacts with estrogen receptors (ERs) to activate estrogen signals.

Conventionally, it is known that endocrine disrupters act via nuclear estrogen receptors as $17 \beta-E_{2}$ acts on ERs, however, the mechanisms of non-genomic effects such as the involvement of membrane receptors or ion channels are not well established. Indeed, xenoestrogens were reported to be much less potent than $17 \beta-\mathrm{E}_{2}$ (Krishnan et al., 1993; Kuiper et al., 1997). Recent studies have demonstrated that the nongenomic action of BPA may be associated with altered intracellular $\mathrm{Ca}^{2+}$ homeostasis (Nadal et al., 2000; Alonso-Magdalena et al., 2005; Walsh et al., 2005). Yet, the exact mechanisms of BPA induced alterations remain unknown. Given that BPA has a low affinity for binding with classical nuclear receptors; it is possible that non-genomic effects of BPA may play an important role in BPA associated altered cellular function in addition to classical genomic ER signaling disruption.

In terms of BPA toxicokinetics, studies have been shown that the half-life of BPA in the blood range from 4 to 6 hours in humans (Volkel et al., 2002; Volkel 
et al., 2005). Considering the studies demonstrating that the half life of BPA in the blood is a relatively short time, and the studies showing the detection of BPA from urine samples in over $90 \%$ of population (Calafat et al., 2005; Calafat et al., 2008), the environmental BPA exposure to humans must be continuous.

Alternatively, it is possible that BPA can be stored in the body and constantly released into the blood. Indeed, toxicological studies have shown that BPA accumulates in brown adipose tissue in rats (Nunez et al., 2001) and BPA and its derivatives were detected in the adipose tissue of women (Fernandez et al., 2007). Since there are no doubts about the prevalence of BPA in our body, further research is needed to explore the pharmacokinetic/dynamics of BPA and how it is related to the BPA associated pathologies seen in epidemiological studies. 

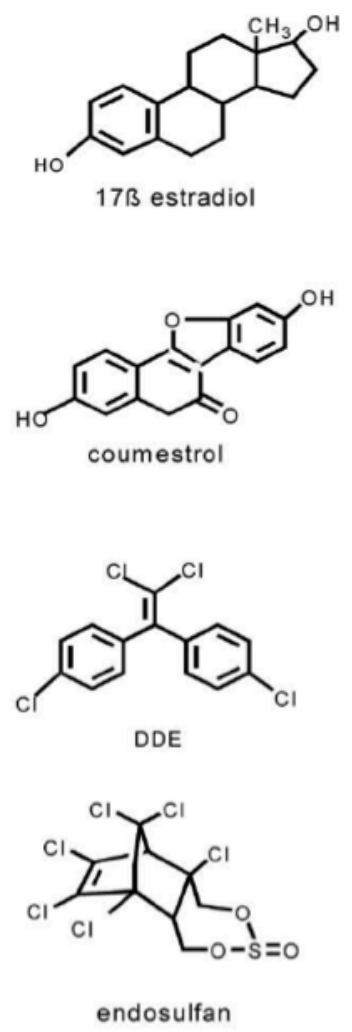
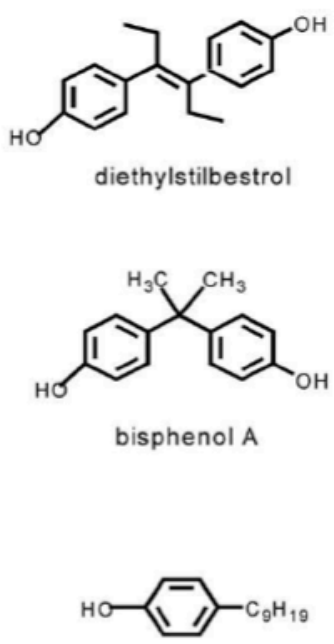

nonylphenol

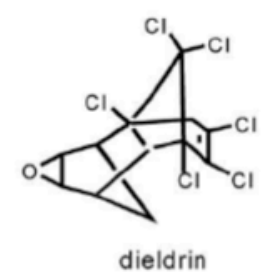

Figure 11 Chemical structures of E2 and xenoestrogens and related compounds.

Structures of $17 \beta$-estradiol and endocrine disruptors are shown. The structure of BPA is very similar to Dichlorodiphenylene (DDE) and Diethylstilbestrol (DES). DDE is a metabolite of DDT, which was banned as a pesticide due to its carcinogenic properties. DES is a pharmaceutical estrogen that was also banned (Watson et al., 2007) 


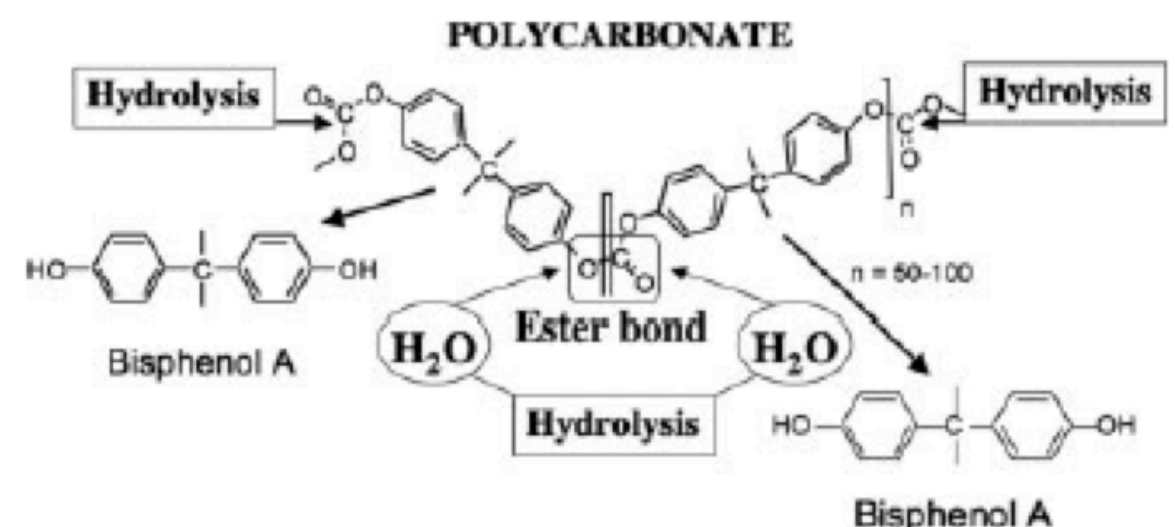

Figure 12 Chemical reactions to release BPA from polycarbonate products.

BPA molecule is released from polycarbonate products by the hydrolysis of the ester bond. The chemical reaction is facilitated during certain conditions, including high temperatures and acidic or basic environments. (Welshons et al., 2006) 


\section{Sources of BPA}

Although BPA has been detected in a variety of sources including food, beverages, air, soil, and house dust, the major BPA exposure source was considered through dietary ingestion (Miyamoto \& Kotake, 2006; Wilson et al., 2007). Particularly, BPA has been shown to leach from polycarbonate compounds such as plastic containers and canned food. The initial report of BPA being released was in an accidental experiment showing that an estrogenic substance was suspected of leaching from autoclaving solution in polycarbonate flasks (Krishnan et al., 1993). As in all general chemical reactions, hydrolysis of ester bonds in polycarbonate products is facilitated at high temperature and $\mathrm{pH}$ levels (Fig. 1-2). Examples commonly seen in our lives may be washing a plastic container with harsh detergent, or heating it, or storing acidic/basic food in it. Indeed some of these conditions are shown to release BPA (Brotons et al., 1995; Kang et al., 2003).

Interestingly, a recent study reported that the BPA levels did not decline with fasting conditions in human subjects (Stahlhut et al., 2009). This study may suggest that the oral route may not be the only route of BPA exposure. Additionally, BPA has been shown to be stored in adipose tissue (Nunez et al., 2001; Fernandez et al., 2007), therefore, cumulative BPA levels may also need to be considered when the source of BPA exposure needs to be determined. Taken together, there are no doubts about human BPA exposure; however, the exact source of BPA is not known. It is likely to be multiple sources responsible for human BPA exposure. 


\section{BPA and cardiovascular diseases}

In 2008, an initial epidemiological study demonstrated a significant relationship between urinary BPA concentration and cardiovascular diseases in the general adult population from the United States (Lang et al., 2008a). This cross-sectional analysis utilized data from the National Health and Nutrition Examination Survey 2003-2004 and the data indicated higher BPA concentrations were associated with cardiovascular diagnosis, diabetes, and altered liver enzyme levels. Later, newer data from the NHANES 2005-2006 also appeared consistent with an association between urinary BPA concentration and cardiovascular disease (Melzer et al., 2010). Additionally, high levels of BPA in serum were associated with atherosclerotic plaques in the aged population (Lind \& Lind, 2011). Occupational levels of BPA exposure also have been associated with an increased risk of male sexual dysfunctions such as erectile dysfunction (Li et al., 2010). Although government agencies have concerns due to BPA's potential harmful effects on fetuses, infants and young children, these studies may suggest that BPA toxicity is not limited to the specific population but rather, a global effect to all populations.

All taken together, BPA has become a public health concern only in the last few years, and many controversies exist about routes of exposure, the quantity we are exposed to, mechanisms of BPA action, and its associations with diseases (Vandenberg et al., 2009). Since constant BPA exposures are suspected and therefore this phenomenon will continue to intensify, early and conclusive studies for safety are extremely important to prevent public health 
hazards like the ones that have been created by the use of materials such as asbestos and dichlorodiphenyltrichloroethane (DDT).

\section{Overview of ion channels in VSM Ion channel and toxicological compounds}

Ion channels are macromolecular protein complexes that form pores in cell membranes, which regulate the movement of ions. The membrane potential determined by these ion channels are critical, since excitable cells utilize electricity for communication between the extracellular side and intracellular side to further propagate intracellular signal transduction to trigger a cellular response. (i.e. $\mathrm{Ca}^{2+}$ flux). Thus, ion channels located in the membrane make very convenient targets for altering cellular function. As shown in nature, many toxins (i.e. tetrodotoxin, iberiotoxin, charybdotoxin) are designed to alter ion channel functions, and are used as predators' weapons to establish a dominant world where the strong prey upon the weak. Furthermore, the disruption of membrane integrity by forming transmembrane pores (gramicidin, amphotericin, nystatin,) is also a great example of how important the ion channel is in the membrane to regulate ionic gradients between extracellular and intracellular spaces. In other words, ion channels may be susceptible to toxicological chemicals.

\section{Potassium channels in VSMC}

The primary function of VSMC is contraction, as in other muscle types such as skeletal and cardiac muscle. Calcium dependent muscle contraction 
obeys the basic principle of excitation-contraction coupling (ECC) which explains the membrane excitability and intracellular $\mathrm{Ca}^{2+}$ concentration that regulates muscle contraction. As in other muscles, the two key players in ECC are voltage dependent L-type $\mathrm{Ca}^{2+}$ channel (Cav1.2) and ryanodine receptor (RYR) in the VSMC. Similar to other muscles, voltage dependent L-type $\mathrm{Ca}^{2+}$ channels are activated by membrane depolarization resulting in $\mathrm{Ca}^{2+}$ flux through extracellular component to increase global intracellular $\mathrm{Ca}^{2+}$ concentration (Moosmang et al., 2003). Therefore, ion channels contributing to the dynamic regulation membrane potential $(\mathrm{Em})$ are key factors for VSMC contraction (Nelson et al., 1990). Particularly, $\mathrm{K}^{+}$channels are important molecules in negative feedback mechanisms to set the resting membrane potential since the equilibrium potential of $\mathrm{K}^{+}$are more negative than the resting membrane potential. Multiple types of $\mathrm{K}^{+}$ channels are identified in VSMC: 1$)$ Inward rectifying $K$ channel $\left.\left(K_{\text {ir }}\right), 2\right)$ ATP sensitive $\mathrm{K}^{+}$channel $\left(\mathrm{K}_{\text {ATP }}\right)$ 3) Voltage dependent $\mathrm{K}^{+}$channels $\left(\mathrm{K}_{\mathrm{V}}\right)$, and 4): Calcium dependent $\mathrm{K}^{+}$channels $\left(\mathrm{K}_{\mathrm{Ca}}\right)$ (Holdefer et al., 1976; Nelson \& Brayden, 1993; Quayle et al., 1997; Dick \& Tune, 2010). These potassium channels in VSMC, that provide hyperpolarizing currents, play a critical role in maintaining the resting membrane potential, and each type of $\mathrm{K}^{+}$channel has its own unique biophysical properties.

\section{$\mathrm{K}_{\mathrm{ir}}$ and $\mathrm{K}_{\mathrm{ATP}}$ channels}

Both $\mathrm{K}_{\text {ir }}$ and $\mathrm{K}_{\text {ATP }}$ channels are categorized in the same phylogenetic tree and have been shown to express in vascular smooth muscle (Kubo et al., 2005). 
The structure of the $\mathrm{K}_{\mathrm{ir}}$ family is composed of 2 transmembrane domains termed $\mathrm{M} 1$ and $\mathrm{M} 2$ with pore forming $\mathrm{H} 5$ regions that serves as ion selectivity filters (Bichet et al., 2003). Functional properties of $\mathrm{K}_{\text {ir }}$ currents in VSMC were characterized by patch clamp recording (Edwards \& Hirst, 1988; Edwards et al., 1988). Patch clamp recordings demonstrated strong inward rectifying barium sensitive currents and increasing extracellular $\left[\mathrm{K}^{+}\right]$increased the conductance. In terms of the physiological role of $\mathrm{K}_{\mathrm{ir}}$ channels in VSM, moderate increases in the extracellular $\left[\mathrm{K}^{+}\right]$(3-20 $\left.\mathrm{mM}\right)$ have been shown to cause vasodilation through a mechanism depending on $\mathrm{K}_{\mathrm{ir}}$ channel activation in cerebral arteriole (Girouard et al., 2010). In VSMC, $\mathrm{K}_{\mathrm{ir}} 2.1$ transcript was detected, but not $\mathrm{K}_{\mathrm{ir}} 2.2$ and $\mathrm{K}_{\mathrm{ir}} 2.3$ from rat cerebral, coronary and mesenteric arteries (Bradley et al., 1999). To support this gene expression data further, functional data also indicated that the cerebral artery from $\mathrm{K}_{\mathrm{ir}} 2.2 \mathrm{KO}$ mice responds to extracellular $\mathrm{K}^{+}$, but not the cerebral artery from $\mathrm{K}_{\mathrm{ir}} 2.1 \mathrm{KO}$ mice (Zaritsky et al., 2000). Thus, this molecular and functional evidence suggests that vascular $\mathrm{K}_{\mathrm{ir}}$ channels are composed of $\mathrm{K}_{\mathrm{ir}} 2.1$.

On the other hand, $\mathrm{K}_{\text {ATP }}$ channels are composed of $\mathrm{K}_{\mathrm{ir}} 6.1$ and $\mathrm{K}_{\mathrm{ir}} 6.2$ with unique subunits known as sulfonylurea receptors (SUR). As in the $\mathrm{K}_{\mathrm{ir}} 2.1$ subunit, $\mathrm{K}_{\mathrm{ir}} 6.1$ and $\mathrm{K}_{\mathrm{ir}} 6.2$ subunits are composed of 2 transmembrane domains, M1 and M2, without voltage sensor domain such as S4 segment, thus $\mathrm{K}_{\mathrm{ATP}}$ channel currents are not voltage dependent. Nonetheless, SUR subunits serve as the intracellular ATP binding site to regulate $\mathrm{K}_{\text {ATP }}$ channel. Although human coronary endothelial $\mathrm{K}_{\mathrm{ATP}}$ channel has been shown to express as a heteromeric complex of $\mathrm{K}_{\mathrm{ir}} 6.1, \mathrm{~K}_{\mathrm{ir}} 6.2$ and SUR2B, it was not demonstrated in human coronary artery 
smooth muscle cells (Yoshida et al., 2004). Indeed, human coronary artery smooth muscle cells expressed $\mathrm{K}_{\mathrm{ir}} 6.1, \mathrm{~K}_{\mathrm{ir}} 6.2$ and SUR2B mRNAs, however, a heteromeric complex of $\mathrm{K}_{\mathrm{ir}} 6.1$ and $\mathrm{K}_{\mathrm{ir}} 6.2$ was not confirmed as in the human coronary endothelial cells. In contrast, another study showed only $\mathrm{K}_{\mathrm{ir}} 6.1$ and SUR2B mRNA expression (Miura et al., 2003). These molecular biological data are further supported by the functional data that demonstrate that the aortic vascular responses to $\mathrm{K}_{\text {ATP }}$ channel agonists/antagonist (pinacidil, diazoxide and glibenclamide) are not different between wild type and $\mathrm{K}_{\mathrm{ir}} 6.2 \mathrm{KO}$ mice (Suzuki et al., 2001). Thus, this molecular and functional evidence suggests that the vascular $\mathrm{K}_{\text {ATP }}$ channel is composed of $\mathrm{K}_{\mathrm{ir}} 6.1$ and SUR2B. In terms of the physiological role of $\mathrm{K}_{\mathrm{ATP}}$ channel in VSM, it has been suggested that $\mathrm{K}_{\mathrm{ATP}}$ channel plays an important role in ischemic vasodilation (Dart \& Standen, 1995). This is because the SUR regulatory subunits serve as the sensor for intracellular ATP levels and the $\mathrm{K}_{\text {ATP }}$ channel is generally inhibited due to sufficient levels of ATP under normal physiological conditions. $\mathrm{K}_{\text {ATP }}$ channel is also activated by the G-protein mediated cAMP dependent protein kinase (PKA) (Standen \& Quayle, 1998). For instance, adenosine induced vasodilation involves adenylyl cyclasecAMP-PKA pathways to activate $\mathrm{K}_{\mathrm{ATP}}$ channel.

\section{$K_{v}$ channels}

$\mathrm{K}_{\mathrm{V}}$ channels are one of the most diverse potassium channels. Although they are classified into $K_{v} 1-K_{v} 12$ subfamilies and each subfamily contains several isoforms, the expression of $\mathrm{K}_{\mathrm{v}} 1, \mathrm{~K}_{\mathrm{v}} 2, \mathrm{~K}_{\mathrm{v}} 3, \mathrm{~K}_{\mathrm{v}} 4, \mathrm{~K}_{\mathrm{v}} 7$ and $\mathrm{K}_{\mathrm{v}} 9$ channel 
subfamilies have been confirmed in vascular smooth muscle. (Gutman et al., 2003; Wulff et al., 2009). $K_{V}$ channel is composed of pore forming alpha subunits that can be homotetramers or heterotetramers of different families. The a subunit contains 6 transmembrane domains and the S4 segment serves as a voltage sensor. The S5-S6 linker and P-loop form the outer funnel and pore in $\mathrm{K}_{V}$ channels. The $\mathrm{K}^{+}$selective filter allows $\mathrm{K}^{+}$ions go through the pore using the highly selective dehydration of $\mathrm{K}^{+}$ions (MacKinnon, 2003). In addition, $\mathrm{K}_{\mathrm{V}}$ channels have been suggested to contain auxiliary $\beta$ subunits that can regulate the channel function. Although the exact molecular composition of $\mathrm{K}_{V}$ channel is not clear because the composition of $K_{V}$ channels seem to be different depending on the vascular beds, $K_{v}$ channels are likely to be composed of heteromultimeric $K_{v} \alpha$ subunits with diversity of $\beta$ subunits that enables the formation of a variety of $\mathrm{K}_{\mathrm{v}}$ channels to response to appropriate physiological demand in the vessels (i.e. conduit vs resistance). For instance, $\mathrm{K}_{v}$ a subunits $\left(\mathrm{K}_{\mathrm{v}} 1.1, \mathrm{~K}_{\mathrm{v}} 1.2, \mathrm{~K}_{\mathrm{v}} 1.4, \mathrm{~K}_{\mathrm{v}} 1.5, \mathrm{~K}_{\mathrm{v}} 1.6, \mathrm{~K}_{\mathrm{v}} 2.1\right.$ and $\left.\mathrm{K}_{\mathrm{v}} 9.3\right)$ are expressed in rat pulmonary arterial smooth muscle cells (Yuan et al., 1998), while $K_{v} \alpha$ subunits $\left(\mathrm{K}_{\mathrm{v}} 1.1-\mathrm{K}_{\mathrm{v}} 1.8\right.$ except $\left.\mathrm{K}_{\mathrm{v}} 1.4\right)$ are expressed in canine coronary artery (Dick et al., 2008). Interestingly, within the diverse family of $K_{v}$ genes, some $K_{v}$ genes are particularly important in vascular function. Specifically, a mutant $K_{v} 1.5$ gene overexpression caused endogenous functional $\mathrm{K}_{\mathrm{V}}$ channels to switch dysfunctional $\mathrm{K}_{\mathrm{v}}$ channels due to the incorporation of mutant $\mathrm{K}_{\mathrm{v}} 1.5$ (Chen et al., 2006). This dominant negative approach resulted in altered myogenic response and membrane potential in the vessels. 


\section{BK channel}

Large conductance $\mathrm{Ca}^{2+} /$ voltage- activated $\mathrm{K}^{+}(\mathrm{BK})$ channels are expressed in variety of tissues and involved in variety of cellular process including circadian rhythms (Meredith et al., 2006) vascular regulation (Nelson et al., 1995; Brenner et al., 2000), hearing function (Pyott et al., 2007). BK channels are composed of $4 \alpha$ subunits encoded by KNCMA1 gene with auxiliary $\beta$ subunits encoded by KCNMB1-4 genes. Although a single gene encodes the $\alpha$ subunit, it undergoes alternative splicing processes to yield several splicing variants that have diverse channel characteristics (Butler et al., 1993; Tseng-Crank et al., 1994). As a schematic BK channel structures are shown in Fig. 1-3, the $\alpha$ subunit contains 7 transmembrane segments ( $\mathrm{S} 0$ to $\mathrm{S} 6$ ) with $\mathrm{N}$-terminus located at the extracellular side and $\mathrm{C}$-terminus located at the intracellular side. Similar to other voltage sensitive K channel families, S4 segment serves as a voltage sensor to regulate BK channel opening/closing states (Cui \& Aldrich, 2000).

In addition to the voltage regulation, there are $\mathrm{Ca}^{2+}$ sensor sites similar to EF hand motif located at cytoplasmic C-terminal tail side. Furthermore, currently, there are 4 auxiliary $\beta$ subunits encoded by $K C N M B 1-4$ genes identified and each $\beta$ subunit provides further unique BK channel properties. Specifically, first $\beta$ subunits are isolated from smooth muscle membrane and identified as $\beta 1$ subunit (Knaus et al., 1994a). The role of the $\beta 1$ subunit is allosteric regulations of BK channel by improving the sensitivity to voltage and intracellular $\mathrm{Ca}^{2+}$ (Fig. 1-4) (Carl \& Sanders, 1989; Cox et al., 1997; Cox \& Aldrich, 2000). Thus, BK channel 
$\beta 1$ subunits have been suggested to play a key role in regulation of vascular tone (Brenner et al., 2000) and urinary bladder function (Petkov et al., 2001). It also regulates the functional surface expression of a subunits (Toro et al., 2006). Furthermore, $\beta 1$ subunit-dependent BK channel activation was reported with steroid hormones (Valverde et al., 1999; Lovell et al., 2004; King et al., 2006; Bukiya et al., 2007). $\beta 2$ subunits are expressed inn adrenal gland and hippocampal neuron and it uniquely causes inactivation of BK channel currents (Solaro \& Lingle, 1992; Hicks \& Marrion, 1998; Wallner et al., 1999). The expression of $\beta 3$ subunit is confirmed in testis, pancreas and spleen and it causes a rapid inactivating BK channel currents (Xia et al., 2000). $\beta 4$ subunits are primary expressed in brain and presence of $\beta 4$ subunits make BK channel insensitive to iberiotoxin (Meera et al., 2000). In summary, $\beta$ subunits alter $\mathrm{Ca}^{2+}$, voltage and chemical agonists/antagonists sensitivities.

The primary role of BK channel has been suggested to act as negative feedback mechanism to regulate the opening of L-type voltage gated $\mathrm{Ca}^{2+}$ channels in vascular smooth muscle cells by voltage and intracellular $\mathrm{Ca}^{2+}$ levels (Fig. 1-5). $\mathrm{Ca}^{2+}$ spark, local increase in subsarcolemmal $\mathrm{Ca}^{2+}$, is coupled with $\mathrm{BK}$ channel activity, causing hyperpolarizing membrane potential to counter vasoconstriction (Nelson et al., 1995). Although BK channel mediate relaxation of arterial smooth muscle by $\mathrm{Ca}^{2+}$ sparks is evident in cerebral artery (Nelson et al., 1995), recent data suggest the heterogeneity in the contribution of BK channels in vasculature tone in vascular beds (Yang et al., 2009). Thus, the physiological 
role and the mechanism of BK channel activation may be far more complex and important than previously envisioned. 


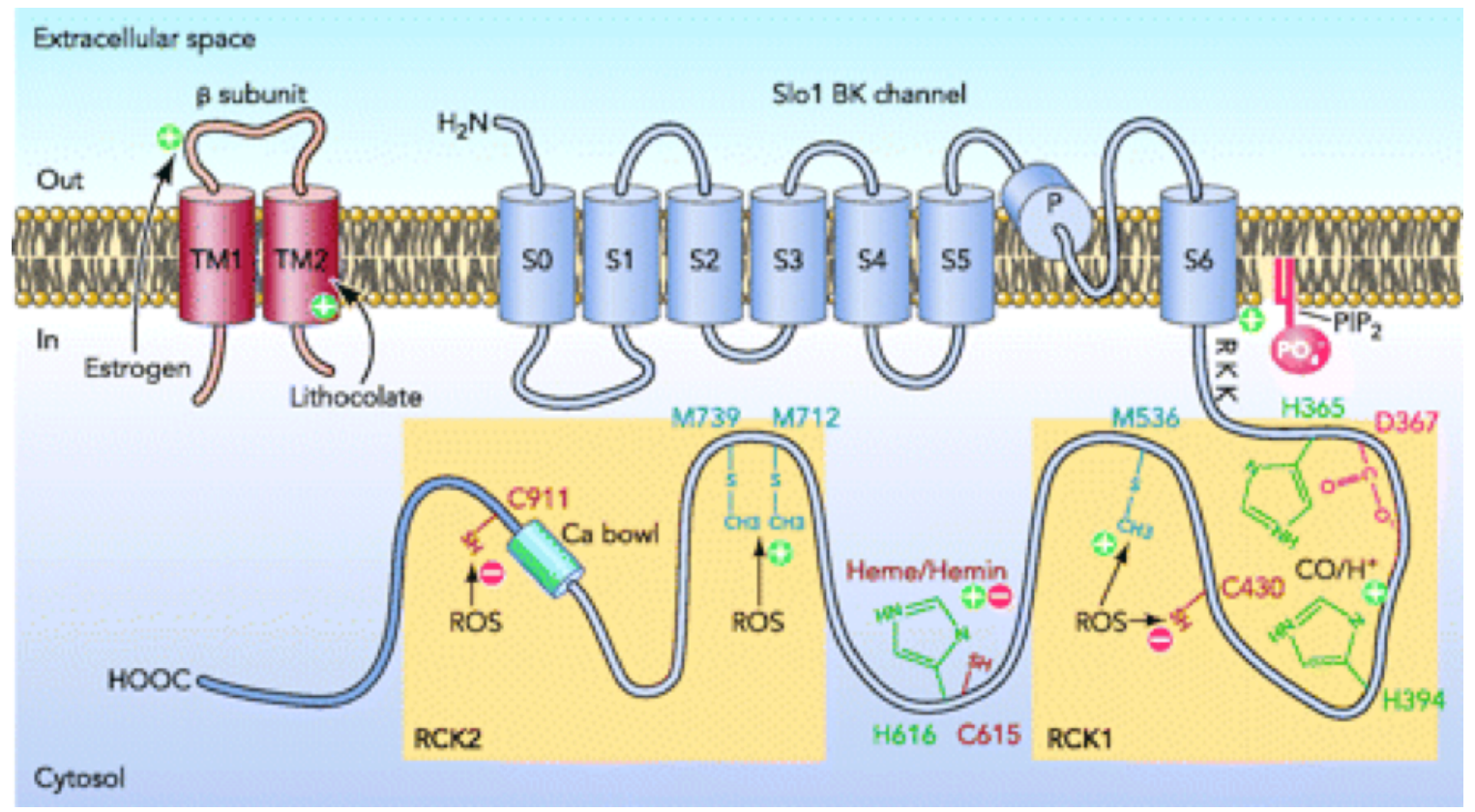

Figure 13 Molecular structure of BK channel $\alpha$ subunit and $\beta 1$ subunit.

The schematic diagram shows the key amino acid residues involved in modulation of BK channel. + indicates activation of BK channel and - indicates inhibition of BK channel. (Hou et al., 2009) 

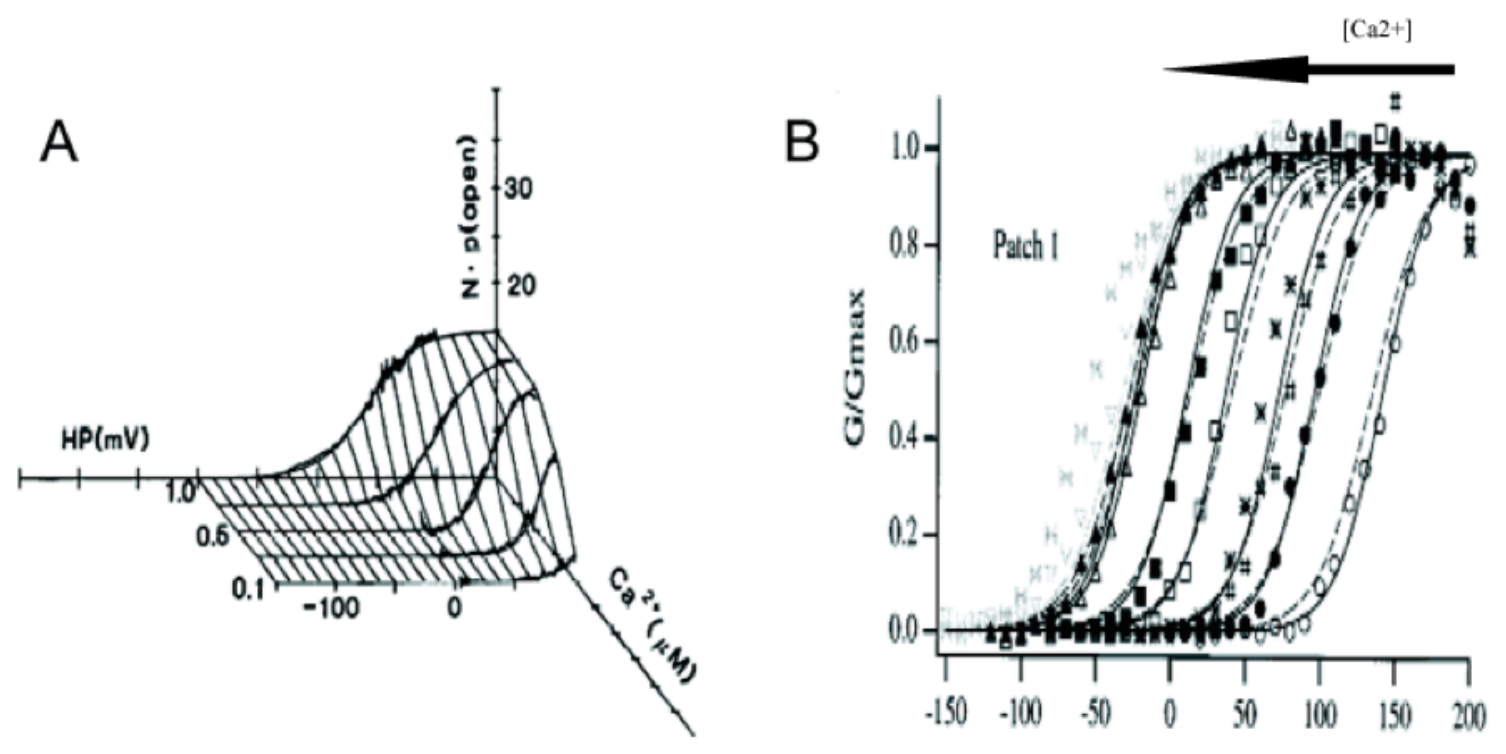

Figure 14 Dual regulation by $\mathrm{Ca}^{2+}$ and voltage on $\mathrm{BK}$ activity.

(A) BK channel activity is plotted against voltage and $\mathrm{Ca}^{2+}$ concentration. (B) G-V relationship shifts toward the left as intracellular $\mathrm{Ca}^{2+}$ concentration increases (Carl \& Sanders, 1989) 


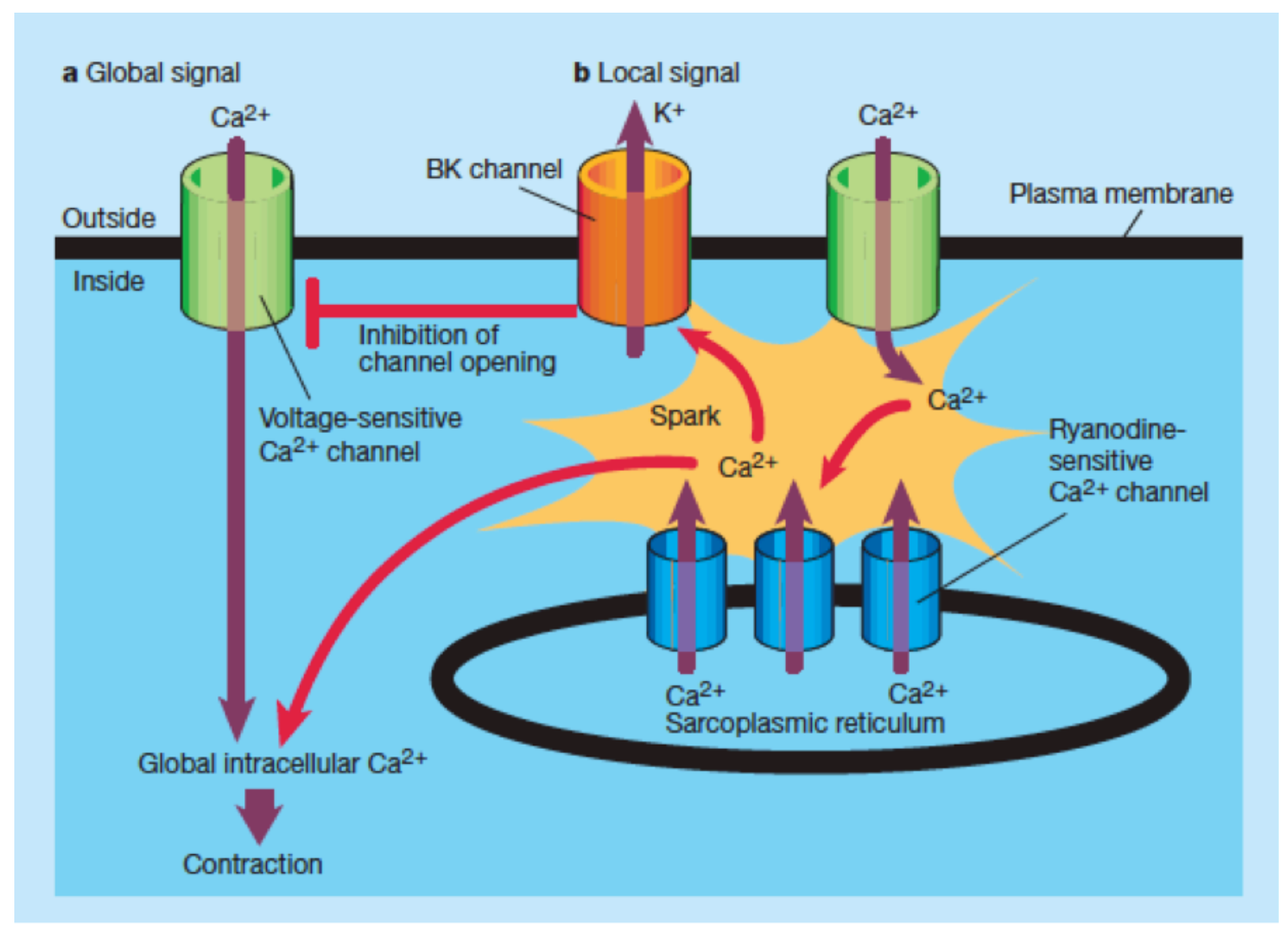

Figure 15 The function of BK channel in vascular smooth muscle cells.

$\mathrm{Ca}^{2+}$ spark activates $\mathrm{BK}$ channel and causes membrane hyperpolarization due to $\mathrm{K}^{+}$efflux. This membrane hyperpolarization blocks L-type $\mathrm{Ca}^{2+}$ channel to decrease the global $\mathrm{Ca}^{2+}$ concentration levels in cytosol. $\mathrm{BK}$ channel regulates intracellular $\mathrm{Ca}^{2+}$ levels using this negative feedback system. (Standen, 2000) 


\section{BK channel and vascular pathologies}

\section{Aging, hypertensive and diabetic vascular BK channels}

In vascular smooth muscle cell, local intracellular $\mathrm{Ca}^{2+}$ increase can paradoxically induce smooth muscle relaxation. This is explained by the activating of the vascular BK channel that results in membrane hyperpolarization (Nelson et al., 1995). Therefore, BK channel has been recognized as one of the key molecules for vascular tone in a variety of vessels. Indeed, alterations in BK channel expression in vascular smooth muscle is associated with hypertension, aging, and diabetic related altered vascular functions in variety of vascular beds (Liu et al., 1997; Liu et al., 1998; Marijic et al., 2001; Lu et al., 2005; McGahon et al., 2007; Lu et al., 2008; Borbouse et al., 2009)

Specifically, cerebral artery smooth muscle cells from genetically hypertensive rats exhibited over 4-fold higher BK channel current density and BK a subunits expression compared to Wistar-Kyoto rat cerebrovascular smooth muscle cells (Liu et al., 1998). Similarly, hypertension-induced increased BK channel has been demonstrated in aortic smooth muscle cells from spontaneously hypertensive rats (Liu et al., 1997). Hypertension induced increased BK channel expression is considered compensatory mechanism to counteract the increased cerebral vascular tone.

On the other hand, age associated altered vascular ion channel remodeling indicated decreased BK channel function as age increased (Toro et al., 2002). Specifically, both rat and human coronary artery smooth muscle cells have been shown to decrease in BK current density and a subunits protein 
content over time (Marijic et al., 2001). Additionally, age associated reduced BK channel $\beta 1$ subunits and the mechanisms of aged associated reduced BK channel current density were reported later (Nishimaru et al., 2004a). Interestingly, a study has demonstrated that age associated decreased BK channel function has been attenuated by exercise training (Albarwani et al., 2010). Therefore, age associated BK channel dysfunction is not an irreversible phenomenon, and therapeutic benefits can be expected from exercise or pharmacological approaches. Surprisingly, decreased BK channel expression with aging was not evident in aged cerebral artery smooth muscle cells (Nishimaru et al., 2004b). Thus, BK channel remodeling mechanisms compensate for age associated dysfunctional vasculature depending on the particular vascular bed, and they could be great pharmacological targets.

Diabetes and metabolic syndrome related to vascular dysfunction is associated with altered BK channel function (Dimitropoulou et al., 2002; Lu et al., 2005; Zhou et al., 2005; Burnham et al., 2006; McGahon et al., 2007; Borbouse et al., 2009). Some studies indicate that alterations in signaling mechanisms, such as arachidonic acid mediated signaling, result in impaired BK channel function, but not BK channel expression (Dimitropoulou et al., 2002; Lu et al., 2005). Other studies demonstrate that BK channel biophysical properties including channel kinetics, sensitivities to voltage, and $\mathrm{Ca}^{2+}$ are impaired with diabetic vessels (Burnham et al., 2006; Lu et al., 2008). On the other hand, altered BK channel expression in diabetes has also been reported (McGahon et al., 2007; Borbouse et al., 2009). Based on these multiple levels of observation, 
diabetes and metabolic syndrome associated altered vascular BK channel function is associated with the combination of altered BK channel upstream signaling, biophysical properties of BK channel and BK channel expression.

\section{Issues in studying BK channels}

\section{BK channel antagonists/agonists}

In addition to wide expression of BK channel in human tissue, the numbers of chemical factors including ethanol (Dopico et al., 1998), hormones (Valverde et al., 1999; Lovell et al., 2004; King et al., 2006) and xenoestrogens (Dick et al., 2001; Coiret et al., 2007) have been shown to modulate BK channel function. Particularly, ethanol is often used as a solvent for a variety of drugs and it requires careful control for assessment of BK channel function when ethanol is used for vehicle of the drug. Common experimental approaches to assess the role of BK channel are pharmacological and genetic manipulation, however, each approach possess a limitation.

A traditional pharmacological approach has been utilized to study the role of BK channel in physiological function before the gene disruption technology was established. Since the identification of peptide toxin including charybdotoxin (ChTX) and iberiotoxin (IBTX) (Miller et al., 1985; Galvez et al., 1990) from scorpion venom, both peptide toxins have been used to study the role of $\mathrm{K}^{+}$ channels in physiological function. Particularly, IBTX has been used as the gold standard to elucidate the physiological role of BK channel as well as the mechanism of gating because IBTX is highly selective to BK channel where 
ChTX is sensitive to other type of $\mathrm{K}^{+}$channels (Galvez et al., 1990). Although IBTX is recognized as a gold standard for BK channel inhibitor, several limitations exist. Originally, the potency of IBTX to BK channel was reported as $I_{50} \mathrm{pM}$ to $\mathrm{nM}$ ranges (IC $50250 \mathrm{pM:} \mathrm{(Galvez} \mathrm{et} \mathrm{al.,} \mathrm{1990)),} \mathrm{(IC} 501.7$ nM:(Kaczorowski et al., 1996), however, a recent study has shown the $\mathrm{IC}_{50}$ of IBTX is much higher (371 nM) (Lippiat et al., 2003) than the concentrations commonly used to assess the physiological role and biophysical properties of BK channels. Furthermore, IBTX is prohibitively expensive and its membrane impermeable characteristics make IBTX difficult to use in whole animal studies.

Recently, a group of indole diterpenes has been reported as potent BK channel inhibitors (Knaus et al., 1994b); which gave a hope to overcome some of the limitations of IBTX, however, the pharmacological properties of each compound seem to be distinctive and have not been fully explored. For instance, some of these mycotoxins are tremorgenic indole alkaloids, but some are nontremorgenic such as paspalinine (Knaus et al., 1994b). Within a group of these mycotoxins, inhibitory effects of paxillne in BK channel have been relatively well characterized (Sanchez \& McManus, 1996). In the original report of the effect of indole diterpenes on BK channel (Knaus et al., 1994b), it was mentioned that paxilline weakly blocks delayed rectifier potassium channels in mouse pancreatic $\beta$ cells. Furthermore, paxilline has been reported to block $\mathrm{Ca}^{2+}$ activate $\mathrm{Cl}^{-}$channels (Sones et al., 2009). Penitrem A is also one of a group of tremorgenic mycotoxins that have been shown to affect the central nervous system by altering the release of neurotransmitters (Norris et al., 1980). The 
ingestion of penitrem A has been associated with neurological disorders such as tremor, ataxia and convulsions in dogs and humans (Eriksen et al.; Lewis et al., 2005), However, in terms of the effect on BK channels, very little data regarding the effect of penitrem A on BK channel and on vasculature tone are available.

A few BK channel agonists have been identified and characterized by patch clamp experiments. For instance, NS004 (1-(2-hydroxy-5-chlorophenyl)-5trifluoromethyl-2- benzimidazolone) has been shown to increase open probability of BK channel and its open dwell time (Olesen et al., 1994b). Additionally, the effects of NS 1619 on BK channel have been well characterized (Edwards et al., 1994; Olesen et al., 1994a) and utilized as well accepted BK channel opener in a variety of studies. Although NS 1619 has been utilized as a BK channel agonist, the issues in the selectivity of NS 1619 have been reported (Holland et al., 1996). It has been shown that NS 1619 not only activates BK channel, but also inhibits L-type $\mathrm{Ca}^{2+}$ channel activity. Therefore, it requires careful interpretation in vasodilation response when NS1619 is used for the analysis of BK channel function.

\section{BK channel KO mice}

As a recent subject of experimental popularity, the genetic modification approach has become the major experimental design; however, there are certain limitations to this approach, such as compensatory alteration to accommodate a gene disruption (Faraci \& Sigmund, 1999). Indeed, constitutive BK a subunit KO mice and smooth muscle specific BK $\alpha$ subunit KO mice exhibit different degrees 
of compensatory proteomic adaptions that resulted in more severe disruption in urinary bladder function from smooth muscle specific BK a subunit KO mice (Sprossmann et al., 2009). Furthermore, inter-laboratory variability exists in experimental results using other transgenic mice. For instance, BK $\beta 1$ subunit KO mice were originally reported as hypertensive (Brenner et al., 2000; Pluger et al., 2000) but a recent study contradicted these original reports (Xu et al., 2011). Thus, although the utilization of $\mathrm{BK}$ channel $\mathrm{KO}$ mice in experiments is increasing, a combination of traditional pharmacological approaches to inhibit or activate BK channel to elucidate a role of BK channel in physiological and pathophysiological conditions is critical.

\section{Significance of study}

Although there is no clear consensus on the adverse health effects of BPA, evidence suggests that BPA may be associated with variety of pathologies including carcinogenesis, altered reproductive function, and developmental issues (Wetherill et al., 2005; Savabieasfahani et al., 2006; Vandenberg et al., 2007; Hugo et al., 2008). Fetuses, infants, and children are more susceptible to effects of BPA; however, a recent epidemiologic study revealed that BPA exposure might be related to cardiovascular disease in adults (Lang et al., 2008b). Because BPA exposure is increasing and these phenomena will continue to intensify, early and conclusive studies on safety and mechanism are needed to prevent public health hazards like the ones created by asbestos and DDT. This project will generate meaningful data useful to the Food and Drug 
Administration and the National Toxicology Program in assessing BPA toxicity and providing regulatory guidance. Since possible links between BPA and disease have appeared relatively recently, controversies and confusion exist regarding its health effects. There is not enough scientific evidence to draw an accurate conclusion as to whether BPA exposure is linked to cardiovascular disease; however, alterations of BK channel function and expression are associated with coronary dysfunction related to hypertension (Brenner et al., 2000; Amberg \& Santana, 2003), diabetes (Lu et al., 2008; Borbouse et al., 2009), and aging (Nishimaru et al., 2004a). Our contribution will be a detailed analysis of cellular and molecular effects of BPA on BK channels of vascular smooth muscle cells. We will elucidate molecular pharmacological and toxicological effects of BPA on BK channels; specifically, we will identify genomic and non-genomic mechanisms of BPA effect on BK channels in vascular smooth muscle cells.

\section{Summary}

In conclusion, although BPA has been utilized in industry because original toxicological studies conclude that the level of exposure to human is below the levels of observed adverse effect, recent studies raised concerns regarding the association with BPA and a number of pathologies. We hypothesize that BPA can alter BK channel function and expression via genomic/non-genomic mechanisms. With regard to our hypothesis, we also raised the issues in studies assessing the function of BK channel. Thus, we will characterize the new BK 
channel inhibitor, penitrem A, and utilize penitrem A to identify the novel mechanisms of BPA induced altered BK channel function. These alterations may explain the link to the BPA exposure and BPA associated increased risk of cardiovascular diseases. 


\section{References}

Albarwani S, Al-Siyabi S, Baomar H \& Hassan MO. (2010). Exercise training attenuates ageing-induced $\mathrm{BKCa}$ channel downregulation in rat coronary arteries. Exp Physio/ 95, 746-755.

Alonso-Magdalena P, Laribi O, Ropero AB, Fuentes E, Ripoll C, Soria B \& Nadal A. (2005). Low doses of bisphenol $A$ and diethylstilbestrol impair $\mathrm{Ca} 2+$ signals in pancreatic alpha-cells through a nonclassical membrane estrogen receptor within intact islets of Langerhans. Environmental health perspectives 113, 969-977.

Amberg GC \& Santana LF. (2003). Downregulation of the BK channel beta1 subunit in genetic hypertension. Circ Res 93, 965-971.

Bichet D, Haass FA \& Jan LY. (2003). Merging functional studies with structures of inward-rectifier $\mathrm{K}(+)$ channels. Nat Rev Neurosci 4, 957-967.

Borbouse L, Dick GM, Asano S, Bender SB, Dincer UD, Payne GA, Neeb ZP, Bratz IN, Sturek M \& Tune JD. (2009). Impaired function of coronary $\mathrm{BK}(\mathrm{Ca})$ channels in metabolic syndrome. Am J Physiol Heart Circ Physiol 297, H1629-1637.

Bradley KK, Jaggar JH, Bonev AD, Heppner TJ, Flynn ER, Nelson MT \& Horowitz B. (1999). Kir2.1 encodes the inward rectifier potassium channel in rat arterial smooth muscle cells. The Journal of physiology 515 ( Pt 3), 639-651.

Brenner R, Perez GJ, Bonev AD, Eckman DM, Kosek JC, Wiler SW, Patterson AJ, Nelson MT \& Aldrich RW. (2000). Vasoregulation by the beta1 subunit of the calcium-activated potassium channel. Nature 407, 870-876.

Brotons JA, Olea-Serrano MF, Villalobos M, Pedraza V \& Olea N. (1995). Xenoestrogens released from lacquer coatings in food cans. Environmental health perspectives 103, 608-612.

Bukiya AN, Liu J, Toro L \& Dopico AM. (2007). Beta1 (KCNMB1) subunits mediate lithocholate activation of large-conductance $\mathrm{Ca} 2+$-activated $\mathrm{K}+$ channels and dilation in small, resistance-size arteries. Mol Pharmacol 72, 359-369.

Burnham MP, Johnson IT \& Weston AH. (2006). Reduced Ca2+-dependent activation of large-conductance $\mathrm{Ca} 2+$-activated $\mathrm{K}+$ channels from arteries of Type 2 diabetic Zucker diabetic fatty rats. American journal of physiology Heart and circulatory physiology 290, H1520-1527. 
Butler A, Tsunoda S, McCobb DP, Wei A \& Salkoff L. (1993). mSlo, a complex mouse gene encoding "maxi" calcium-activated potassium channels. Science 261, 221-224.

Calafat AM, Kuklenyik Z, Reidy JA, Caudill SP, Ekong J \& Needham LL. (2005). Urinary concentrations of bisphenol $A$ and 4-nonylphenol in a human reference population. Environmental health perspectives 113, 391-395.

Calafat AM, Ye X, Wong LY, Reidy JA \& Needham LL. (2008). Exposure of the U.S. population to bisphenol A and 4-tertiary-octylphenol: 2003-2004. Environmental health perspectives 116, 39-44.

Carl A \& Sanders KM. (1989). Ca2+-activated K channels of canine colonic myocytes. The American journal of physiology 257, C470-480.

Chen TT, Luykenaar KD, Walsh EJ, Walsh MP \& Cole WC. (2006). Key role of $\mathrm{Kv1}$ channels in vasoregulation. Circulation research 99, 53-60.

Coiret G, Borowiec AS, Mariot P, Ouadid-Ahidouch H \& Matifat F. (2007). The antiestrogen tamoxifen activates BK channels and stimulates proliferation of MCF-7 breast cancer cells. Molecular pharmacology 71, 843-851.

Cox DH \& Aldrich RW. (2000). Role of the beta1 subunit in large-conductance $\mathrm{Ca}(2+)$-activated $\mathrm{K}(+)$ channel gating energetics. Mechanisms of enhanced $\mathrm{Ca}(2+)$ sensitivity. The Journal of general physiology 116, 411432.

Cox DH, Cui J \& Aldrich RW. (1997). Allosteric gating of a large conductance Caactivated $\mathrm{K}+$ channel. The Journal of general physiology 110, 257-281.

Cui J \& Aldrich RW. (2000). Allosteric linkage between voltage and $\mathrm{Ca}(2+)$ dependent activation of BK-type mslo1 K(+) channels. Biochemistry 39, 15612-15619.

Dart C \& Standen NB. (1995). Activation of ATP-dependent K+ channels by hypoxia in smooth muscle cells isolated from the pig coronary artery. The Journal of physiology 483 ( Pt 1), 29-39.

Dick GM, Bratz IN, Borbouse L, Payne GA, Dincer UD, Knudson JD, Rogers PA \& Tune JD. (2008). Voltage-dependent $\mathrm{K}+$ channels regulate the duration of reactive hyperemia in the canine coronary circulation. American journal of physiology Heart and circulatory physiology 294, H2371-2381.

Dick GM, Rossow CF, Smirnov S, Horowitz B \& Sanders KM. (2001). Tamoxifen activates smooth muscle BK channels through the regulatory beta 1 subunit. The Journal of biological chemistry 276, 34594-34599. 
Dick GM \& Tune JD. (2010). Role of potassium channels in coronary vasodilation. Exp Biol Med (Maywood) 235, 10-22.

Dimitropoulou C, Han G, Miller AW, Molero M, Fuchs LC, White RE \& Carrier GO. (2002). Potassium (BK(Ca)) currents are reduced in microvascular smooth muscle cells from insulin-resistant rats. American journal of physiology Heart and circulatory physiology 282, H908-917.

Dopico AM, Anantharam V \& Treistman SN. (1998). Ethanol increases the activity of $\mathrm{Ca}(++)$-dependent $\mathrm{K}+(\mathrm{mslo})$ channels: functional interaction with cytosolic Ca++. J Pharmacol Exp Ther 284, 258-268.

Edwards FR \& Hirst GD. (1988). Inward rectification in submucosal arterioles of guinea-pig ileum. The Journal of physiology 404, 437-454.

Edwards FR, Hirst GD \& Silverberg GD. (1988). Inward rectification in rat cerebral arterioles; involvement of potassium ions in autoregulation. The Journal of physiology 404, 455-466.

Edwards G, Niederste-Hollenberg A, Schneider J, Noack T \& Weston AH. (1994). Ion channel modulation by NS 1619, the putative BKCa channel opener, in vascular smooth muscle. British journal of pharmacology 113, 1538-1547.

Eriksen GS, Jaderlund KH, Moldes-Anaya A, Schonheit J, Bernhoft A, Jaeger G, Rundberget $T$ \& Skaar I. Poisoning of dogs with tremorgenic Penicillium toxins. Med Mycol 48, 188-196.

Faraci FM \& Sigmund CD. (1999). Vascular biology in genetically altered mice : smaller vessels, bigger insight. Circ Res 85, 1214-1225.

Fernandez MF, Arrebola JP, Taoufiki J, Navalon A, Ballesteros O, Pulgar R, Vilchez JL \& Olea N. (2007). Bisphenol-A and chlorinated derivatives in adipose tissue of women. Reproductive toxicology 24, 259-264.

Galvez A, Gimenez-Gallego G, Reuben JP, Roy-Contancin L, Feigenbaum P, Kaczorowski GJ \& Garcia ML. (1990). Purification and characterization of a unique, potent, peptidyl probe for the high conductance calciumactivated potassium channel from venom of the scorpion Buthus tamulus. The Journal of biological chemistry 265, 11083-11090.

Girouard H, Bonev AD, Hannah RM, Meredith A, Aldrich RW \& Nelson MT. (2010). Astrocytic endfoot Ca2+ and BK channels determine both arteriolar dilation and constriction. Proceedings of the National Academy of Sciences of the United States of America 107, 3811-3816. 
Gutman GA, Chandy KG, Adelman JP, Aiyar J, Bayliss DA, Clapham DE, Covarriubias M, Desir GV, Furuichi K, Ganetzky B, Garcia ML, Grissmer S, Jan LY, Karschin A, Kim D, Kuperschmidt S, Kurachi Y, Lazdunski M, Lesage $F$, Lester HA, McKinnon D, Nichols CG, O'Kelly I, Robbins J, Robertson GA, Rudy B, Sanguinetti M, Seino S, Stuehmer W, Tamkun MM, Vandenberg CA, Wei A, Wulff H \& Wymore RS. (2003). International Union of Pharmacology. XLI. Compendium of voltage-gated ion channels: potassium channels. Pharmacol Rev 55, 583-586.

Hicks GA \& Marrion NV. (1998). Ca2+-dependent inactivation of large conductance $\mathrm{Ca} 2+-$ activated $\mathrm{K}+(\mathrm{BK})$ channels in rat hippocampal neurones produced by pore block from an associated particle. The Journal of physiology 508 ( Pt 3), 721-734.

Holdefer WF, Sheppard LC, Todd NW \& Carney EK. (1976). The application of a semiautomated postoperative care program in a community hospital: early results. Ann Thorac Surg 21, 431-435.

Holland M, Langton PD, Standen NB \& Boyle JP. (1996). Effects of the BKCa channel activator, NS1619, on rat cerebral artery smooth muscle. British journal of pharmacology 117, 119-129.

Hou S, Heinemann SH \& Hoshi T. (2009). Modulation of BKCa channel gating by endogenous signaling molecules. Physiology 24, 26-35.

Hugo ER, Brandebourg TD, Woo JG, Loftus J, Alexander JW \& Ben-Jonathan N. (2008). Bisphenol A at environmentally relevant doses inhibits adiponectin release from human adipose tissue explants and adipocytes. Environ Health Perspect 116, 1642-1647.

Kaczorowski GJ, Knaus HG, Leonard RJ, McManus OB \& Garcia ML. (1996). High-conductance calcium-activated potassium channels; structure, pharmacology, and function. J Bioenerg Biomembr 28, 255-267.

Kang JH, Kito K \& Kondo F. (2003). Factors influencing the migration of bisphenol A from cans. J Food Prot 66, 1444-1447.

King JT, Lovell PV, Rishniw M, Kotlikoff MI, Zeeman ML \& McCobb DP. (2006). Beta2 and beta4 subunits of BK channels confer differential sensitivity to acute modulation by steroid hormones. J Neurophysio/ 95, 2878-2888.

Knaus HG, Garcia-Calvo M, Kaczorowski GJ \& Garcia ML. (1994a). Subunit composition of the high conductance calcium-activated potassium channel from smooth muscle, a representative of the mSlo and slowpoke family of potassium channels. The Journal of biological chemistry 269, 3921-3924. 
Knaus HG, McManus OB, Lee SH, Schmalhofer WA, Garcia-Calvo M, Helms LM, Sanchez M, Giangiacomo K, Reuben JP, Smith AB, 3rd \& et al. (1994b). Tremorgenic indole alkaloids potently inhibit smooth muscle highconductance calcium-activated potassium channels. Biochemistry 33, 5819-5828.

Krishnan AV, Stathis P, Permuth SF, Tokes L \& Feldman D. (1993). Bisphenol-A: an estrogenic substance is released from polycarbonate flasks during autoclaving. Endocrinology 132, 2279-2286.

Kubo Y, Adelman JP, Clapham DE, Jan LY, Karschin A, Kurachi Y, Lazdunski M, Nichols CG, Seino S \& Vandenberg CA. (2005). International Union of Pharmacology. LIV. Nomenclature and molecular relationships of inwardly rectifying potassium channels. Pharmacol Rev 57, 509-526.

Kuiper GG, Carlsson B, Grandien K, Enmark E, Haggblad J, Nilsson S \& Gustafsson JA. (1997). Comparison of the ligand binding specificity and transcript tissue distribution of estrogen receptors alpha and beta. Endocrinology 138, 863-870.

Lang IA, Galloway TS, Scarlett A, Henley WE, Depledge M, Wallace RB \& Melzer D. (2008a). Association of urinary bisphenol A concentration with medical disorders and laboratory abnormalities in adults. JAMA : the journal of the American Medical Association 300, 1303-1310.

Lang IA, Galloway TS, Scarlett A, Henley WE, Depledge M, Wallace RB \& Melzer D. (2008b). Association of urinary bisphenol A concentration with medical disorders and laboratory abnormalities in adults. JAMA 300, 1303-1310.

Lewis PR, Donoghue MB, Hocking AD, Cook L \& Granger LV. (2005). Tremor syndrome associated with a fungal toxin: sequelae of food contamination. Med J Aust 182, 582-584.

Li D, Zhou Z, Qing D, He Y, Wu T, Miao M, Wang J, Weng X, Ferber JR, Herrinton LJ, Zhu Q, Gao E, Checkoway H \& Yuan W. (2010). Occupational exposure to bisphenol-A (BPA) and the risk of self-reported male sexual dysfunction. Hum Reprod 25, 519-527.

Lind PM \& Lind L. (2011). Circulating levels of bisphenol A and phthalates are related to carotid atherosclerosis in the elderly. Atherosclerosis 218, 207213. 
Lippiat JD, Standen NB, Harrow ID, Phillips SC \& Davies NW. (2003). Properties of $\mathrm{BK}(\mathrm{Ca})$ channels formed by bicistronic expression of hSloalpha and beta1-4 subunits in HEK293 cells. J Membr Biol 192, 141-148.

Liu Y, Hudetz AG, Knaus HG \& Rusch NJ. (1998). Increased expression of $\mathrm{Ca} 2+-$ sensitive $\mathrm{K}+$ channels in the cerebral microcirculation of genetically hypertensive rats: evidence for their protection against cerebral vasospasm. Circ Res 82, 729-737.

Liu Y, Pleyte K, Knaus HG \& Rusch NJ. (1997). Increased expression of Ca2+sensitive $\mathrm{K}+$ channels in aorta of hypertensive rats. Hypertension 30, 1403-1409.

Lovell PV, King JT \& McCobb DP. (2004). Acute modulation of adrenal chromaffin cell BK channel gating and cell excitability by glucocorticoids. $J$ Neurophysiol 91, 561-570.

Lu T, Wang XL, He T, Zhou W, Kaduce TL, Katusic ZS, Spector AA \& Lee HC. (2005). Impaired arachidonic acid-mediated activation of largeconductance $\mathrm{Ca} 2+-$ activated $\mathrm{K}+$ channels in coronary arterial smooth muscle cells in Zucker Diabetic Fatty rats. Diabetes 54, 2155-2163.

Lu T, Ye D, He T, Wang XL, Wang HL \& Lee HC. (2008). Impaired Ca2+dependent activation of large-conductance $\mathrm{Ca} 2+$-activated $\mathrm{K}+$ channels in the coronary artery smooth muscle cells of Zucker Diabetic Fatty rats. Biophysical journal 95, 5165-5177.

MacKinnon R. (2003). Potassium channels. FEBS letters 555, 62-65.

Marijic J, Li Q, Song M, Nishimaru K, Stefani E \& Toro L. (2001). Decreased expression of voltage- and $\mathrm{Ca}(2+)$-activated $\mathrm{K}(+)$ channels in coronary smooth muscle during aging. Circ Res 88, 210-216.

McGahon MK, Dash DP, Arora A, Wall N, Dawicki J, Simpson DA, Scholfield CN, McGeown JG \& Curtis TM. (2007). Diabetes downregulates largeconductance $\mathrm{Ca2}+$-activated potassium beta 1 channel subunit in retinal arteriolar smooth muscle. Circulation research 100, 703-711.

Meera P, Wallner M \& Toro L. (2000). A neuronal beta subunit (KCNMB4) makes the large conductance, voltage- and $\mathrm{Ca} 2+$-activated $\mathrm{K}+$ channel resistant to charybdotoxin and iberiotoxin. Proceedings of the National Academy of Sciences of the United States of America 97, 5562-5567.

Melzer D, Rice NE, Lewis C, Henley WE \& Galloway TS. (2010). Association of urinary bisphenol a concentration with heart disease: evidence from NHANES 2003/06. PLoS One 5, e8673. 
Meredith AL, Wiler SW, Miller BH, Takahashi JS, Fodor AA, Ruby NF \& Aldrich RW. (2006). BK calcium-activated potassium channels regulate circadian behavioral rhythms and pacemaker output. Nature neuroscience 9, 10411049.

Miller C, Moczydlowski E, Latorre R \& Phillips M. (1985). Charybdotoxin, a protein inhibitor of single $\mathrm{Ca} 2+-$ activated $\mathrm{K}+$ channels from mammalian skeletal muscle. Nature 313, 316-318.

Miura H, Wachtel RE, Loberiza FR, Jr., Saito T, Miura M, Nicolosi AC \& Gutterman DD. (2003). Diabetes mellitus impairs vasodilation to hypoxia in human coronary arterioles: reduced activity of ATP-sensitive potassium channels. Circulation research 92, 151-158.

Miyamoto K \& Kotake M. (2006). Estimation of daily bisphenol a intake of Japanese individuals with emphasis on uncertainty and variability. Environ Sci 13, 15-29.

Moosmang S, Schulla V, Welling A, Feil R, Feil S, Wegener JW, Hofmann F \& Klugbauer N. (2003). Dominant role of smooth muscle L-type calcium channel Cav1.2 for blood pressure regulation. Embo J 22, 6027-6034.

Nadal A, Ropero AB, Laribi O, Maillet M, Fuentes E \& Soria B. (2000). Nongenomic actions of estrogens and xenoestrogens by binding at a plasma membrane receptor unrelated to estrogen receptor alpha and estrogen receptor beta. Proceedings of the National Academy of Sciences of the United States of America 97, 11603-11608.

Nelson MT \& Brayden JE. (1993). Regulation of arterial tone by calciumdependent $\mathrm{K}+$ channels and ATP-sensitive $\mathrm{K}+$ channels. Cardiovasc Drugs Ther 7 Suppl 3, 605-610.

Nelson MT, Cheng H, Rubart M, Santana LF, Bonev AD, Knot HJ \& Lederer WJ. (1995). Relaxation of arterial smooth muscle by calcium sparks. Science 270, 633-637.

Nelson MT, Patlak JB, Worley JF \& Standen NB. (1990). Calcium channels, potassium channels, and voltage dependence of arterial smooth muscle tone. The American journal of physiology 259, C3-18.

Nishimaru K, Eghbali M, Lu R, Marijic J, Stefani E \& Toro L. (2004a). Functional and molecular evidence of MaxiK channel beta1 subunit decrease with coronary artery ageing in the rat. The Journal of physiology 559, 849-862. 
Nishimaru K, Eghbali M, Stefani E \& Toro L. (2004b). Function and clustered expression of MaxiK channels in cerebral myocytes remain intact with aging. Exp Gerontol 39, 831-839.

Norris PJ, Smith CC, De Belleroche J, Bradford HF, Mantle PG, Thomas AJ \& Penny RH. (1980). Actions of tremorgenic fungal toxins on neurotransmitter release. J Neurochem 34, 33-42.

Nunez AA, Kannan K, Giesy JP, Fang J \& Clemens LG. (2001). Effects of bisphenol $A$ on energy balance and accumulation in brown adipose tissue in rats. Chemosphere 42, 917-922.

Olesen SP, Munch E, Moldt P \& Drejer J. (1994a). Selective activation of Ca(2+)dependent $\mathrm{K}+$ channels by novel benzimidazolone. Eur J Pharmacol 251, 53-59.

Olesen SP, Munch E, Watjen F \& Drejer J. (1994b). NS 004--an activator of $\mathrm{Ca}(2+)$-dependent $\mathrm{K}+$ channels in cerebellar granule cells. Neuroreport $\mathbf{5}$, 1001-1004.

Petkov GV, Bonev AD, Heppner TJ, Brenner R, Aldrich RW \& Nelson MT. (2001). Beta1-subunit of the Ca2+-activated $\mathrm{K}+$ channel regulates contractile activity of mouse urinary bladder smooth muscle. The Journal of physiology 537, 443-452.

Pluger S, Faulhaber J, Furstenau M, Lohn M, Waldschutz R, Gollasch M, Haller H, Luft FC, Ehmke H \& Pongs O. (2000). Mice with disrupted BK channel beta1 subunit gene feature abnormal $\mathrm{Ca}(2+)$ spark/STOC coupling and elevated blood pressure. Circ Res 87, E53-60.

Pyott SJ, Meredith AL, Fodor AA, Vazquez AE, Yamoah EN \& Aldrich RW. (2007). Cochlear function in mice lacking the BK channel alpha, beta1, or beta4 subunits. The Journal of biological chemistry 282, 3312-3324.

Quayle JM, Nelson MT \& Standen NB. (1997). ATP-sensitive and inwardly rectifying potassium channels in smooth muscle. Physiological reviews 77 , 1165-1232.

Sanchez M \& McManus OB. (1996). Paxilline inhibition of the alpha-subunit of the high-conductance calcium-activated potassium channel. Neuropharmacology 35, 963-968.

Savabieasfahani M, Kannan K, Astapova O, Evans NP \& Padmanabhan V. (2006). Developmental programming: differential effects of prenatal exposure to bisphenol-A or methoxychlor on reproductive function. Endocrinology 147, 5956-5966. 
Solaro CR \& Lingle CJ. (1992). Trypsin-sensitive, rapid inactivation of a calciumactivated potassium channel. Science $257,1694-1698$.

Sones WR, Leblanc N \& Greenwood IA. (2009). Inhibition of vascular calciumgated chloride currents by blockers of $\mathrm{KCa} 1.1$, but not by modulators of KCa2.1 or KCa2.3 channels. Br J Pharmacol 158, 521-531.

Sprossmann F, Pankert P, Sausbier U, Wirth A, Zhou XB, Madlung J, Zhao H, Bucurenciu I, Jakob A, Lamkemeyer T, Neuhuber W, Offermanns S, Shipston MJ, Korth M, Nordheim A, Ruth P \& Sausbier M. (2009). Inducible knockout mutagenesis reveals compensatory mechanisms elicited by constitutive BK channel deficiency in overactive murine bladder. Febs J 276, 1680-1697.

Stahlhut RW, Welshons WV \& Swan SH. (2009). Bisphenol A data in NHANES suggest longer than expected half-life, substantial nonfood exposure, or both. Environ Health Perspect 117, 784-789.

Standen N. (2000). Tuning channels for blood pressure. Nature 407, 845, 847848.

Standen NB \& Quayle JM. (1998). K+ channel modulation in arterial smooth muscle. Acta Physiol Scand 164, 549-557.

Suzuki M, Li RA, Miki T, Uemura H, Sakamoto N, Ohmoto-Sekine Y, Tamagawa M, Ogura T, Seino S, Marban E \& Nakaya H. (2001). Functional roles of cardiac and vascular ATP-sensitive potassium channels clarified by Kir6.2-knockout mice. Circulation research 88, 570-577.

Toro B, Cox N, Wilson RJ, Garrido-Sanabria E, Stefani E, Toro L \& Zarei MM. (2006). KCNMB1 regulates surface expression of a voltage and Ca2+activated $\mathrm{K}+$ channel via endocytic trafficking signals. Neuroscience 142 , 661-669.

Toro L, Marijic J, Nishimaru K, Tanaka Y, Song M \& Stefani E. (2002). Aging, ion channel expression, and vascular function. Vascul Pharmacol 38, 73-80.

Tseng-Crank J, Foster CD, Krause JD, Mertz R, Godinot N, DiChiara TJ \& Reinhart PH. (1994). Cloning, expression, and distribution of functionally distinct $\mathrm{Ca}(2+)$-activated $\mathrm{K}+$ channel isoforms from human brain. Neuron 13, 1315-1330.

Valverde MA, Rojas P, Amigo J, Cosmelli D, Orio P, Bahamonde MI, Mann GE, Vergara C \& Latorre R. (1999). Acute activation of Maxi-K channels (hSlo) by estradiol binding to the beta subunit. Science 285, 1929-1931. 
Vandenberg LN, Maffini MV, Sonnenschein C, Rubin BS \& Soto AM. (2009). Bisphenol-A and the great divide: a review of controversies in the field of endocrine disruption. Endocr Rev 30, 75-95.

Vandenberg LN, Maffini MV, Wadia PR, Sonnenschein C, Rubin BS \& Soto AM. (2007). Exposure to environmentally relevant doses of the xenoestrogen bisphenol-A alters development of the fetal mouse mammary gland. Endocrinology 148, 116-127.

Volkel W, Bittner N \& Dekant W. (2005). Quantitation of bisphenol A and bisphenol A glucuronide in biological samples by high performance liquid chromatography-tandem mass spectrometry. Drug Metab Dispos 33, 1748-1757.

Volkel W, Colnot T, Csanady GA, Filser JG \& Dekant W. (2002). Metabolism and kinetics of bisphenol a in humans at low doses following oral administration. Chem Res Toxicol 15, 1281-1287.

Wallner M, Meera P \& Toro L. (1999). Molecular basis of fast inactivation in voltage and $\mathrm{Ca} 2+$-activated $\mathrm{K}+$ channels: a transmembrane beta-subunit homolog. Proceedings of the National Academy of Sciences of the United States of America 96, 4137-4142.

Walsh DE, Dockery P \& Doolan CM. (2005). Estrogen receptor independent rapid non-genomic effects of environmental estrogens on $[\mathrm{Ca} 2+] \mathrm{i}$ in human breast cancer cells. Molecular and cellular endocrinology 230, 2330.

Watson CS, Alyea RA, Jeng YJ \& Kochukov MY. (2007). Nongenomic actions of low concentration estrogens and xenoestrogens on multiple tissues. Molecular and cellular endocrinology 274, 1-7.

Welshons WV, Nagel SC \& vom Saal FS. (2006). Large effects from small exposures. III. Endocrine mechanisms mediating effects of bisphenol A at levels of human exposure. Endocrinology 147, S56-69.

Wetherill YB, Fisher NL, Staubach A, Danielsen M, de Vere White RW \& Knudsen KE. (2005). Xenoestrogen action in prostate cancer: pleiotropic effects dependent on androgen receptor status. Cancer Res 65, 54-65.

Wetherill YB, Petre CE, Monk KR, Puga A \& Knudsen KE. (2002). The xenoestrogen bisphenol $A$ induces inappropriate androgen receptor activation and mitogenesis in prostatic adenocarcinoma cells. Mol Cancer Ther 1, 515-524. 
Wilson NK, Chuang JC, Morgan MK, Lordo RA \& Sheldon LS. (2007). An observational study of the potential exposures of preschool children to pentachlorophenol, bisphenol-A, and nonylphenol at home and daycare. Environ Res 103, 9-20.

Wulff H, Castle NA \& Pardo LA. (2009). Voltage-gated potassium channels as therapeutic targets. Nat Rev Drug Discov 8, 982-1001.

Xia XM, Ding JP, Zeng XH, Duan KL \& Lingle CJ. (2000). Rectification and rapid activation at low $\mathrm{Ca} 2+$ of $\mathrm{Ca} 2+$-activated, voltage-dependent $\mathrm{BK}$ currents: consequences of rapid inactivation by a novel beta subunit. The Journal of neuroscience : the official journal of the Society for Neuroscience 20, 4890-4903.

Xu H, Garver H, Galligan JJ \& Fink GD. (2011). Large-conductance Ca2+activated $\mathrm{K}+$ channel beta1-subunit knockout mice are not hypertensive. Am J Physiol Heart Circ Physiol 300, H476-485.

Yang Y, Murphy TV, Ella SR, Grayson TH, Haddock R, Hwang YT, Braun AP, Peichun G, Korthuis RJ, Davis MJ \& Hill MA. (2009). Heterogeneity in function of small artery smooth muscle BKCa: involvement of the beta1subunit. The Journal of physiology 587, 3025-3044.

Yoshida H, Feig JE, Morrissey A, Ghiu IA, Artman M \& Coetzee WA. (2004). K ATP channels of primary human coronary artery endothelial cells consist of a heteromultimeric complex of Kir6.1, Kir6.2, and SUR2B subunits. $J$ Mol Cell Cardiol 37, 857-869.

Yuan XJ, Wang J, Juhaszova M, Golovina VA \& Rubin LJ. (1998). Molecular basis and function of voltage-gated $\mathrm{K}+$ channels in pulmonary arterial smooth muscle cells. The American journal of physiology 274, L621-635.

Zaritsky JJ, Eckman DM, Wellman GC, Nelson MT \& Schwarz TL. (2000). Targeted disruption of Kir2.1 and Kir2.2 genes reveals the essential role of the inwardly rectifying $\mathrm{K}(+)$ current in $\mathrm{K}(+)$-mediated vasodilation. Circulation research 87, 160-166.

Zhou W, Wang XL, Kaduce TL, Spector AA \& Lee HC. (2005). Impaired arachidonic acid-mediated dilation of small mesenteric arteries in Zucker diabetic fatty rats. American journal of physiology Heart and circulatory physiology 288, $\mathrm{H} 2210-2218$. 
CHAPTER 2 Penitrem A as a tool to understand the role of BK channels in vascular function

As reviewed in JPET

Shinichi Asano, Ian N. Bratz, Zachary C. Berwick, Ibra S. Fancher, Johnathan D. Tune, and Gregory M. Dick

Division of Exercise Physiology, Center for Cardiovascular \& Respiratory Sciences, West Virginia University School of Medicine, Morgantown, WV (SA, ISF, GMD)

Department of Integrative Medical Sciences, Northeast Ohio Medical University, Rootstown, OH (INB)

Department of Cellular \& Integrative Physiology, Indiana University School of Medicine, Indianapolis, IN (ZCB, JDT)

Running title: Penitrem $A$ and vascular reactivity

Corresponding author: Gregory M. Dick, Ph.D., 1 Medical Center Drive, P.O. Box 9105, Morgantown, WV 26506, Phone (304) 293-2542, Fax (304) 293-5513, E-mail gmdick@hsc.wvu.edu

Number of text pages: 14

Number of tables: 1

Number of figures: 7

Number of references: 38

Number of words in the abstract: 230

Number of words in the introduction: 565

Number of words in the discussion: 1453

List of nonstandard abbreviations:

$\mathrm{BK}$ channel, large conductance $\mathrm{Ca}^{2+} /$ voltage-sensitive $\mathrm{K}^{+}$channel; $\mathrm{K}_{\mathrm{V}}$ channel, voltage-dependent $\mathrm{K}^{+}$channel; $\mathrm{K}_{\text {ATP }}$, ATP-dependent $\mathrm{K}^{+}$channel

Recommended section: Cardiovascular 


\section{Abstract}

Large conductance, $\mathrm{Ca}^{2+} /$ voltage-sensitive $\mathrm{K}^{+}(\mathrm{BK})$ channels are well characterized, but physiological roles, often determined through pharmacological manipulation, are less clear. Iberiotoxin is considered the "gold standard" antagonist, but cost and membrane-impermeability limit usefulness. Economical and membrane-permeable alternatives could facilitate the study of BK channels. Thus, we characterized the effect of penitrem A, a tremorgenic mycotoxin, on BK channels and demonstrate utility for studying vascular function in vitro and in vivo. Whole-cell currents from HEK 293 cells transfected with $h$ Slo $\alpha$ or $\alpha+\beta 1$ were blocked $>95 \%$ by penitrem A ( $\mathrm{IC}_{50} 6.4$ vs. $\left.64.4 \mathrm{nM} ; p<0.05\right)$. Further, penitrem A inhibited BK channels in inside-out and cell-attached patches, whereas iberiotoxin could not. Inhibitory effects of penitrem A on whole-cell $\mathrm{K}^{+}$ currents were equivalent to iberiotoxin in canine coronary smooth muscle cells. As for specificity, penitrem $\mathrm{A}$ had no effect on native delayed rectifier $\mathrm{K}^{+}$current in canine coronary smooth muscle, cloned human $\mathrm{K}_{\mathrm{v}} 1.5$ channels, or pinacidilinduced relaxation of canine coronary arteries. Penitrem A enhanced sensitivity to $\mathrm{K}^{+}$-induced contraction in canine coronary arteries by $23 \pm 5 \%(p<0.05)$ and increased the blood pressure response to phenylephrine in anesthetized mice by $36 \pm 11 \%(p<0.05)$. Our data indicate that penitrem $A$ is a useful tool to study the role of BK channels in vascular function and is practical for cell and tissue (in vitro) studies as well as anesthetized whole animal (in vivo) experiments. 


\section{Introduction}

Large conductance, $\mathrm{Ca}^{2+} /$ voltage-sensitive (BK) channels, composed of pore forming $\alpha$ and auxiliary $\beta 1$ subunits, may be key regulators of arterial tone via negative feedback (Nelson et al., 1995; Jaggar et al., 2000). Indeed, altered $\alpha$ or $\beta 1$ expression is associated with vascular dysfunction in hypertension, diabetes, and aging (Liu et al., 1998; Brenner et al., 2000; Amberg et al., 2003; Borbouse et al., 2009). Genetic deletion of $\alpha$ or $\beta 1$ subunits produces hypertension; however, in addition to presumed changes total peripheral resistance, the role of adrenal BK channels to regulate aldosterone production must also be considered (Cysewski et al., 1975; Sausbier et al., 2005). In contrast to the original report (Brenner et al., 2000), a recent study indicated that $\beta 1$ knockout mice are normotensive (Xu et al., 2011). Thus, much remains to be determined about the physiological roles of BK channels and/or compensations in response to $\mathrm{BK}$ channel gene deletion.

Adding complexity to our understanding of BK channel function is heterogeneity between vascular beds (Yang et al., 2009). While BK channels appear extremely important in regulating cerebral vascular tone (Brayden \& Nelson, 1992; Knot et al., 1998), these channels are arguably less important in skeletal muscle arteries (Kotecha \& Hill, 2005; Yang et al., 2009) or coronary arteries (Rogers et al., 2006; Borbouse et al., 2010a; Borbouse et al., 2010b). Clearly, the regulation of BK channels is extremely complex and governed by multiple endogenous signaling molecules (Hou et al., 2009). Thus, understanding the physiological roles and mechanisms of BK channel activation will require 
additional research using a combination of genetic models and pharmacological tools.

Since the identification and characterization of peptide toxins in scorpion venom, iberiotoxin has become the "gold standard" for pharmacological study of BK channels due to selectivity and potency ( $\left.\mathrm{IC}_{50} 0.25 \mathrm{nM}\right)$ (Galvez et al., 1990). However, a recent study determined the $\mathrm{IC}_{50}$ of iberiotoxin is much higher (33$371 \mathrm{nM}$ ) than the concentrations commonly used (Lippiat et al., 2003). Additionally, iberiotoxin is prohibitively expensive for many isolated organ and whole-animal studies and its membrane-impermeability creates difficulty for cellattached or inside-out patch clamp experiments. It would be beneficial to identify an economical and membrane-permeable alternative to facilitate physiological and pharmacological studies of BK channels. Penitrem A is one such candidate molecule (Knaus et al., 1994) and has been used previously as an inhibitor of BK channels in smooth muscle (Cotton et al., 1997; Borbouse et al., 2009; Asano et al., 2010).

Little, however, is known about the basic pharmacological properties of penitrem $\mathrm{A}$. For example, the $\mathrm{IC}_{50}$ for block of $\mathrm{BK}$ channels has not been published, nor are there reports of its specificity in regard to other $\mathrm{K}^{+}$channels. Our study was designed to characterize some pharmacological properties of penitrem $A$ as a BK channel antagonist and to demonstrate utility in determining the physiological role of BK channels in vascular smooth muscle. Experiments were performed at the cell, tissue, and whole animal level. We used patch clamp techniques to assess the inhibitory effect, determine whether the $\beta 1$ subunit 
influenced block, and illustrate advantages of a membrane-permeable inhibitor. We measured the isometric tension of coronary arteries and the blood pressure of anesthetized mice to determine whether penitrem A altered vascular reactivity in vitro or in vivo. We conclude that penitrem A, compared to iberiotoxin, is an antagonist of BK channels that is comparable in potency and efficacy, but is more useful and less expensive. 


\section{Methods}

\section{Animal models}

All animal procedures and protocols were approved by institutional committees and followed guidelines set forth in the Guide for the Care and Use of Laboratory Animals (National Academy Press, 2011). Male C57BL/6 mice 10-12 weeks of age were used for in vivo blood pressure experiments. As described below, mice were anesthetized to a surgical plane of anesthesia prior to experiments and euthanized thereafter. Coronary arteries from male mongrel dogs were used for in vitro isometric tension experiments as described previously (Rogers et al., 2006). In brief, anesthetized dogs were used for unrelated experiments involving a thoracotomy; the heart was fibrillated and removed to isolate coronary arteries. For patch clamp experiments on native vascular smooth muscle cells, arteries were obtained from a variety of different species (rat, mouse, dog, and pig). Arteries (cerebral, coronary, femoral, and aorta) were taken from animals euthanized following unrelated experiments.

\section{Cell culture and transfection}

HEK 293 cells (Stratagene, La Jolla, CA) were grown in Dulbecco's Modified Eagle Medium supplemented with $10 \%$ FBS, 100 units $/ \mathrm{ml}$ penicillin, $100 \mu \mathrm{g} / \mathrm{ml}$ streptomycin, and culture flasks were incubated in a $5 \% \mathrm{CO}_{2}$ incubator at $37{ }^{\circ} \mathrm{C}$. Plasmids encoding $h$ Slo $\alpha$ and $h$ Slo $\alpha+\beta 1$ were kindly provided by Dr. Jonathan Lippiat (Lippiat et al., 2003) and $h K_{V} 1.5$ plasmid was a generous gift from Dr. Jeffrey R Martens (McEwen et al., 2007). Cells were transiently transfected with 
$p \mathrm{IRES}-h$ Slo $\alpha$ or $p \mathrm{RES}-h$ Slo $\alpha \beta 1$ and pmaxGFP (AMAXA, Gaithersburg, MD) using Lipofectamine LTX with PLUS reagent (Invitrogen, Carlsbad, CA). Cells at 50-70\% confluence in $35 \mathrm{~mm}$ dishes were transfected with $0.5-2.5 \mathrm{mg}$ of DNA and currents were recorded from GFP positive cells 1-3 days later. Transfected cells were selected in media supplemented with $0.5 \mathrm{mg} / \mathrm{ml} \mathrm{G418} \mathrm{(Invitrogen,}$ Carlsbad, CA), 1\% FBS, $100 \mathrm{U} / \mathrm{ml}$ penicillin, and $100 \mu \mathrm{g} / \mathrm{ml}$ streptomycin.

\section{Electrophysiology}

BK channel currents were recorded at room temperature from inside-out and whole-cell patches as previously described (Asano et al., 2010). The bath flowed $\sim 2-3 \mathrm{ml} / \mathrm{min}$ into a $\sim 0.2-0.3 \mathrm{ml}$ chamber throughout the recordings. For whole-cell recordings, bath solution contained $(\mathrm{mM}) 135 \mathrm{NaCl}, 5 \mathrm{KCl}, 2 \mathrm{CaCl}_{2}, 1 \mathrm{MgCl}_{2}, 10$ glucose, 10 HEPES, and 5 Tris; pH 7.4. Pipette solution contained (mM) 140 $\mathrm{KCl}, 1 \mathrm{MgCl}_{2}, 1 \mathrm{EGTA}, 10$ HEPES, $1 \mathrm{Mg}-\mathrm{ATP}, 0.1 \mathrm{Na}-\mathrm{GTP}$ and 5 Tris; $\mathrm{pH}$ 7.1. Inside-out recordings were made in symmetrical $(\mathrm{mM}) 140 \mathrm{KCl}, 1 \mathrm{MgCl}_{2}, 1$ EGTA, 10 HEPES, 5 Tris; pH 7.1; pCa 7 (Maxchelator; http://www.stanford.edu/ cpatton/maxc.html). Stock solutions of penitrem A (MP Biomedicals, Solon, OH) were prepared in DMSO and diluted for 1:10,000 for experiments. Iberiotoxin (AnaSpec, San Jose, CA) was dissolved in water and diluted 1:1000 for experiments.

\section{Isometric tension studies}


Isometric tension was measured from segments of canine left circumflex coronary arteries as described previously (Rogers et al., 2006). Arteries were denuded of endothelium and the lack of a relaxant response to acetylcholine (10 $\mu \mathrm{M})$ in pre-contracted arterial tissue confirmed the functional loss of endothelium. For the pinacidil concentration-response experiments, arteries were precontracted with $1 \mu \mathrm{M} \cup 46619$, a thromboxane $A_{2}$ mimetic, and the relaxation elicited by cumulative additions of pinacidil in the presence or absence of $1 \mu \mathrm{M}$ penitrem $\mathrm{A}$. For the $\mathrm{K}^{+}$concentration-response experiments, $\mathrm{KCl}$ was added cumulatively in the presence or absence of $1 \mu \mathrm{M}$ penitrem $\mathrm{A}$.

\section{Blood pressure measurements}

Mean arterial pressure was measured as described previously (Ohanyan et al., 2011). Mice were anesthetized with sevoflurane gas (supplemented with $\mathrm{O}_{2}$ ) and placed on a heating table to maintain body temperature at $37^{\circ} \mathrm{C}$. A polyethylene catheter was placed into the jugular vein for bolus administrations of heparin (50 $\mathrm{U} / \mathrm{ml}$ ) and hexamethonium (5 mg/kg), a ganglionic blocker. A micro-tip transducer (Millar Instruments, Houston, TX) was placed in the femoral artery to measure mean arterial pressure and heart rate. Data were recorded with a Power Lab acquisition system (ADInstruments, Colorado Springs, CO). Phenylephrine (0.5 $\mu \mathrm{g} / \mathrm{kg} / \mathrm{min})$ and penitrem A (100 $\mu \mathrm{g} / \mathrm{kg} / \mathrm{min})$ were administered intravenously. Stock solutions of penitrem A were dissolved in ethanol and subsequently diluted in lactated Ringer's solution; phenylephrine was diluted in lactated Ringer's solution. 


\section{Statistics}

Data are presented as the mean and standard error of $n$ number of samples (e.g., number of patches, cells, dogs, or mice as described in the text and figure legends). When two values were compared, paired or unpaired $t$-tests were used as appropriate. When three values were compared, one-way analysis of variance (ANOVA) was used. Current-voltage relationships and concentration-response curves were analyzed by two-way ANOVA. Bonferroni post hoc tests followed ANOVA to determine differences. In all tests, $p<0.05$ was considered significant. 


\section{Results}

Penitrem A inhibits BK channels in a concentration-dependent manner: influence of the $\beta 1$ subunit.

Whole-cell patch clamp techniques were used to determine the effect of penitrem A on cloned BK channels ( $\alpha$ or $\alpha+\beta 1$ ) expressed in HEK 293 cells. Currents at $+100 \mathrm{mV}$ were recorded under control conditions (in the presence of vehicle; $0.01 \%$ DMSO) and after addition of penitrem A (Fig. 1A \& B). In cells expressing BK channels composed solely of $\alpha$ subunits, inhibition of current by $100 \mathrm{nM}$ penitrem A was $93 \pm 1 \%(n=13$ cells; Fig. 1A\&C). In contrast, when BK channels contained the regulatory $\beta 1$ subunit, block by $100 \mathrm{nM}$ penitrem $A$ was only $41 \pm 9 \%$ ( $n=9$ cells; Fig. 1B\&C). Over several log orders of penitrem A concentrations, BK channels composed of $\alpha$ subunits alone were more sensitive to block than BK channels containing the $\beta 1$ subunit (Fig. 1C). The half-maximal inhibitory concentration $\left(\mathrm{IC}_{50}\right)$ of penitrem $\mathrm{A}$ for $\mathrm{BK} \alpha$ was $6.4 \mathrm{nM}\left(\log \mathrm{IC}_{50}=-8.20\right.$ $\pm 0.08 ; n=7-16$ cells). The $I_{50}$ of penitrem $A$ on $B K \alpha+\beta 1$ subunits was 64.4 $\mathrm{nM}\left(\log \mathrm{IC}_{50}=-7.19 \pm 0.07 ; \mathrm{n}=4-15\right.$ cells; $\left.p<0.05\right)$. Hill slopes were equivalent $(-$ $0.91 \pm 0.12$ vs. $-1.07 \pm 0.15)$. In addition to reduced sensitivity, the time course of channel block by penitrem A was slowed by the $\beta 1$ subunit (Fig. 1D \& E). The inhibitory effect of penitrem A on BK channel current was, for all practical purposes, irreversible (Fig. 2). When current in cells expressing BK channels composed of $\alpha+\beta 1$ subunits was inhibited by $1 \mu \mathrm{M}$ penitrem $A, 10$ or more min of washing was insufficient time for appreciable reversal (Fig. 2A). After 2 min of penitrem $A(1 \mu M)$ exposure, current was inhibited $91 \pm 2 \%(n=5$; Fig. 2B). Cells 
were studied in a $\sim 0.2-0.3 \mathrm{ml}$ chamber that was perfused at $\sim 2-3 \mathrm{ml} / \mathrm{min}$; however, washing cells for 14 min with penitrem A-free bath solution did not allow BK current to recover (Fig. 2B; current at the 20 min mark was only $6 \pm 2 \%$ of the control level). Similar irreversibility was observed in native smooth muscle cells (e.g., rat aorta) with lower concentrations of penitrem A (e.g., 50 nM; Fig. $2 C \& D)$

\section{Penitrem A, but not iberiotoxin, inhibits BK channels in inside-out patches.} Iberiotoxin blocks BK channels by "plugging" the pore from the extracellular side (Giangiacomo et al., 1992); therefore, one cannot use bath application of iberiotoxin to block BK channels in cell-attached or inside-out patches. A common strategy to overcome this limitation is to backfill patch pipettes with iberiotoxin, thus allowing some time for control measurements while iberiotoxin diffuses to the tip. A membrane-permeable BK channel antagonist could strengthen experimental design and allow more time for control measurements and/or interventions prior to BK channel block. We compared the effects of iberiotoxin (100 nM) and penitrem A (100 nM) on BK channels in cell-attached and inside-out patches (Fig. 3). As expected, bath application of iberiotoxin to inside-out patches of had no inhibitory effect on BK channel activity. In contrast, bath application of penitrem A inhibited BK channel activity in inside-out patches. Mean $\mathrm{NP}_{\mathrm{o}}$ of $\mathrm{BK} \alpha$ alone under control conditions, with iberiotoxin, and with penitrem A was $0.077 \pm 0.040,0.103 \pm 0.076$, and $0.002 \pm 0.001$, respectively. ( $p<0.05$ for penitrem $A, n=7-10)$. Similarly, mean $N_{\circ}$ of $B K \alpha+\beta 1$ under control 
conditions, with iberiotoxin, and with penitrem A was $0.401 \pm 0.158,0.564 \pm$ $0.235,0.015 \pm 0.014(p<0.05$ for penitrem $A, n=7-13)$. Like the whole-cell recordings, BK channel block by penitrem $A$ was not readily reversible with extensive washing. In contrast to the whole-cell recordings where $100 \mathrm{nM}$ penitrem $A$ inhibited $B K \alpha+\beta 1$ by less than half (Fig. 1), $100 \mathrm{nM}$ penitrem $A$ inhibited BK $\alpha+\beta 1$ in inside-out patches by $97 \pm 1 \%$. This increased inhibitory effect at the cytoplasmic face was also noted in the original description of penitrem A (Knaus et al., 1994).

\section{Specificity of penitrem A: block of BK, but not $K_{V}$ or $K_{A T P}$ channels.}

The effect of penitrem $\mathrm{A}$ to inhibit $\mathrm{K}^{+}$current in coronary artery smooth muscle cells is equivalent to iberiotoxin (Fig. 4). In coronary myocytes, penitrem A (300 $\mathrm{nM}$ ) inhibited BK current significantly, and the remaining current appeared to be mediated by $\mathrm{K}_{\mathrm{V}}$ channels (Fig. 4A \& B). After penitrem A treatment, iberiotoxin (100 nM) had no further inhibitory effect on current at +100 mV (Fig. 4C); when iberiotoxin was added first, penitrem A had no further inhibitory effect (Fig. 4D). It is unclear what $\mathrm{K}_{\mathrm{V}}$ channel type(s) mediate the delayed rectifier $\mathrm{K}^{+}$currents in smooth muscle, but $\mathrm{K}_{\mathrm{v}} 1.5$ has been suggested as a component (Chen et al., 2006; Dick et al., 2008). Thus, we determined whether penitrem A could inhibit cloned $\mathrm{K}_{\mathrm{V}} 1.5$ channels (Fig. 5A \& B). Whole-cell recordings of $\mathrm{K}_{\mathrm{V}} 1.5$ current were made from HEK 293 cells transfected with $h K_{V} 1.5$ plasmid (McEwen et al., 2007). Penitrem $A(1 \mu \mathrm{M})$ had no effect on $\mathrm{K}_{\mathrm{v}} 1.5$ channels; current at $+60 \mathrm{mV}$ in the presence of penitrem A was $105 \pm 6 \%$ of control $(n=5)$. We tested the effect of 
penitrem $\mathrm{A}$ on total outward $\mathrm{K}^{+}$current in a variety of other native vascular smooth muscle cells (Supplemental figure). In each species and tissue, penitrem A (1 mM) inhibited BK current (i.e., strongly outwardly rectifying current at positive potentials) and appeared to have little or no effect on native delayed rectifier channels.

$\mathrm{K}_{\mathrm{ATP}}$ channels are another major type of $\mathrm{K}^{+}$channel in coronary smooth muscle (Dart \& Standen, 1995); therefore, we determined whether penitrem A could inhibit $\mathrm{K}_{\text {ATP }}$ channels. Dog coronary arteries were contracted with U44619 (a thromboxane $A_{2}$ mimetic; $1 \mu \mathrm{M}$ ) and relaxed with pinacidil, a $\mathrm{K}_{\mathrm{ATP}}$ channel opener. These experiments were performed in the presence or absence of penitrem $A(1 \mu M)$. Pinacidil-induced relaxation was unaffected by penitrem $A$ (Fig. 5C \& D; arteries from $n=3$ dogs; maximum relaxation $91 \pm 5$ vs. $94 \pm 2 \%$ and $\log \mathrm{IC}_{50}=-5.94 \pm 0.11$ vs. $\left.-5.85 \pm 0.07\right)$. We performed patch clamp experiments to measure directly the effects penitrem $A$ on pinacidil-induced $\mathrm{K}_{\text {ATP }}$ current activation. Whole-cell current in mouse aortic myocytes $(n=6)$ was measured at $-50 \mathrm{mV}$ in symmetrical $140 \mathrm{mM} \mathrm{K}^{+}$. Pinacidil $(10 \mu \mathrm{M})$ activated 165 $\pm 49 \mathrm{pA}$ of inward current. Penitrem $\mathrm{A}(1 \mu \mathrm{M})$ had no effect on pinacidil-activated current ( $87 \pm 6 \%$ of control); however, glibenclamide $(10 \mu \mathrm{M})$ inhibited pinacidilactivated current $80 \pm 7 \%(p<0.05)$.

\section{Penitrem A augments smooth muscle contractility in vitro and in vivo.}

To test penitrem $A$ as a functional inhibitor of smooth muscle BK channels in vitro, $\mathrm{K}^{+}$concentration-response curves were constructed for coronary arteries in 
the presence or absence of $1 \mu \mathrm{M}$ penitrem $\mathrm{A}$. Inhibition of BK channels produced a leftward shift in the $\mathrm{K}^{+}$concentration-response curve (Fig. 6). Contractions with 20, 30, and $40 \mathrm{mM} \mathrm{K}^{+}$were increased $79 \pm 12,26 \pm 5$ and $12 \pm 4 \%$ by blocking BK channels with $1 \mu \mathrm{M}$ penitrem A ( $p<0.05$; arteries from $n=8$ dogs). To test penitrem $\mathrm{A}$ as a functional inhibitor of smooth muscle BK channels in vivo, blood pressure responses to phenylephrine, an $a_{1}$ adrenergic agonist, were measured in anesthetized mice. Hexamethonium (5 mg/kg i.v.), a nicotinic receptor antagonist, was used to eliminate reflex responses to blood pressure changes. Phenylephrine $(0.5 \mu \mathrm{g} / \mathrm{kg} / \mathrm{min}$ i.v. $)$ increased blood pressure to a steady state level and then addition of penitrem A (100 $\mu \mathrm{g} / \mathrm{kg} / \mathrm{min})$ increased blood pressure further (Fig. 7A). In 5 mice (Fig. 7B), phenylephrine increased mean blood pressure from $57 \pm 2$ to $77 \pm 1 \mathrm{mmHg}(p<0.05)$, while the addition of penitrem $\mathrm{A}$ further increased blood pressure to $84 \pm 3 \mathrm{mmHg}(p<0.05 \mathrm{vs}$. control and phenylephrine). 


\section{Discussion}

The objective of this study was to better characterize penitrem A as an inhibitor of BK channels (Knaus et al., 1994). Penitrem A has been used previously as inhibitor of BK channels in smooth muscle (Cotton et al., 1997;

Borbouse et al., 2009; Asano et al., 2010). Importantly, however, employment of penitrem $\mathrm{A}$ as a BK channel antagonist has been without a complete understanding of its pharmacological properties. For example, the $\mathrm{IC}_{50}$ was not known and it was unclear whether BK channel subunit composition might affect the block. We show that penitrem $A$ inhibits $B K \alpha$ and $\alpha+\beta 1$ with $\mathrm{IC}_{50}$ values of 6.4 and $64.4 \mathrm{nM}$ (Fig. 1) Additionally, the use of penitrem A to study BK channels has been, until recently (Borbouse et al., 2009; Borbouse et al., 2010a; Borbouse et al., 2010b), limited to in vitro studies, particularly patch clamp experiments. Thus, we further investigated penitrem A as a BK channel inhibitor to assess vascular function in vitro and in in vivo. We show that penitrem $A$ enhances smooth muscle contraction in vitro (Fig. 6) and increases total peripheral resistance in vivo (Fig. 7). Information regarding the specificity of penitrem A against other ion channels was limited to $\mathrm{Ca}^{2+}$-activated $\mathrm{Cl}^{-}$channels (Sones et al., 2009), where it had very little effect. Here we demonstrate no effect of penitrem $\mathrm{A}$ on native delayed rectifier, cloned $\mathrm{K}_{\mathrm{V}} 1.5$, or $\mathrm{K}_{\mathrm{ATP}}$ channels (Figs. 4 and 5 and Supplement). Iberiotoxin and penitrem $A$ are roughly equivalent in potency and efficacy (Fig. 4 and Table 1), but penitrem A is less than $0.1 \%$ of the cost on a per mole basis. We conclude that penitrem $A$ is comparable to 
iberiotoxin in potency, efficacy, and selectivity and, further, that penitrem A can be a more useful and economical alternative.

BK channel subunit knockout mice have become a popular experimental model for studying smooth muscle reactivity and a great deal of important information has been gleaned; however, this approach comes with certain limitations. For example, deletion of $\mathrm{K}^{+}$channel genes elicits phenotypic compensations that may compromise interpretation (Nerbonne et al., 2008). Such changes may explain variable observations regarding blood pressure in BK channel subunit knockout mice. For instance, BK $\beta 1$ subunit knockout mice were originally reported as hypertensive (Brenner et al., 2000; Pluger et al., 2000), but a recent study contradicted this (Xu et al., 2011). The earlier studies included acute measurements of blood pressure in conscious mice with arterial catheters, whereas the later study used radiotelemetry to monitor blood pressure continuously for 1 wk. Both approaches are valid and it remains unknown whether differences in the method of blood pressure measurement or the response to stress could explain the discrepancies; however, compensatory changes in other $\mathrm{K}^{+}$channels or physiological mechanisms might be responsible for observations of normal blood pressure in BK $\beta 1$ subunit knockout mice. An alternative explanation is that BK channels may play a minimal role in regulating total peripheral resistance. Thus, the power of traditional pharmacological approaches to inhibit BK channels in order to elucidate a mechanism of action should not be underestimated, as we (Borbouse et al., 2009; Borbouse et al., 2010a; Borbouse et al., 2010b) and others (Node et al., 1997) have previously 
demonstrated little, if any role, for BK channels in regulating coronary vascular tone using penitrem A, charybdotoxin, or iberiotoxin. No comparable studies of organ blood flow are available for BK channel subunit knockout mice; this is likely due to the difficulty of instrumenting small animals. Studies of BK channels in regional and systemic hemodynamics might be made more readily in larger animals by employing suitable pharmacological tools such as paxilline, lolitrem B, and penitrem A (Table 1). It must be kept in mind, however, that penitrem $A$ was first reported in the literature due to its tremorgenic effects; therefore, its use in vivo may best be limited to anesthetized animals because of potential neurological side effects and convulsant properties.

Some characteristics of BK channel block by penitrem $A$ are compared to those of other BK channel antagonists in Table 1. It is important to note that while experimental details such as patch potential and free $\mathrm{Ca}^{2+}$ are not identical, a fairly consistent picture emerges. Moreover, our data were generated using the plasmids of Lippiat and colleagues (2003), allowing a relatively direct comparison. Penitrem A appears to be one-half to one log order more potent than iberiotoxin, while the presence of $\beta 1$ subunits reduces sensitivity to either agent by a factor of 10 . All of the pharmacological tools characterized in Table 1 block BK channels with similar efficacy (>95\%). Penitrem A can inhibit BK channels whether it is applied from intracellular or extracellular side of the membrane; this property is shared by paxilline and lolitrem B, but not iberiotoxin. We found that $\beta 1$ subunits decrease BK channel sensitivity to penitrem $A$. This is different from paxilline or lolitrem $B$, which block BK $\alpha, \alpha+\beta 1$, and $\alpha+\beta 4$ with 
similar potency (Imlach et al., 2008). Specificity for BK channels is another issue surrounding the available antagonists. Paxilline has been reported as an inhibitor of $\mathrm{Ca}^{2+}$-activated $\mathrm{Cl}^{-}$channels, whereas penitrem $\mathrm{A}$ and iberiotoxin have much less effect (Sones et al., 2009). In the original report (Knaus et al., 1994), it was mentioned that paxilline weakly blocks delayed rectifier $\mathrm{K}^{+}$channels in mouse pancreatic $\beta$ cells, but we show here that penitrem A has no effect on native delayed rectifier, cloned $\mathrm{K}_{\mathrm{V}} 1.5$, or $\mathrm{K}_{\mathrm{ATP}}$ channels (Fig. 4 and 5). More studies will be necessary to determine possible off-target interactions of penitrem $A$; these, if any, may be expected to arise from introducing penitrem A into complex systems such as isolated organ or whole animal experiments.

Importantly, however, the effects of penitrem A we observed in isolated arteries in vitro and on blood pressure in vivo were relatively straightforward and can be interpreted as specific effects on BK channels (Figs. 6 and 7). For example, in Fig. 6, the effect of penitrem A to increase smooth muscle contraction is consistent with what has been reported previously for iberiotoxin (Brayden \& Nelson, 1992; Bratz et al., 2005). We assessed the effect of penitrem A on smooth muscle tone in vivo by measuring blood pressure in anesthetized mice (Fig. 7). C57BL/6 mice are a common background for engineered mice; therefore, these data may be a reference for those interested in using penitrem $A$ in knockout or transgenic mice. A recent study demonstrated that lolitrem B had no effect on blood pressure, but decreased heart, in mice (Imlach et al., 2010). Our first impression was that these results could be explained by a reflex adjustment of heart rate, and thus cardiac output, and ultimately blood pressure 
in response to an increase in total peripheral resistance. However, Imlach et al. went on to demonstrate an inhibitory effect of lolitrem B on heart rate in Langendorff-perfused hearts, where neural input is removed. The mechanism(s) by which lolitrem B reduces heart rate are unknown; however, it is important to note that they are not shared by penitrem A. We used hexamethonium to block autonomic responses and heart rate was unchanged during penitrem A-induced increases blood pressure (Fig. 7).

We demonstrated the efficacy and selectivity of penitrem A on BK channel function in vitro and in vivo; however, our study has several limitations that need to be addressed. First, penitrem A is well known to cause muscle tremor, thus, the use of penitrem A to study the role of vascular BK channels might best be limited to anesthetized animals for in vivo experiments. Second, in addition to vascular smooth muscle BK channels, systemic penitrem $\mathrm{A}$ administration will inhibit BK channels in other cells and tissues that might affect the regulation of vascular tone and blood pressure. For instance, a recent study indicated that BK channels in astrocytes are key regulators of neurovascular coupling (Girouard et al., 2010). Additionally, BK channels in endothelium may regulate membrane potential, $\mathrm{Ca}^{2+}$ influx, and the production of relaxing factors (Sandow \& Grayson, 2009). Since BK channel expression is ubiquitous, in vivo experiments with penitrem $\mathrm{A}$ will require careful design and interpretation.

In conclusion, we have further characterized penitrem A as an inhibitor of BK channels, particularly BK $a+b 1$ channels that are generally found in smooth muscle. This information could be put to important use determining the roles of 
BK channels in vascular function and serve as a complement to studies performed in BK channel subunit knockout mice. We demonstrate that penitrem $A$ is a useful and economical alternative for studying the role of BK channels in vitro and in vivo. That is, we show that that the use of penitrem $A$ is not limited to patch clamp experiments, rather this agent is practical for tissue, organ, and whole animal studies. 


\section{Acknowledgements}

We thank Dr. Jonathan D. Lippiat (University of Leeds) for providing the two plasmids encoding human BK channels and Dr. Jeffrey R. Martens (University of Michigan) for providing the $\mathrm{K}_{\mathrm{v}} 1.5$ plasmid. 


\section{Authorship Contributions}

Participated in research design: Asano, Tune, Bratz, and Dick

Conducted experiments: Asano, Bratz, Berwick, Tune, and Fancher

Contributed new reagents or analytic tools: None

Performed data analysis: Asano and Dick

Wrote or contributed to the writing of the manuscript: Asano and Dick 


\section{Footnotes}

This work was supported by a Research Funds Development Grant from West

Virginia University and the National Institutes of Health [HL092245, T32

HL090610]. 


\section{Legends for figures}

Fig. 1 Presence of the $\beta 1$ subunit decreases the sensitivity of BK channels to penitrem A. Representative traces of BK current at $+100 \mathrm{mV}$ in HEK 293 cells transfected with $h$ Slo $\alpha$ (Panel A) or $h$ Slo $\alpha+\beta 1$ (Panel B). Whole-cell current was measured before (control) and after addition of penitrem A (100 nM). Group data (Panel C; $n=4-16$ cells at each concentration) show the effect of BK channel subunit composition on sensitivity to block by penitrem A. Asterisks indicate $p<0.05$ between the two groups as determined by two-way ANOVA. Group data $(n=3-9)$ show time- and concentration-dependent block of BK a (Panel D) and $\alpha+\beta 1$ (Panel E) by penitrem A. Note that, compared to a, a 10x higher concentration of penitrem $\mathrm{A}$ is required to achieve a similar timedependent block in $\alpha+\beta 1$.

Fig. 2 Irreversible block of BK channels by penitrem A. Current traces are shown from a representative HEK 293 cell expressing BK channels composed of $\alpha+\beta 1$ subunits (Panel $A)$. The voltage template used is shown below the current. Penitrem A (1 $\mu \mathrm{M})$ abolished current within 1-2 min; however, 10 min of washing in penitrem A-free bath solution was not sufficient time for current to recover appreciably. (Panel B) Group data ( $\mathrm{n}=5$ cells) illustrate the practical irreversibility of a 2 min exposure to penitrem A; BK current at $+100 \mathrm{mV}$ is plotted vs. time. Current traces are shown from a representative rat aortic smooth muscle cell (Panels $C$ and $D$ ). The voltage template was same as above. Penitrem A (50 $\mathrm{nM})$ reduced native BK current and was practically irreversible. 


\section{Fig. 3 Penitrem A blocks BK channels in inside-out and cell-attached}

patches. Recordings of channel activity from representative inside-out patches are shown for BK $\alpha$ (Panel A) or $\alpha+\beta 1$ (Panel B). Patch potential was $+40 \mathrm{mV}$ and solutions were symmetrical $140 \mathrm{mM} \mathrm{K}^{+}$with $100 \mathrm{nM}$ free $\mathrm{Ca}^{2+}$. Channel activity was recorded under control conditions and with bath application of iberiotoxin (100 nM) or penitrem A (100 nM). (Panel C) Penitrem A blocks BK channel $(\alpha+\beta 1)$ activity in a cell-attached patch. Channel activity was recorded under control conditions and with bath application of penitrem A (100 nM). (Panel D) Group data ( $n=23$ patches $)$ show that the exposure of the cytosolic side of inside-out patches to penitrem A, but not iberiotoxin, inhibits BK channel activity. Asterisk indicates $p<0.05$ vs. control by one-way ANOVA.

Fig. 4 lberiotoxin and penitrem A block the same current in canine coronary smooth muscle cells. (Panel A) Families of current traces from a representative dog coronary artery smooth muscle cell are shown under control conditions, with penitrem A (300 nM), and with iberiotoxin (100 nM). These experiments were performed with a bath solution containing $0.01 \%$ bovine serum albumin to limit nonspecific binding of iberiotoxin to plastic. (Panel B) The I-V relationships from traces in A are shown. Penitrem A and iberiotoxin block the same current (inset). (Panel C) Group data (cells from $\mathrm{n}=5$ dogs) demonstrate that penitrem A blocks iberiotoxin-sensitive current; current at $+100 \mathrm{mV}$ is shown. (Panel D) Similarly, 
iberiotoxin blocks penitrem A-sensitive current at $+100 \mathrm{mV}$. Asterisks indicate $p<0.05$ vs. control by one-way ANOVA.

Fig. 5 Penitrem $A$ has no effect on $K_{V} 1.5$ or $K_{A T P}$ channels. (Panel A) Wholecell recordings were made from HEK 293 cells transfected with $h K V 1.5$. Representative $\mathrm{K}_{\mathrm{v}} 1.5$ currents in the absence or presence of $1 \mu \mathrm{M}$ penitrem $\mathrm{A}$. (Panel B) Group data ( $n=5$ cells) show that penitrem A $(1 \mu M)$ has no effect on $\mathrm{K}_{\mathrm{V}} 1.5$ current. (Panel C) Representative isometric tension recordings show that penitrem A (1 $\mu \mathrm{M})$ does not inhibit pinacidil-induced relaxation. (Panel D) Group data (arteries from $n=3$ dogs) show that penitrem $A(1 \mu M)$ has no effect on $K_{\text {ATP }}$ channels. Arteries were contracted with $1 \mu \mathrm{M} \mathrm{U} 46619$ and relaxed with cumulative additions of pinacidil.

Fig. 6. Penitrem A selectively inhibits BK channel to alter vascular contraction from in vitro vascular functional experiments.

Panel A) Representative traces for $\mathrm{KCl}$ induced contraction with/without penitrem A are shown. (Panel B) Group data showed a leftward shift in contraction response with penitrem A. Asterisks $\left(^{*}\right)$ indicate significant difference $(p<0.05)$ from control by two-way ANOVA.

Fig. 7 Block of BK channels by penitrem A augments phenylephrineinduced blood pressure responses in mice. (Panel A) Mean arterial pressure and heart rate are shown for a representative mouse. The mouse received 
phenylephrine $(0.5 \mu \mathrm{g} / \mathrm{kg} / \mathrm{min}$ i.v. $)$, which increased pressure. There was no reflex change in heart rate, as the ganglionic blocker hexamethonium $(5 \mathrm{mg} / \mathrm{kg}$ i.v.) was injected prior to the experiment. Penitrem A (100 $\mu \mathrm{g} / \mathrm{kg} / \mathrm{min}$ i.v.) was added and increased pressure further. (Panel B) Group data ( $n=5$ mice) illustrate effect of penitrem A to augment phenylephrine-induced pressor responses. Asterisk and dagger indicate significant difference $(p<0.05)$ from control and phenylephrine, respectively, by one-way ANOVA. 


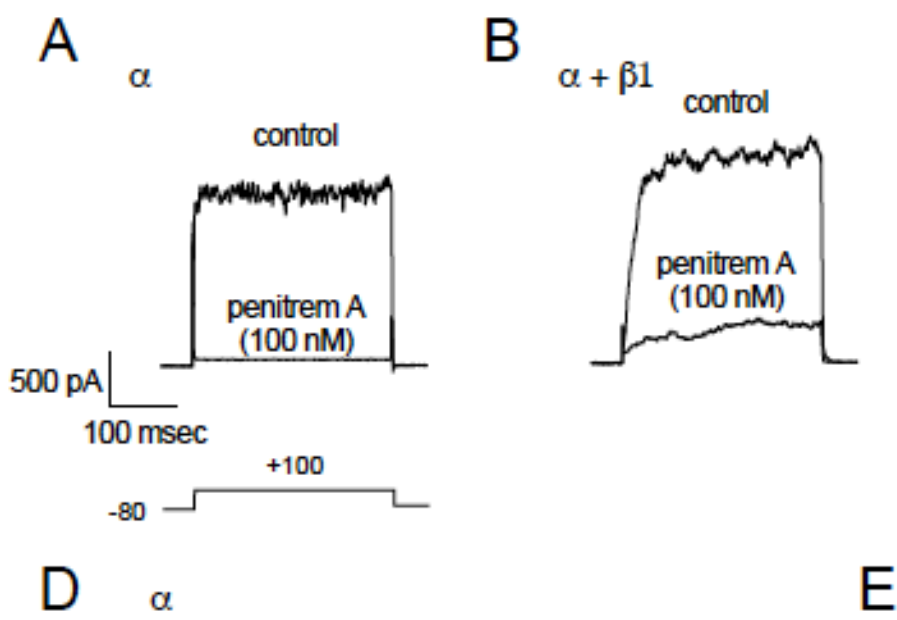

C
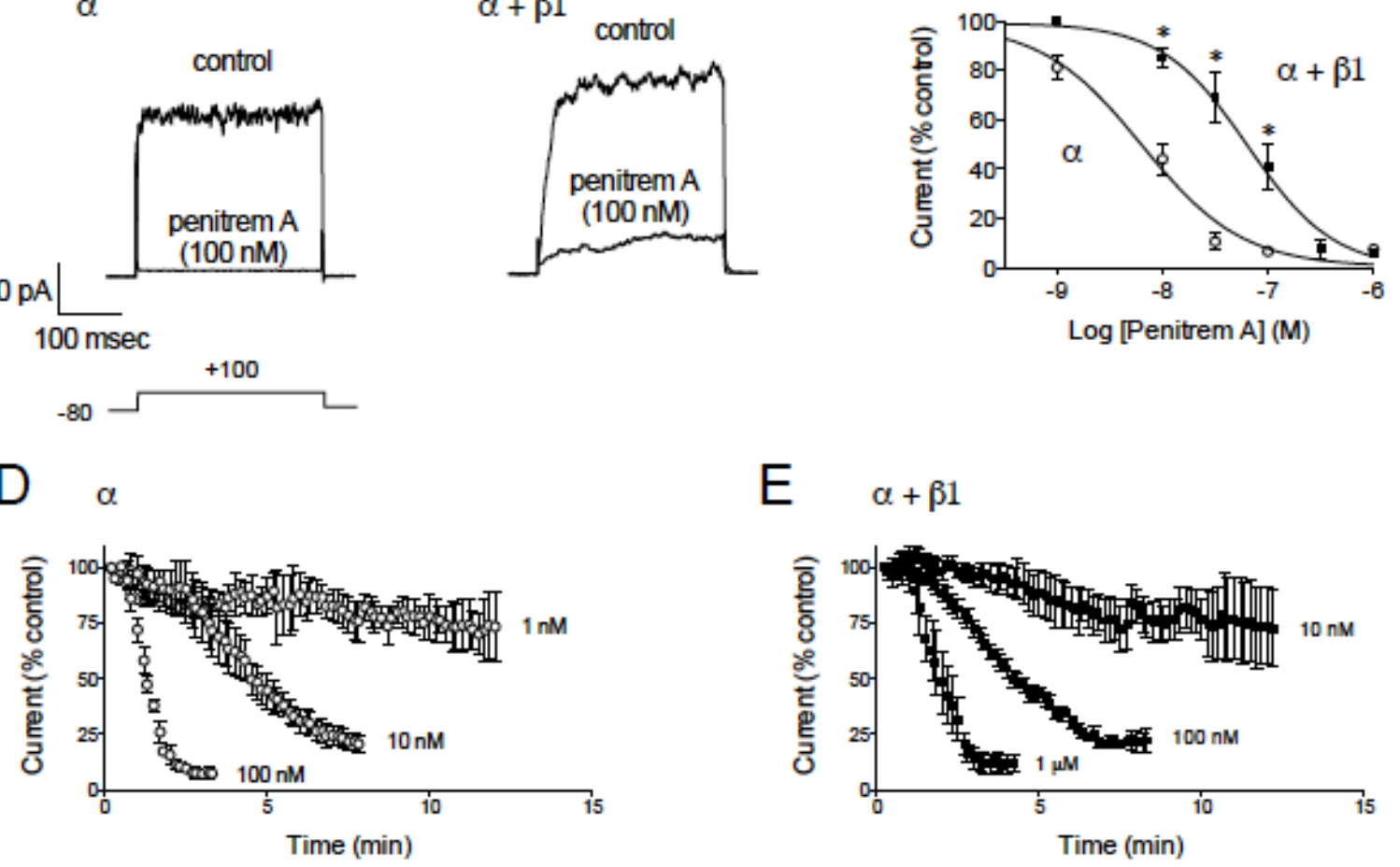

E $\quad \alpha+\beta 1$

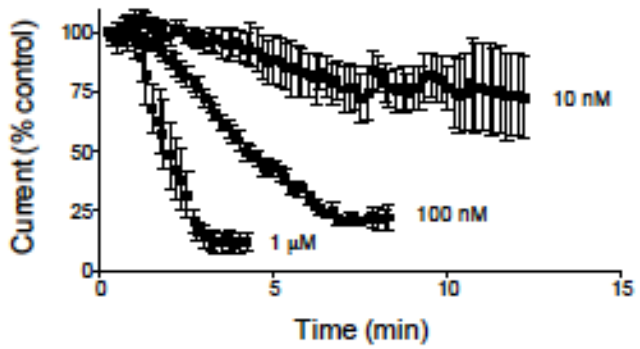

Figure 21 Presence of the $\beta 1$ subunit decreases the sensitivity of BK channels to penitrem $A$ 

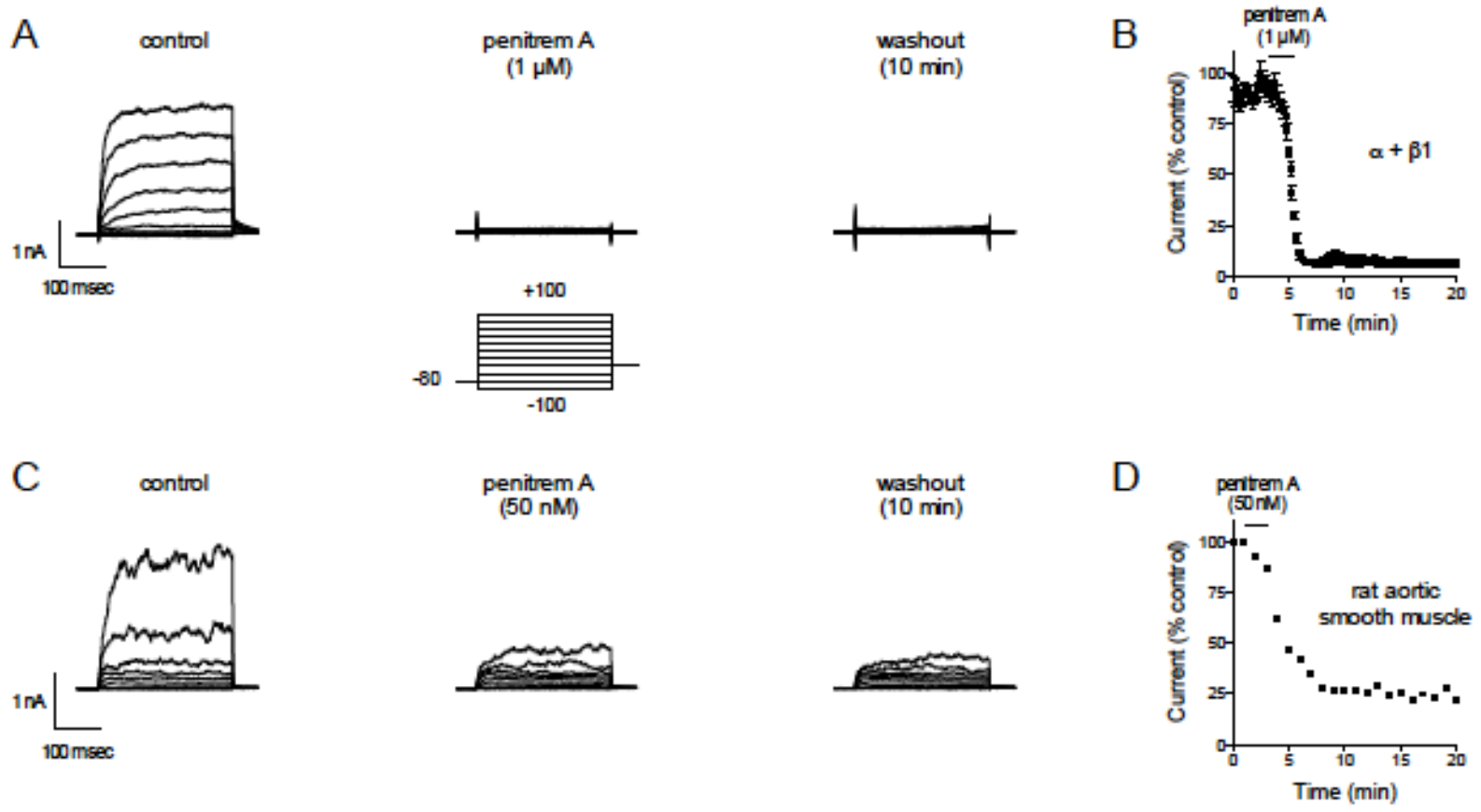

Figure 22 Irreversible block of BK channels by penitrem A 

A
$\alpha$
B $\quad \alpha+\beta 1$

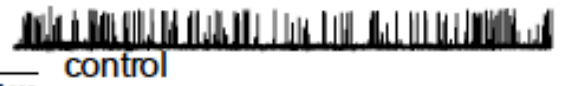

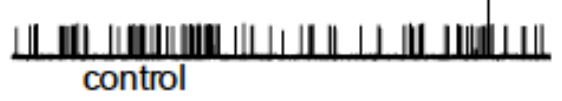

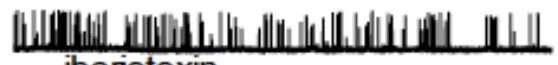 iberiotoxin Lلـ
penitrem A
penitrem $A$
C cell-attached $\alpha+\beta 1$ control
penitrem A

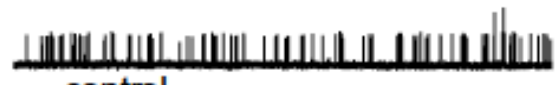

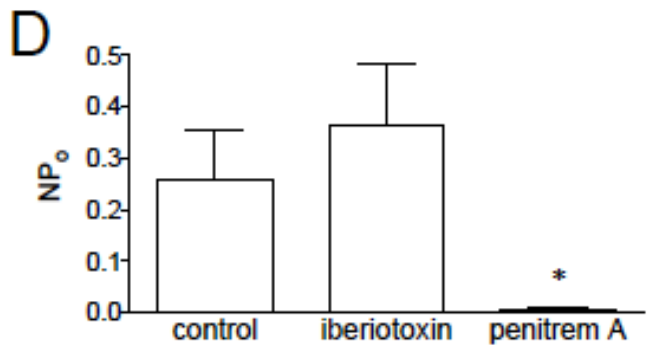

Figure 23 Penitrem A blocks BK channels in inside-out and cell-attached patches. 

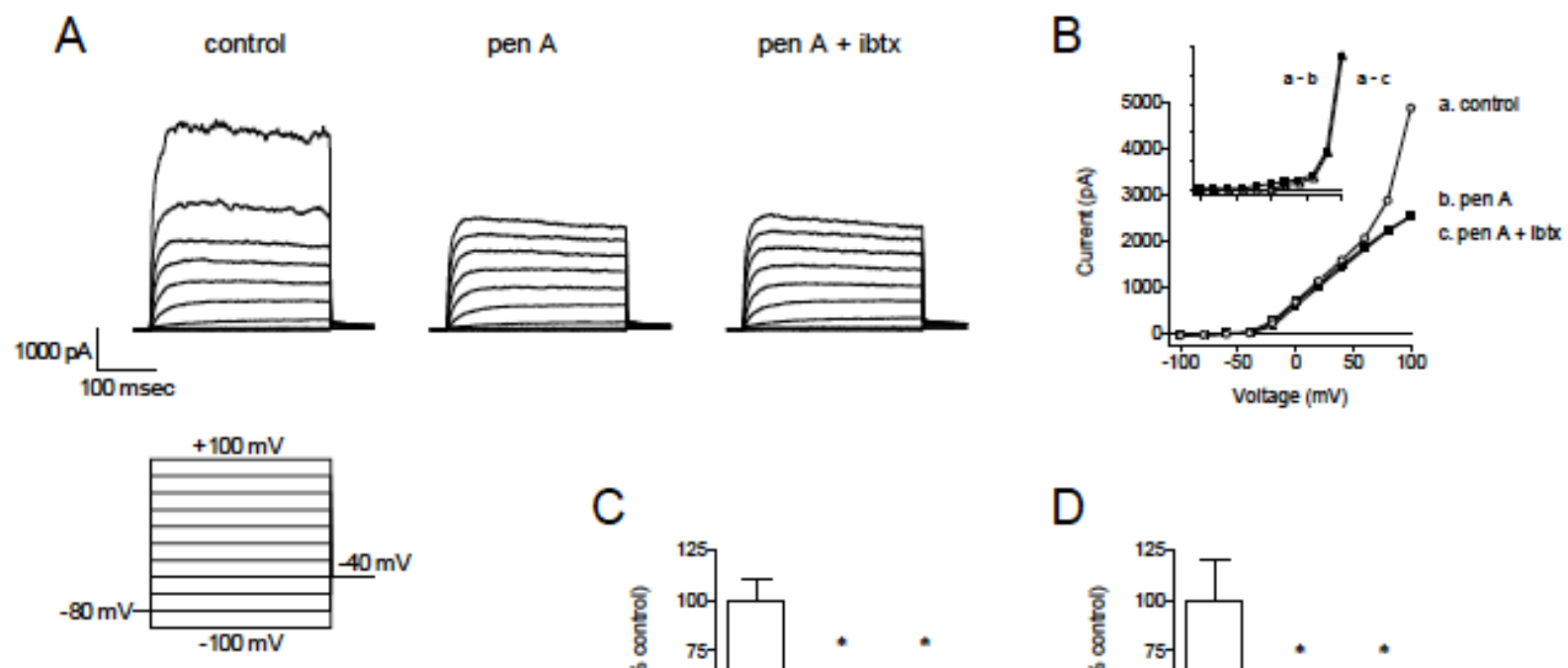

C

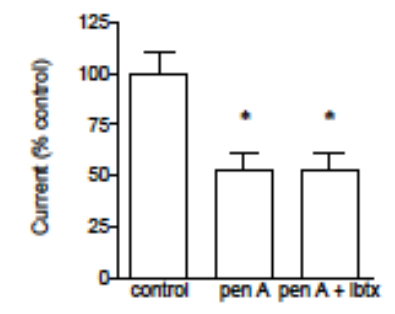

D

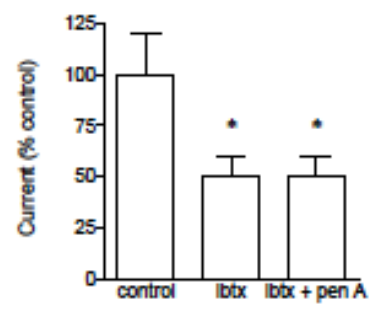

Figure 24 lberiotoxin and penitrem A block the same current in canine coronary smooth muscle cells. 

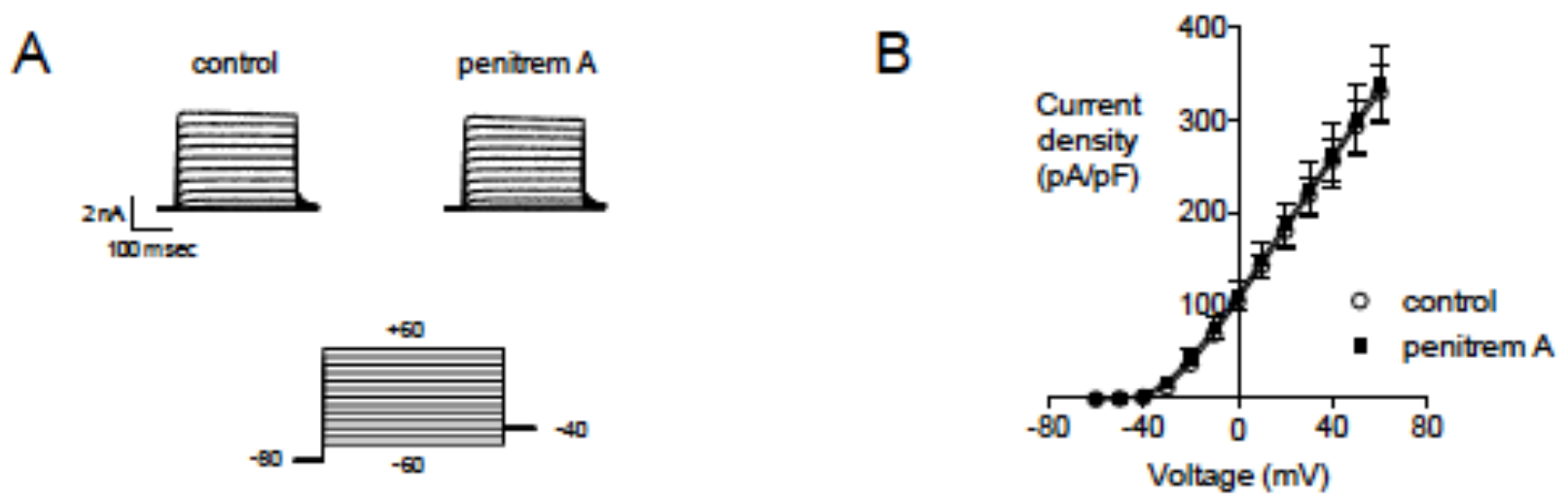

C
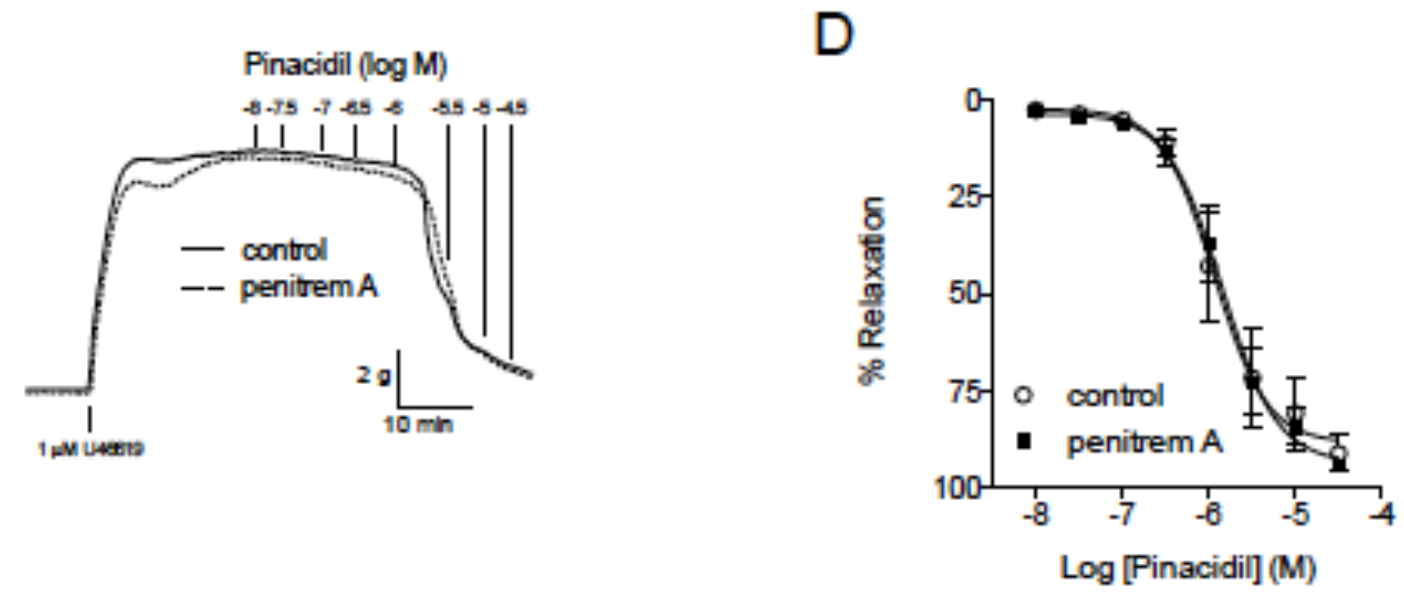

Figure 25 Penitrem A has no effect on $K_{V} 1.5$ or $K_{A T P}$ channels. 
A

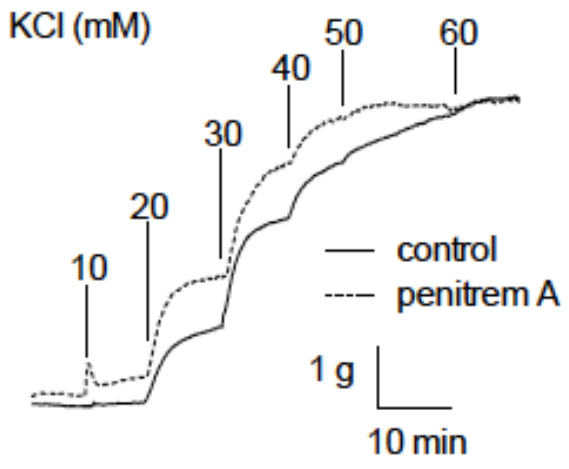

B

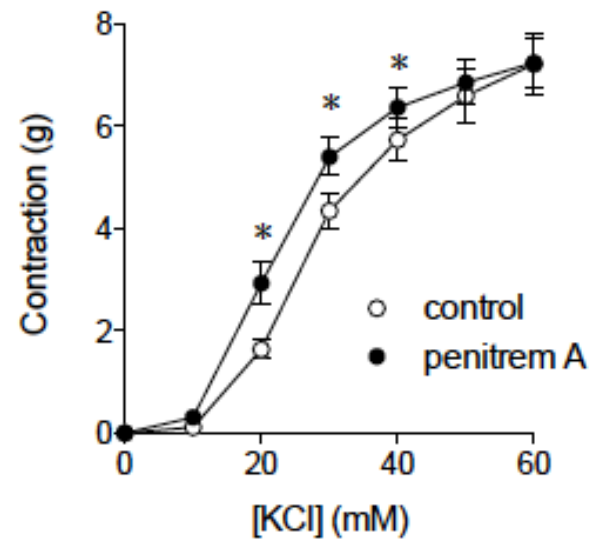

Figure 26 Penitrem A selectively inhibits BK channel to alter vascular contraction from in vitro vascular functional experiments 
A
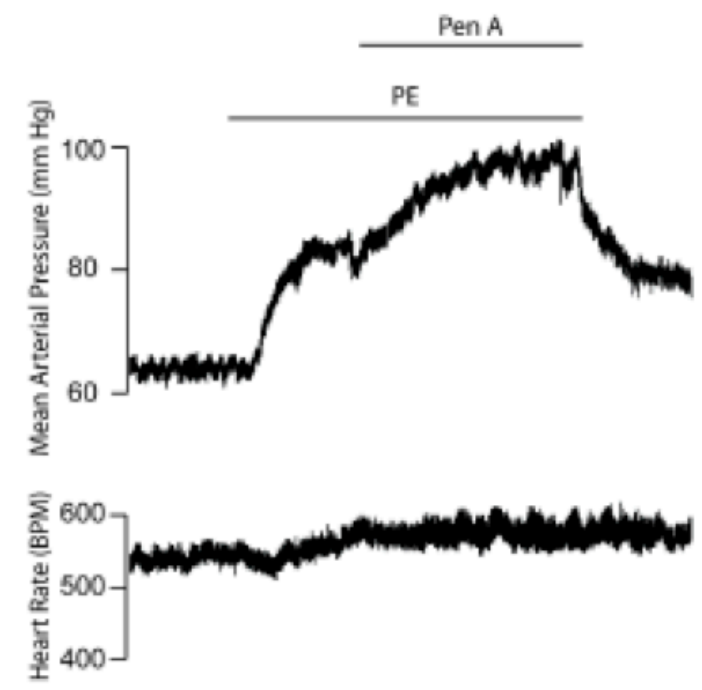

B

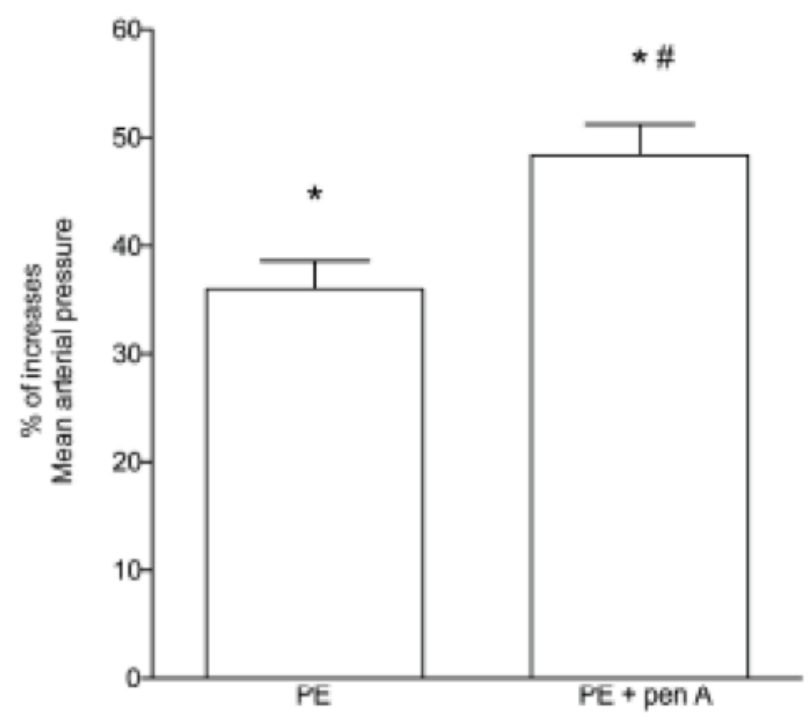

Figure 27 Block of BK channels by penitrem A augments phenylephrineinduced blood pressure responses in mice 


\section{References}

Amberg GC, Bonev AD, Rossow CF, Nelson MT \& Santana LF. (2003). Modulation of the molecular composition of large conductance, $\mathrm{Ca}(2+)$ activated $\mathrm{K}(+)$ channels in vascular smooth muscle during hypertension. J Clin Invest 112, 717-724.

Asano S, Tune JD \& Dick GM. (2010). Bisphenol A activates Maxi-K (K(Ca)1.1) channels in coronary smooth muscle. Br J Pharmacol 160, 160-170.

Borbouse L, Dick GM, Asano S, Bender SB, Dincer UD, Payne GA, Neeb ZP, Bratz IN, Sturek M \& Tune JD. (2009). Impaired function of coronary BK(Ca) channels in metabolic syndrome. Am J Physiol Heart Circ Physiol 297, H1629-1637.

Borbouse L, Dick GM, Payne GA, Berwick ZC, Neeb ZP, Alloosh M, Bratz IN, Sturek M \& Tune JD. (2010a). Metabolic syndrome reduces the contribution of $\mathrm{K}+$ channels to ischemic coronary vasodilation. Am J Physiol Heart Circ Physiol 298, H1182-1189.

Borbouse L, Dick GM, Payne GA, Payne BD, Svendsen MC, Neeb ZP, Alloosh M, Bratz IN, Sturek M \& Tune JD. (2010b). Contribution of $\mathrm{BK}(\mathrm{Ca})$ channels to local metabolic coronary vasodilation: Effects of metabolic syndrome. Am J Physiol Heart Circ Physiol 298, H966-973.

Bratz IN, Dick GM, Partridge LD \& Kanagy NL. (2005). Reduced molecular expression of $\mathrm{K}(+)$ channel proteins in vascular smooth muscle from rats made hypertensive with N\{omega\}-nitro-L-arginine. American journal of physiology Heart and circulatory physiology 289, H12771283.

Brayden JE \& Nelson MT. (1992). Regulation of arterial tone by activation of calcium-dependent potassium channels. Science 256, 532-535.

Brenner R, Perez GJ, Bonev AD, Eckman DM, Kosek JC, Wiler SW, Patterson AJ, Nelson MT \& Aldrich RW. (2000). Vasoregulation by the beta1 subunit of the calcium-activated potassium channel. Nature 407, 870-876.

Chen TT, Luykenaar KD, Walsh EJ, Walsh MP \& Cole WC. (2006). Key role of Kv1 channels in vasoregulation. Circulation research 99, 53-60. 
Cotton KD, Hollywood MA, McHale NG \& Thornbury KD. (1997). Outward currents in smooth muscle cells isolated from sheep mesenteric lymphatics. J Physiol 503 ( Pt 1), 1-11.

Cysewski SJ, Baetz AL \& Pier AC. (1975). Penitrem A intoxication of calves: blood chemical and pathologic changes. Am J Vet Res 36, 53-58.

Dart C \& Standen NB. (1995). Activation of ATP-dependent K+ channels by hypoxia in smooth muscle cells isolated from the pig coronary artery. J Physiol 483 ( Pt 1), 29-39.

Dick GM, Bratz IN, Borbouse L, Payne GA, Dincer UD, Knudson JD, Rogers PA \& Tune JD. (2008). Voltage-dependent $K+$ channels regulate the duration of reactive hyperemia in the canine coronary circulation. Am J Physiol Heart Circ Physiol 294, H2371-2381.

Galvez A, Gimenez-Gallego G, Reuben JP, Roy-Contancin L, Feigenbaum P, Kaczorowski GJ \& Garcia ML. (1990). Purification and characterization of a unique, potent, peptidyl probe for the high conductance calcium-activated potassium channel from venom of the scorpion Buthus tamulus. J Biol Chem 265, 11083-11090.

Giangiacomo KM, Garcia ML \& McManus OB. (1992). Mechanism of iberiotoxin block of the large-conductance calcium-activated potassium channel from bovine aortic smooth muscle. Biochemistry 31, 6719-6727.

Girouard H, Bonev AD, Hannah RM, Meredith A, Aldrich RW \& Nelson MT. (2010). Astrocytic endfoot $\mathrm{Ca} 2+$ and $\mathrm{BK}$ channels determine both arteriolar dilation and constriction. Proceedings of the National Academy of Sciences of the United States of America 107, 3811-3816.

Hou S, Heinemann SH \& Hoshi T. (2009). Modulation of BKCa channel gating by endogenous signaling molecules. Physiology (Bethesda) 24, 26-35.

Imlach WL, Finch SC, Dunlop J, Meredith AL, Aldrich RW \& Dalziel JE. (2008). The molecular mechanism of "ryegrass staggers," a neurological disorder of $\mathrm{K}+$ channels. J Pharmacol Exp Ther 327, 657-664.

Imlach WL, Finch SC, Miller JH, Meredith AL \& Dalziel JE. (2010). A role for BK channels in heart rate regulation in rodents. PLoS One 5, e8698.

Jaggar JH, Porter VA, Lederer WJ \& Nelson MT. (2000). Calcium sparks in smooth muscle. Am J Physiol Cell Physiol 278, C235-256. 
Knaus HG, McManus OB, Lee SH, Schmalhofer WA, Garcia-Calvo M, Helms LM, Sanchez M, Giangiacomo K, Reuben JP, Smith AB, 3rd \& et al. (1994). Tremorgenic indole alkaloids potently inhibit smooth muscle high-conductance calcium-activated potassium channels. Biochemistry 33, 5819-5828.

Knot HJ, Standen NB \& Nelson MT. (1998). Ryanodine receptors regulate arterial diameter and wall $\left[\mathrm{Ca}_{2}+\right]$ in cerebral arteries of rat via $\mathrm{Ca2+-}$ dependent $\mathrm{K}+$ channels. The Journal of physiology 508 ( Pt 1), 211 221.

Kotecha N \& Hill MA. (2005). Myogenic contraction in rat skeletal muscle arterioles: smooth muscle membrane potential and $\mathrm{Ca}(2+)$ signaling. American journal of physiology Heart and circulatory physiology 289, H1326-1334.

Lippiat JD, Standen NB, Harrow ID, Phillips SC \& Davies NW. (2003). Properties of $\mathrm{BK}(\mathrm{Ca})$ channels formed by bicistronic expression of hSloalpha and beta1-4 subunits in HEK293 cells. J Membr Biol 192, 141-148.

Liu Y, Hudetz AG, Knaus HG \& Rusch NJ. (1998). Increased expression of Ca2+-sensitive $\mathrm{K}+$ channels in the cerebral microcirculation of genetically hypertensive rats: evidence for their protection against cerebral vasospasm. Circ Res 82, 729-737.

McEwen DP, Schumacher SM, Li Q, Benson MD, Iniguez-Lluhi JA, Van Genderen KM \& Martens JR. (2007). Rab-GTPase-dependent endocytic recycling of Kv1.5 in atrial myocytes. J Biol Chem 282, 29612-29620.

Nelson MT, Cheng H, Rubart M, Santana LF, Bonev AD, Knot HJ \& Lederer WJ. (1995). Relaxation of arterial smooth muscle by calcium sparks. Science 270, 633-637.

Nerbonne JM, Gerber BR, Norris A \& Burkhalter A. (2008). Electrical remodelling maintains firing properties in cortical pyramidal neurons lacking KCND2-encoded A-type $\mathrm{K}+$ currents. The Journal of physiology 586, 1565-1579.

Node K, Kitakaze M, Kosaka H, Minamino T \& Hori M. (1997). Bradykinin mediation of $\mathrm{Ca}(2+)$-activated $\mathrm{K}+$ channels regulates coronary blood flow in ischemic myocardium. Circulation 95, 1560-1567. 
Ohanyan VA, Guarini G, Thodeti CK, Talasila PK, Raman P, Haney RM, Meszaros JG, Damron DS \& Bratz IN. (2011). Endothelin-mediated in vivo pressor responses following TRPV1 activation. American journal of physiology Heart and circulatory physiology 301, H11351142.

Pluger S, Faulhaber J, Furstenau M, Lohn M, Waldschutz R, Gollasch M, Haller H, Luft FC, Ehmke H \& Pongs O. (2000). Mice with disrupted BK channel beta1 subunit gene feature abnormal $\mathrm{Ca}(2+)$ spark/STOC coupling and elevated blood pressure. Circ Res 87, E53-60.

Rogers PA, Dick GM, Knudson JD, Focardi M, Bratz IN, Swafford AN, Jr., Saitoh S, Tune JD \& Chilian WM. (2006). H2O2-induced redoxsensitive coronary vasodilation is mediated by 4-aminopyridinesensitive K+ channels. Am J Physiol Heart Circ Physiol 291, H24732482.

Sandow SL \& Grayson TH. (2009). Limits of isolation and culture: intact vascular endothelium and BKCa. American journal of physiology Heart and circulatory physiology 297, H1-7.

Sausbier M, Arntz C, Bucurenciu I, Zhao H, Zhou XB, Sausbier U, Feil S, Kamm S, Essin K, Sailer CA, Abdullah U, Krippeit-Drews P, Feil R, Hofmann F, Knaus HG, Kenyon C, Shipston MJ, Storm JF, Neuhuber W, Korth M, Schubert R, Gollasch M \& Ruth P. (2005). Elevated blood pressure linked to primary hyperaldosteronism and impaired vasodilation in BK channel-deficient mice. Circulation 112, 60-68.

Sones WR, Leblanc N \& Greenwood IA. (2009). Inhibition of vascular calcium-gated chloride currents by blockers of KCa1.1, but not by modulators of KCa2.1 or KCa2.3 channels. Br J Pharmacol 158, 521531.

Xu H, Garver H, Galligan JJ \& Fink GD. (2011). Large-conductance Ca2+activated K+ channel beta1-subunit knockout mice are not hypertensive. Am J Physiol Heart Circ Physiol 300, H476-485.

Yang Y, Murphy TV, Ella SR, Grayson TH, Haddock R, Hwang YT, Braun AP, Peichun G, Korthuis RJ, Davis MJ \& Hill MA. (2009). Heterogeneity in function of small artery smooth muscle BKCa: involvement of the beta1-subunit. J Physiol 587, 3025-3044. 
Table 21 Characteristics of BK channel blockers

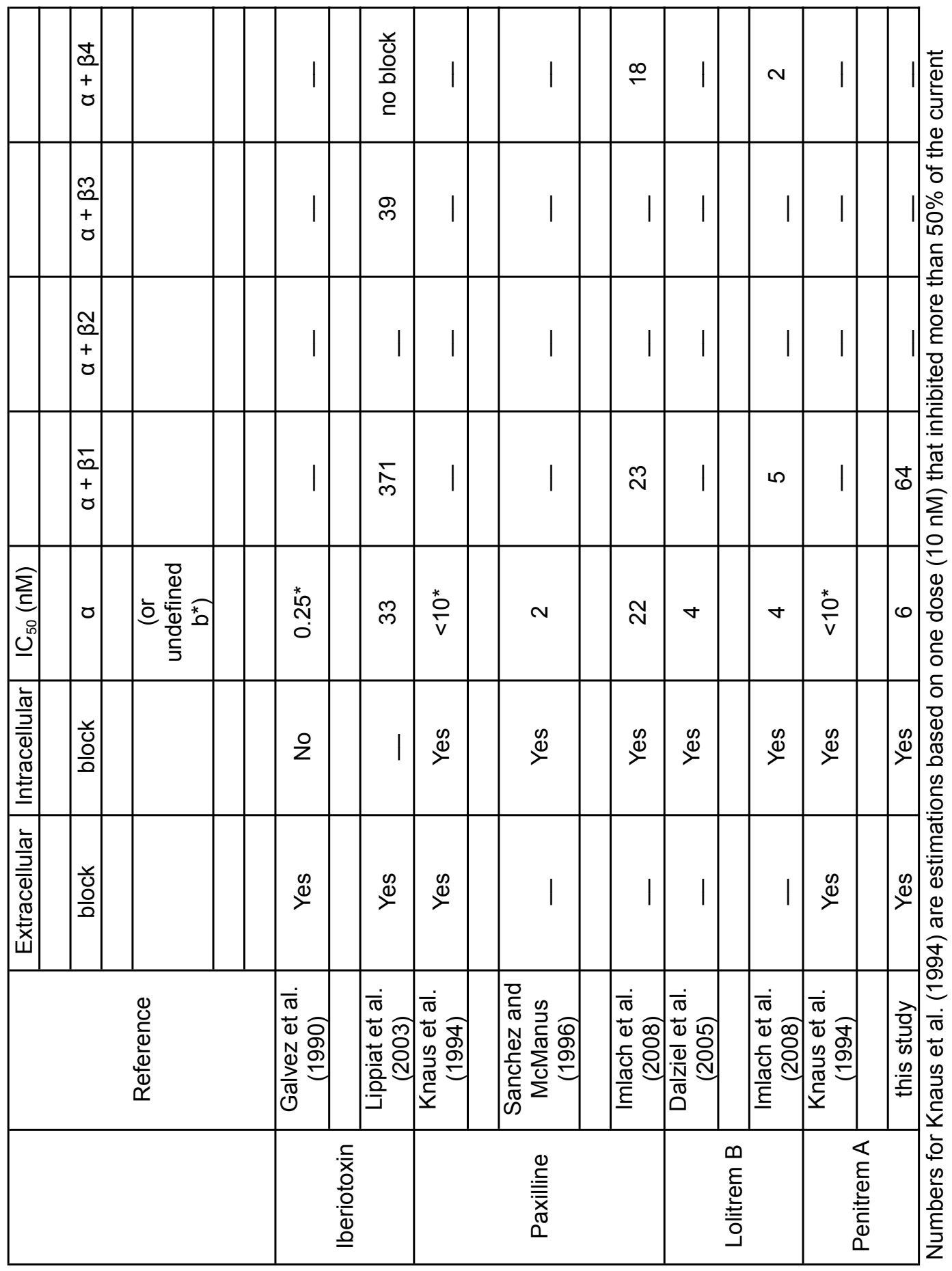




\section{Supplemental Data}

We determined the effect of penitrem $\mathrm{A}$ on $\mathrm{K}^{+}$currents in a variety of native vascular smooth muscle cells. The point of these experiments is to demonstrate that penitrem $A(1 \mu \mathrm{M})$ inhibits the same type of strongly outwardly rectifying current without effect on native delayed rectifiers. Panels A-E show currents in smooth muscle cells isolated from rat middle cerebral artery $(n=3)$, rat femoral artery $(n=3)$, mouse aorta $(n=3)$, pig coronary artery $(n=5)$, and dog coronary artery $(n=7)$. The voltage template (shown in A) was the same for all experiments. Solutions for whole-cell currents are described in the Methods. Panel $\mathrm{F}$ contains data showing that penitrem A $1 \mu \mathrm{M}$ inhibits the a subunit cloned from cow (courtesy of Dr. Michael Davis, University of Missouri) and expressed in HEK 293 cells $(n=3)$. 
A Rat cerebal artery
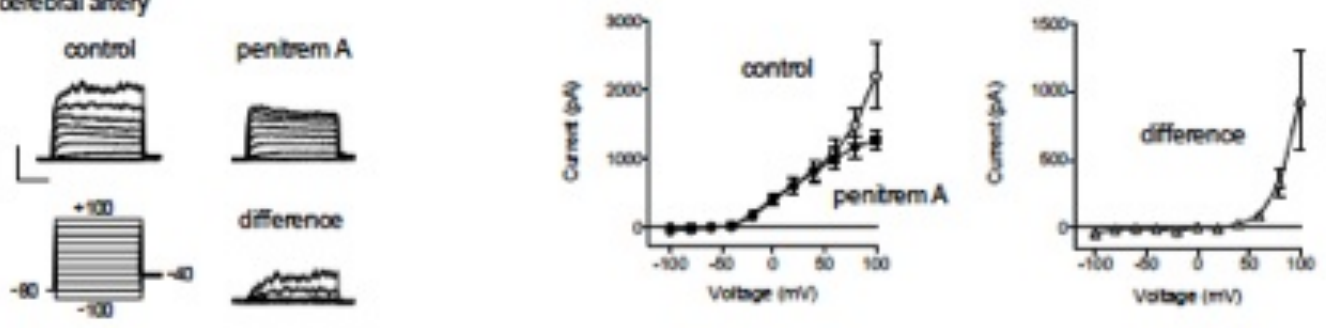

B Fat femoral atery
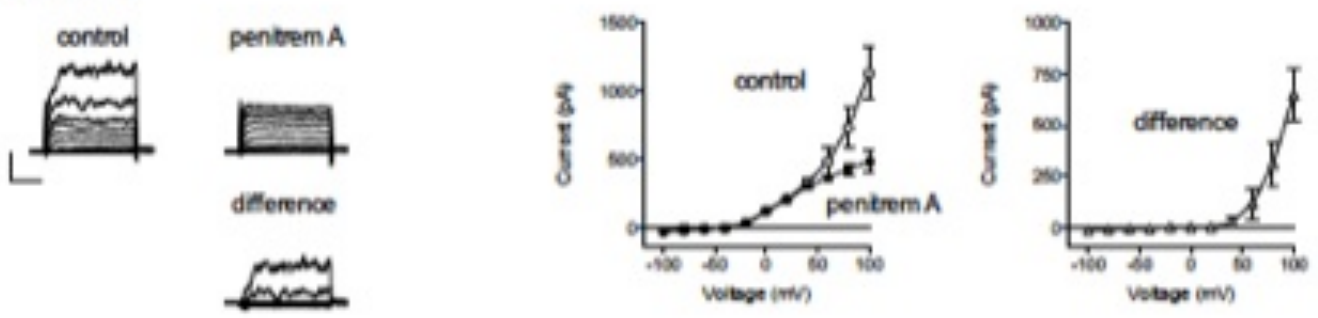

C Mouse aota
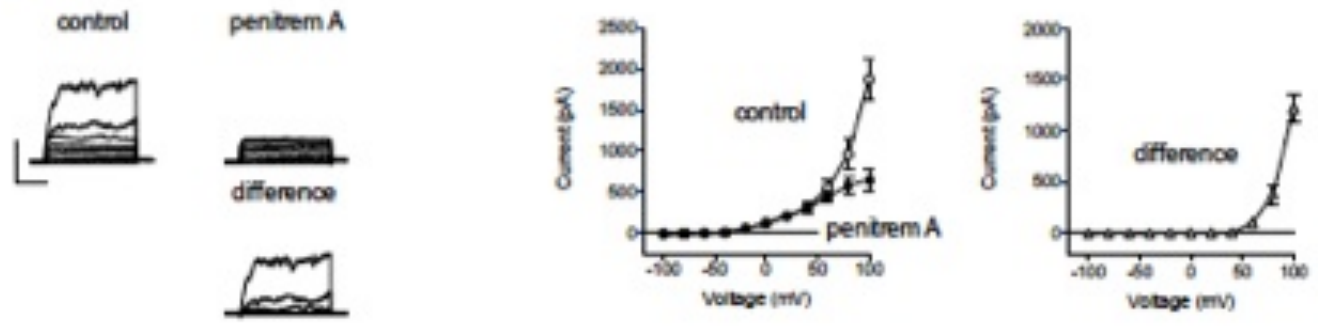

Figure 28 Supplemental Figure1 Penitrem A on $\mathrm{K}^{+}$currents in a variety of vascular smooth muscle cells 
D Porche coronary atery
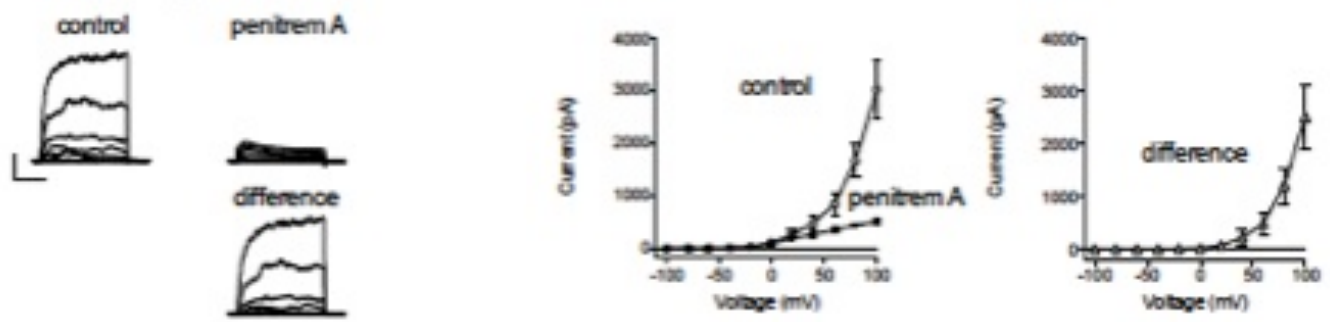

$\mathrm{E}$ Canine coronary antery
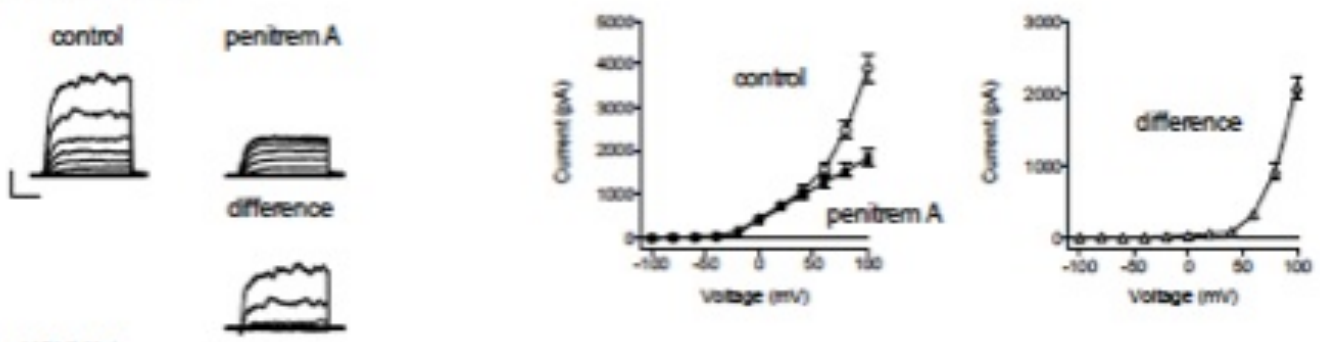

F Bovine Karma1

control penitrom $A$
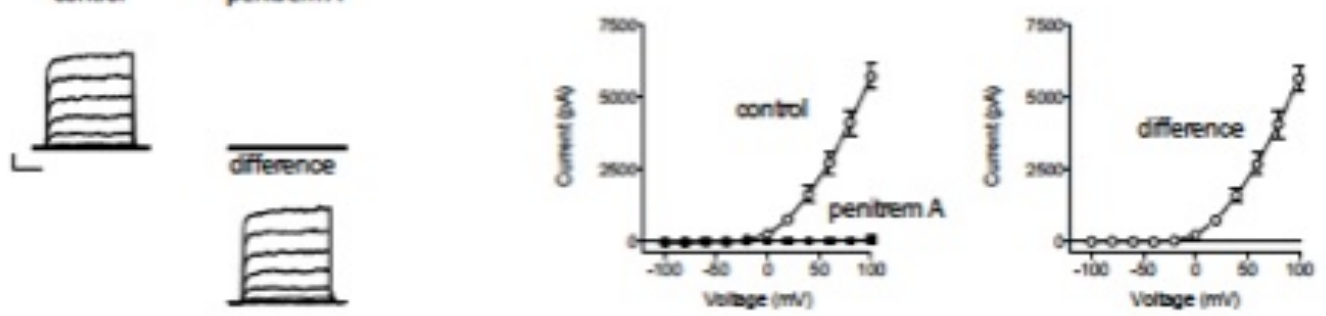

Figure 29 Supplemental Figure2 Penitrem A on $\mathrm{K}^{+}$currents in a variety of vascular smooth muscle cells 
CHAPTER 3 Bisphenol A activates maxi-K channels in coronary smooth

muscle

As published in Br J Pharmacol. 2010 May;160(1):160-70

Shinichi Asano ${ }^{1}$, Johnathan D. Tune ${ }^{2}$, and Gregory M. Dick ${ }^{1}$

${ }^{1}$ Division of Exercise Physiology, Center for Cardiovascular \& Respiratory Sciences, West Virginia University School of Medicine

${ }^{2}$ Department of Cellular \& Integrative Physiology, Indiana University School of Medicine

Running head: BPA activates Maxi-K

Address correspondence to: Gregory M. Dick, Ph.D., 1 Medical Center Drive, P.O. Box 9105, Morgantown, WV 26506, Phone (304) 293-2542, Fax (304) 2935513, E-mail gdick@hsc.wvu.edu 


\section{Abstract}

Background and purpose: Bisphenol A (BPA) is used to manufacture plastics, including food containers into which it leaches. High levels of exposure to this estrogenic endocrine disruptor are associated with diabetes and heart disease. Estrogen and estrogen receptor modulators increase the activity of large conductance $\mathrm{Ca}^{2+} /$ voltage-sensitive $\mathrm{K}^{+}$(Maxi-K) channels, but the effects of BPA on Maxi-K channels are unknown. We tested the hypothesis that BPA activates Maxi-K channels through a mechanism that depends upon the regulatory $\beta 1$ subunit.

Experimental approach: Patch clamp recordings of Maxi-K channels were made in human and canine coronary smooth muscle cells as well as in AD-293 cells expressing pore-forming $\alpha$ or $\alpha$ plus $\beta 1$ subunits.

Key results: BPA $(10 \mu \mathrm{M})$ activated an outward current in smooth muscle cells that was inhibited by penitrem A ( $1 \mu \mathrm{M})$, a Maxi-K blocker. BPA increased Maxi-K activity in inside-out patches from coronary smooth muscle, but had no effect on single channel conductance. In AD-293 cells with Maxi-K channels composed of a subunits alone, $10 \mu \mathrm{M}$ BPA did not affect channel activity. When channels in AD-293 cells contained $\beta 1$ subunits, $10 \mu \mathrm{M}$ BPA increased channel activity. Effects of BPA were rapid ( $<1 \mathrm{~min})$ and reversible. A higher concentration of BPA $(100 \mu \mathrm{M})$ increased Maxi-K current independent of the $\beta 1$ subunit.

Conclusions and implications: These data indicate BPA increases the activity of Maxi-K channels and may represent a basis for some potential toxicological effects. 


\section{Introduction}

Although there is no clear consensus on detrimental health effects of BPA, evidence suggests it possesses endocrine disrupting activity. BPA may affect fetal and neonatal development (Vandenberg et al., 2007), reproductive function (Savabieasfahani et al., 2006), metabolism (Hugo et al., 2008), and carcinogenesis (Wetherill et al., 2002; Wetherill et al., 2005). A recent study demonstrated an association between BPA levels and adverse cardiovascular diagnoses (Lang et al., 2008). Environmental exposure through polycarbonate plastic bottles, epoxy linings of canned foods, and dental sealants makes BPA a potential public health hazard.

BPA interacts with nuclear estrogen receptors, although much less potently than 17ß-estradiol (Krishnan et al., 1993; Kuiper et al., 1997). BPA also exerts nongenomic effects, independent of nuclear estrogen receptors. For example, BPA rapidly disrupts intracellular $\mathrm{Ca}^{2+}$ homeostasis in a variety of cells (Nadal et al., 2000; Alonso-Magdalena et al., 2005; Walsh et al., 2005). These data suggest that BPA influences the activity of cellular transport mechanisms, perhaps including ion channels. Importantly, however, there are no data available regarding effects of BPA on the function of an ion channel per se. Maxi-K channels offer themselves as an excellent model to test for interactions with BPA, as they are estrogen-sensitive (Valverde et al., 1999).

Maxi-K channels, identified as $\mathrm{K}_{\mathrm{Ca}} 1.1$ in the Guide to Receptors and Channels (Alexander et al., 2008), are formed by 4 pore-forming a subunits encoded by KCNMA1 (Butler et al., 1993); when $\beta 1$ subunits are present, 
sensitivity to estrogenic substances is conferred (Valverde et al., 1999; Dick et al., 2001; Dick \& Sanders, 2001; Dick et al., 2002; Duncan, 2005; Coiret et al., 2007). The majority of Maxi-K channels in vascular smooth muscle contain this regulatory $\beta 1$ subunit, encoded by KCNMB1 (Tanaka et al., 1997), which increases $\mathrm{Ca}^{2+}$ - and voltage-sensitivity (McManus et al., 1995; Meera et al., 1996). Maxi-K channels (Nelson et al., 1995) and the $\beta 1$ subunit (Brenner et al., 2000) play key roles in regulating smooth muscle excitability. The present study was designed to determine whether BPA activates Maxi-K channels and to ascertain the role of the $\beta 1$ subunit. We hypothesized that BPA would activate Maxi-K channels through a mechanism that depends upon the $\beta 1$ subunit. To test this hypothesis, Maxi-K channel currents were analyzed in smooth muscle cells and in AD-293 cells expressing $\alpha$ or $\alpha+\beta 1$ subunits. 


\section{Methods}

Smooth muscle cells. Three coronary artery smooth muscle preparations were used; these include cells: a) freshly isolated from the canine left anterior descending (LAD) artery; b) cultured from the canine LAD; and c) cultured from human hearts. Canine LAD arteries were collected from dogs euthanized under surgical anesthesia for unrelated experiments. Protocols were approved and followed guidelines set forth in the Guide for the Care and Use of Laboratory Animals (National Academy Press, 1996). LAD segments were incubated for 30 min at $37{ }^{\circ} \mathrm{C}$ in 20 units $\mathrm{ml}^{-1}$ papain in low $\mathrm{Ca}^{2+}$ HEPES buffer containing (mM) $135 \mathrm{NaCl}, 5 \mathrm{KCl}, 0.36 \mathrm{CaCl}_{2}, 1 \mathrm{MgCl}_{2}, 10$ glucose, 10 HEPES, and 5 Tris; $\mathrm{pH}$ 7.4. After washing, tissue was incubated for another $30 \mathrm{~min}$ at $37^{\circ} \mathrm{C}$ in low $\mathrm{Ca}^{2+}$ HEPES buffer containing $\left(\mathrm{mg} \mathrm{ml}^{-1}\right) 2$ type II collagenase and 1 hyaluronidase. The solution was gently agitated with a fire-polished Pasteur pipette to disperse single cells. This suspension was filtered through $100 \mu \mathrm{m}$ nylon mesh and centrifuged at $600 \mathrm{~g}$ for $5 \mathrm{~min}$. For patch clamp recordings, the pellet was resuspended with low $\mathrm{Ca}^{2+} \mathrm{HEPES}$ buffer and kept at $4{ }^{\circ} \mathrm{C}$. Patch-clamp recordings were performed within $8 \mathrm{~h}$ of cell dispersion. For primary cell culture, solutions mentioned above also contained 100 units $\mathrm{ml}^{-1}$ penicillin and $100 \mathrm{mg}$ $\mathrm{ml}^{-1}$ streptomycin and the pellet was resuspended in Medium 231 with smooth muscle growth supplement (Invitrogen). Cells were plated on 1\% gelatin-coated dishes and incubated in a $5 \% \mathrm{CO}_{2}$ incubator at $37{ }^{\circ} \mathrm{C}$. Media was replaced once or twice as cells grew to confluence; after subculturing, the medium was changed every 2-3 days. To induce differentiation in confluent cultures, growth medium 
was switched to Medium 231 containing smooth muscle differentiation supplement (Invitrogen), which was replaced every 2-3 days. Human coronary artery smooth muscle cells (Genlantis) were cultured in Medium 231 with growth and differentiation supplements, the latter added at $~ 80 \%$ confluence.

Transient transfection. AD-293 cells (Stratagene) were grown in DMEM supplemented with $10 \% \mathrm{FBS}, 100$ units $\mathrm{ml}^{-1}$ penicillin, and $100 \mathrm{mg} \mathrm{ml}^{-1}$ streptomycin. Antibiotic-free media was added $1 \mathrm{~h}$ prior to transfection. Plasmids encoding bovine KCNMA1 (ENSG00000156113) and KCNMB1 (ENSG00000145936) were kindly provided by Dr. Michael J. Davis (University of Missouri; (Wu et al., 2008)). A plasmid encoding GFP, pmaxGFP, was purchased from AMAXA. Cells grown to $50-70 \%$ confluence were cotransfected with plasmids containing GFP and $K C N M A 1$ with or without $K C N M B 1$ using Lipofectamine LTX with PLUS reagent (Invitrogen). Transfection with GFP plasmid only was used as a negative control. The optimal molar ratios of KCNMA1 to KCNMB1 were determined to be $>1: 3$. After incubation with DNAlipid complexes in opti-MEM for $6 \mathrm{~h}$, the medium was changed to DMEM supplemented with FBS and antibiotic. Current recordings from GFP-positive cells were performed 1-2 days after transfection.

Electrophysiology. Freshly isolated cells were placed directly in a recording chamber on an inverted microscope, while cultured cells were plated on cover glass that was transferred to the recording chamber. The recording chamber had a volume of $0.2-0.3 \mathrm{ml}$ and solutions were fed by gravity at a rate of 2-3 $\mathrm{ml} \mathrm{min}^{-1}$. BPA (Sigma-Aldrich; product number 133027) and penitrem A (MP 
Biomedicals) were dissolved in DMSO and diluted 1:1000 or 1:10,000 for experiments. For whole-cell recordings, cells were suffused with a solution containing (mM) $135 \mathrm{NaCl}, 5 \mathrm{KCl}, 2 \mathrm{CaCl}_{2}, 1 \mathrm{MgCl}_{2}, 10$ glucose, $10 \mathrm{HEPES}$, and 5 Tris; pH 7.4. Pipette solution contained (mM) $140 \mathrm{KCl}, 1 \mathrm{MgCl}_{2}, 1 \mathrm{EGTA}, 10$ HEPES, and 5 Tris; $\mathrm{pH}$ 7.1. The $\mathrm{Ca}^{2+}$ concentration of the pipette solution was brought to $100 \mathrm{nM}$ by adding $281 \mu \mathrm{M} \mathrm{CaCl}_{2}$ (http://www.stanford.edu/ $\sim$ cpatton/maxc.html). G $\Omega$ seals were made with heat-polished borosilicate pipettes (BF150-86; Sutter Instruments) that had tip resistances of 3-5 M 2 . The cell was ruptured with suction and membrane capacitance determined from the capacity transient (pClamp 9; Axon Instruments). Series resistance and capacitance were compensated as much as possible using the amplifier circuitry (PC-505B; Warner Instruments). In whole-cell records, mean current during the last $80 \mathrm{~ms}$ of the test pulse was measured for analysis. For single channel recordings, cells were suffused with the $140 \mathrm{mM} \mathrm{K}^{+}$solution described above and pipettes had tip resistances of 5-10 M $\Omega$. After forming $\mathrm{G} \Omega$ seals, patches were excised for inside-out recordings in symmetrical $140 \mathrm{mM} \mathrm{K}^{+}$. Channel conductance was determined from peak-to-peak differences in all-points amplitude histograms; $\mathrm{NP}_{\mathrm{o}}$ was calculated by dividing the mean current in a trace by the single channel amplitude. Currents were low pass filtered at $1 \mathrm{kHz}$ and digitized at $5 \mathrm{kHz}$.

RT-PCR. Total RNA was extracted using PureLink RNA Mini kit and PureLink DNase (Invitrogen). One microgram of template was reverse transcribed with Oligo(dT) ${ }_{20}$ primers using the SuperScript First-Strand Synthesis 
System (Invitrogen). PCR primers were designed against KCNMA1 (NM_001014797; 5'-GAGGATGCCTCGAATATCA-3' and 5'-AGCTCG GGATGTTTAGCAGA-3'; product size 119 bp) and KCNMB1 (NM_004137; 5'GCCGGG AAGACTAAATGATC-3' and 5'-TGGGAT GTAGGAGCACTG-3'; product size $357 \mathrm{bp})$. PCR amplification was performed in $50 \mu \mathrm{l}$ reactions containing 1x PCR buffer, $0.2 \mathrm{mM}$ each dNTP, $1.5 \mathrm{mM} \mathrm{MgCl}_{2}, 0.4 \mu \mathrm{M}$ each primer, $1 \mu$ template cDNA, and 2 units Platinum Taq DNA polymerase (Invitrogen). The protocol included: denature at $94{ }^{\circ} \mathrm{C}$ for $2 \mathrm{~min}, 40$ cycles of 94 ${ }^{\circ} \mathrm{C}$ for $15 \mathrm{~s}, 55^{\circ} \mathrm{C}$ for $30 \mathrm{~s}$, and $70{ }^{\circ} \mathrm{C}$ for $1 \mathrm{~min}$; the reaction was terminated at 4 ${ }^{\circ} \mathrm{C}$. As a positive control, human brain cDNA (Ambion) was used. PCR products were separated by electrophoresis on $2 \%$ agarose with ethidium bromide and images captured using a GeneFlash unit (Syngene).

Statistics. Data are presented as the mean and standard error of $n$ number of cells or membrane patches. When two values were compared, a paired t-test was used. When more than two values were compared, one-way ANOVA was used. Current-voltage relationships were analyzed by two-way repeated measures ANOVA. Bonferroni post hoc tests followed ANOVA to determine where differences exist. In all tests, $p<0.05$ was considered significant. 


\section{Results}

The patch clamp technique was used to measure $\mathrm{K}^{+}$current in coronary smooth muscle cells and determine the effect of BPA on Maxi-K current using penitrem A, a potent and selective inhibitor of Maxi-K channels (Knaus et al., 1994). Whole-cell recording revealed prominent Maxi-K current in smooth muscle cells cultured from the canine LAD coronary artery (Fig. 1A, left). Timedependent current increased sharply at potentials positive to $+40 \mathrm{mV}$ and was "noisy", indicating channels with a large unitary conductance were responsible. Current density at $+100 \mathrm{mV}$ was $35 \pm 12 \mathrm{pA} \mathrm{pF}^{-1}(\mathrm{n}=5)$. Whole-cell current increased with the application of $10 \mu \mathrm{M}$ BPA (Fig. 1A, middle; current density at $+100 \mathrm{mV}$ was $\left.64 \pm 24 \mathrm{pA} \mathrm{pF}^{-1}, p<0.05\right)$. The effect of BPA was not voltagedependent. Penitrem A (1 $\mu \mathrm{M})$ blocked nearly all of the whole-cell current in smooth muscle cells cultured from the canine LAD coronary artery (Fig. 1A, right; current density at $+100 \mathrm{mV}$ was $3 \pm 2 \mathrm{pA} \mathrm{pF}^{-1}, p<0.05$ ). In separate experiments $(n=4)$ when $1 \mu \mathrm{M}$ penitrem A was added first, whole-cell current was reduced and could not be increased by $10 \mu \mathrm{M}$ BPA (Fig. 1B; current density at $+100 \mathrm{mV}$ was $33 \pm 10,6 \pm 3$, and $4 \pm 2 \mathrm{pA} \mathrm{pF}^{-1}$, for control, with penitrem $\mathrm{A}$, and penitrem A plus BPA, respectively; $p<0.05)$. The voltage template used to elicit currents is shown in Fig. 1C. Group data for both experiments in cultured canine coronary smooth muscle cells are shown in Figs. 1D and E. Cultured canine coronary smooth muscle cells were derived from 3 different dogs and a characterization of the smooth muscle phenotype of these cells is available in the Supplement. 
Excised patch recordings were used to determine the effect of BPA on Maxi-K channel $\mathrm{NP}_{\mathrm{o}}$ in smooth muscle cells freshly isolated from the canine LAD coronary artery. Inside-out recordings were made in symmetrical $140 \mathrm{mM} \mathrm{K}^{+}$at a patch potential of $+80 \mathrm{mV}$ with free $\mathrm{Ca}^{2+}$ buffered to $100 \mathrm{nM}$. BPA $(10 \mu \mathrm{M})$ increased Maxi-K channel NP $742 \pm 302 \%(n=10$ cells from 4 dogs; $p<0.05$;

Fig. 2A \& B). Single channel conductance was not affected by $10 \mu \mathrm{M}$ BPA (100 \pm $3 \%$ of control; Fig. 2 C).

To determine the role of the $\beta 1$ subunit in responses to $10 \mu \mathrm{M}$ BPA, whole-cell recordings were performed on AD-293 cells transfected with GFP and $\alpha$ or $\alpha+\beta 1$ subunits. Cells transfected with GFP only had very small outward currents (Fig. 3A; current at $+100 \mathrm{mV}$ was $0.04 \pm 0.01 \mathrm{nA} ; \mathrm{n}=3$ ). Cells transfected with Maxi-K a subunits demonstrated large outward currents with fast activation and little or no inactivation (Fig. 3B). The current and time constant of activation at $+100 \mathrm{mV}$ were $5.4 \pm 1.0 \mathrm{nA}$ and $1.0 \pm 0.3 \mathrm{~ms}$, respectively $(\mathrm{n}=11)$. Cells transfected with both Maxi-K $\alpha$ and $\beta 1$ subunits possessed large outward currents with slower activation and demonstrated little or no inactivation (Fig. $3 \mathrm{C})$. Current and time constant of activation at $+100 \mathrm{mV}$ were $5.0 \pm 1.0 \mathrm{nA}$ and $13 \pm 7$ ms, respectively $(n=7)$. In cells with Maxi-K channels composed of $\alpha$ subunits alone, $10 \mu \mathrm{M}$ BPA did not substantially increase current (Fig. 3D; current at $+100 \mathrm{mV}$ was $101 \pm 13 \%$ of control). When Maxi-K channels were composed of $\alpha$ and $\beta 1$ subunits, $10 \mu \mathrm{M}$ BPA increased current by $53 \pm 12 \%$ (Fig. $3 E)$. Penitrem $A(1 \mu M)$ blocked virtually all Maxi-K current, regardless of whether channels were composed of $\alpha$ or $\alpha+\beta 1$ subunits (93 \pm 4 and $93 \pm 2 \%$ inhibition, 
respectively). Group data illustrating the effects of BPA and penitrem A on Maxi$\mathrm{K}$ channels composed of $\alpha$ or $\alpha+\beta 1$ subunits are shown in Fig. 3F \& G.

Inside-out patch recordings were made to determine the effect of $10 \mu \mathrm{M}$ BPA on Maxi-K channels composed of $\alpha$ or $\alpha+\beta 1$ subunits in AD-293 cells. NP。 and single channel conductance were determined at a patch potential of $+40 \mathrm{mV}$ in solutions containing $140 \mathrm{mM} \mathrm{K}^{+}$and $100 \mathrm{nM}$ free $\mathrm{Ca}^{2+}$. BPA had no significant effect on $\mathrm{NP}_{\mathrm{o}}$ or single channel conductance in Maxi-K channels composed of $\alpha$ subunits alone (Fig. 4A \& C). NPo was $123 \pm 20 \%$ of control in the presence of 10 $\mu$ M BPA (Table 1; $\mathrm{n}=6 ; p=$ N.S.). In contrast, in Maxi-K channels containing the $\beta 1$ subunit, $10 \mu \mathrm{M}$ BPA increased $N P_{\circ}$ (Fig. 4B \& D). BPA increased the $N P_{\circ}$ of Maxi-K channels containing the $\beta 1$ subunit $204 \pm 41 \%$ (Table $1 ; n=6, p<0.05$ ). BPA had no effect on conductance in channels composed of $\alpha$ or $\alpha+\beta 1$ subunits (99 \pm 1 and $103 \pm 2 \%$ of control, respectively).

Experiments were performed on $\alpha$ and $\alpha+\beta 1$ Maxi-K channels in AD-293 cells to determine whether the effects of BPA were concentration-dependent and reversible. The response to BPA depended upon the molecular composition of Maxi-K channels (Fig. 5A). When Maxi-K channels contained the $\beta 1$ subunit, 1 , 10 , and $100 \mu \mathrm{M}$ BPA increased current. This was sharply different from the response of Maxi-K channels composed of $\alpha$ subunits alone, where neither 1 nor $10 \mu$ M BPA significantly increased current. Surprisingly, however, at a concentration of $100 \mu \mathrm{M}$, BPA increased significantly the current in AD-293 cells expressing only the $\alpha$ subunit. The effect of BPA to increase whole-cell Maxi-K current was rapid and readily reversible (Fig. 5B). Current through channels 
composed of $\alpha+\beta 1$ subunits increased dramatically during exposure to $10 \mu \mathrm{M}$ BPA (from $4.5 \pm 0.4$ to $5.6 \pm 0.6 \mathrm{nA} ; p<0.05, \mathrm{n}=4$ ). In cells expressing $\alpha$ subunits only, $10 \mu \mathrm{M}$ BPA modestly increased current from $4.4 \pm 0.3$ to $4.6 \pm 0.1$ $n A(n=4)$. There was no difference in the time course for the onset of BPA effect between cells expressing $\alpha$ or $\alpha+\beta 1$ subunits (time constants of $2.0 \pm 0.1$ vs. 2.1 $\pm 0.1 \mathrm{~min}$ ) (Fig. 5C). Washing the cells with BPA-free solution rapidly returned current towards baseline.

Whole-cell patch clamp experiments were also performed on cultured human coronary smooth muscle cells (Fig. 6). The smooth muscle phenotype of these cells is demonstrated in the Supplement. The lower concentrations of BPA (1 and $10 \mu \mathrm{M}$ ) did not increase Maxi-K current; however, $100 \mu \mathrm{M}$ BPA increased current significantly (Fig. 6B). Maxi-K current at $+100 \mathrm{mV}$ under control conditions was $843 \pm 218 \mathrm{pA}$ and increased to $1446 \pm 393 \mathrm{pA}$ with application of $100 \mu \mathrm{M}$ BPA $(\mathrm{n}=6 ; p<0.05)$. Based on concentration-response results with BPA in AD-293 cells expressing $\alpha$ or $\alpha+\beta 1$ subunits (Fig. 5), we investigated whether cultured human coronary smooth muscle cells expressed the $\beta 1$ subunit. Thus, RT-PCR was used to analyze Maxi-K channel subunit mRNA expression. Cultured human coronary smooth muscle cells expressed KCNMA1 mRNA, but mRNA for KCNMB1 was undetectable (Fig. 6C). A positive control, using human brain cDNA, however, demonstrated the applicability of the KCNMB1 primers (Fig. 6C). Moreover, Western blots and immunocytochemistry experiments also failed to detect the $\beta 1$ subunit in these cells (data not shown). Thus, the activation of Maxi-K channels in cultured human coronary smooth muscle cells 
by a minimum concentration of $100 \mu \mathrm{M} \mathrm{BPA}$ is likely due to a lack of $K C N M B 1$

expression (Yang et al., 2009). 


\section{Discussion}

These studies demonstrate that BPA, an estrogenic endocrine disruptor, increases Maxi-K channel current via a nongenomic mechanism. The activation of Maxi-K channels by BPA depends, in a concentration-dependent manner, on the presence of the regulatory $\beta 1$ subunit. Several lines of evidence support these novel observations. First, BPA-induced activation of Maxi-K channels was observed in freshly isolated and cultured coronary smooth muscle cells, as well as in AD-293 cells expressing cloned Maxi-K channel subunits. Furthermore, BPA increased Maxi-K channel $\mathrm{NP}_{\mathrm{o}}$ without affecting single channel conductance. Second, BPA-induced Maxi-K channel activation was detected in both whole-cell and single channel experiments. Moreover, results of the single channel studies clearly indicate that the effect of BPA is non-genomic, as the inside-out patches of membrane were removed from the cell. Third, the effects of BPA were rapid, reversible, and concentration-dependent. While we hypothesized that BPA activation of Maxi-K channels would depend on the presence of the regulatory $\beta 1$ subunit, this prediction was upheld only partially by our studies. Specifically, the $\beta 1$ subunit played a compulsory role in activation of Maxi-K channels by BPA when concentrations of 1 and $10 \mu \mathrm{M}$ were tested; however, at a concentration of $100 \mu \mathrm{M}, \mathrm{BPA}$ activated Maxi-K channels without the $\beta 1$ subunit. The latter finding suggests that the $\alpha$ subunit itself might be the target of BPA and that the $\beta 1$ subunit simply enhances the response. The activating effect of BPA on Maxi-K channels and the transformative influence of the $\beta 1$ subunit represent original observations of multifaceted mechanisms that 
merit additional study. Because of the potential public health impact of BPA exposure and the fact that so many cell types express Maxi-K channels, the implications of these studies may be widespread.

Previous studies document the activation of Maxi-K channels by estrogenic substances, including $17 \beta$-estradiol (Valverde et al., 1999). Thus, to find that BPA activates Maxi-K channels may not seem surprising at first glance. However, the lack of a relationship between the estrogenic nature of a compound and its effect on Maxi-K channels makes such presumptions difficult. For example, tamoxifen, an estrogen receptor modulator with mixed agonist and antagonist properties, activates Maxi-K channels more potently and efficaciously than 17 $\beta$-estradiol (Dick et al., 2001). Moreover, the pure anti-estrogen ICI 182,780 also activates Maxi-K channels (Dick, 2002). Studies generally agree, however, that the $\beta 1$ subunit confers sensitivity upon Maxi-K channels to estrogens and xenoestrogens (Valverde et al., 1999; Dick et al., 2001; Dick \& Sanders, 2001). Other steroid hormones, including androgens, also activate Maxi-K channels (Deenadayalu et al., 2001; Han et al., 2008). The role of Maxi-K channel $\beta$ subunits, of which there are 4 known types, differs depending upon the agonist. For example, the $\beta 1$ subunit is important for Maxi-K channel activation by $17 \beta$-estradiol (Valverde et al., 1999), while $\beta 2$ and $\beta 4$ subunits are important for responses to and discriminate between dehydroepiandrosterone and corticosterone (a stress-related adrenal androgen and a glucocorticoid, respectively) (Lovell et al., 2004; King et al., 2006). 
It is clear that xenoestrogens impact not only the interaction of $17 \beta-$ estradiol with nuclear receptors (Krishnan et al., 1993; Kuiper et al., 1997), but also initiate nongenomic signaling mechanisms. For instance, BPA increases intracellular $\mathrm{Ca}^{2+}$ in $\mathrm{GH} 3 / \mathrm{B} 6$ pituitary tumor cells (Watson et al., 2005; Wozniak et al., 2005; Watson et al., 2007) and pancreatic $\beta$ cells (Alonso-Magdalena et al., 2005). Elevated intracellular $\mathrm{Ca}^{2+}$ could explain the ability of BPA to activate Maxi-K channels; however, experiments in excised patches with solutions clamped to a known $\mathrm{Ca}^{2+}$ concentration eliminate the possibility of this mechanism in the present study. Additionally, while BPA activates signaling by protein kinases A and G in JKT-1 tesicular seminoma cells (Bouskine et al., 2009) and these kinases are linked to Maxi-K channel activation (Kume et al., 1989; Robertson et al., 1993), these mechanisms seem unlikely to explain our results. This is because ATP and other cofactors necessary for kinase signaling were absent in the excised patch studies.

Thus, questions remain as to what mechanism(s) underlies the activation of Maxi-K channels by BPA. The same general uncertainty exists across the field for activation of Maxi-K channels by steroid hormones and their mimetics. At present, two types of data support the idea that an extracellular site of the $\beta 1$ subunit comprises at least a part of the binding domain for these compounds. First, membrane-impermeable conjugates of estrogen (Valverde et al., 1999) and tamoxifen (Dick et al., 2002) activate Maxi-K channels containing the $\beta 1$ subunit from the extracellular, but not the intracellular, side of the membrane. Second, a putative binding site for steroid functional groups has been identified in the $\beta 1$ 
subunit (Bukiya et al., 2007; Bukiya et al., 2008a; Bukiya et al., 2008b). Bukiya and colleagues show that lithocholate, a bile acid formed from cholesterol, activates Maxi-K channels containing $\beta 1$, but not $\beta 4$, subunits. Using a series of chimeric $\beta 1-\beta 4$ subunits, they demonstrate a region of the second transmembrane segment of the $\beta 1$ subunit that may be particularly important for binding steroids. $\beta 1$ subunits, however, are unlikely to be completely responsible for Maxi-K channel responses to steroids and xenoestrogens. Our data demonstrating differential BPA sensitivity of $\alpha$ or $\alpha+\beta 1$ Maxi-K channels support this concept. It seems possible that the a subunit could be the target of BPA and $\beta 1$ subunits enhance BPA binding to the $\alpha$ subunit. In support of this idea, Korovkina and coworkers have demonstrated that the Maxi-K channel a subunit itself functions as a binding site for $17 \beta$-estradiol, and that $\beta 1$ subunits enhance binding by approximately three-fold (Korovkina et al., 2004). Assuming that BPA may bind to the same site, their observations may explain why the $\beta 1$ subunit, while not requisite for BPA-induced activation, increased the BPA-sensitivity of Maxi-K channels. The idea that the $\alpha$ subunit may be the target of BPA is further supported by the study of Perez suggesting that the tamoxifen binding site is located on the Maxi-K $\alpha$ subunit and that $\beta 1$ subunits facilitate or stabilize the interaction (Perez, 2005). The possibility remains, however, that BPA interacts with an unknown molecule to transmit a nongenomic signal that activates Maxi-K channels. Further experiments are necessary to clarify the molecular mechanism(s) of BPA induced Maxi-K channel activation. 
An important concern is relevance of the present findings in light of the levels of BPA exposure, and thus the concentrations of BPA measured, in humans. Worldwide, annual BPA production exceeds 6 billion pounds and hundreds of tons of BPA enter the atmosphere. Thus, it is surprising that data regarding BPA exposure levels remain scarce. Free unconjugated BPA in human serum ranges from approximately 0.9-90 nM (Vandenberg et al., 2007). Because free BPA is a minor fraction (5\%) of the total BPA load (Csanady et al., 2002), total serum concentrations are estimated to be $0.017-1.7 \mu \mathrm{M}$. Nonetheless, BPA became a public health concern relatively recently and many controversies exist about routes of exposure, how much we are exposed to, mechanisms of BPA action, and associations with disease (Vandenberg et al., 2009). Our data obtained with micromolar concentrations of BPA appear to be higher than what most humans are exposed to; however, certain occupational populations are at much higher risk (Hanaoka et al., 2002). Much remains to be resolved about human exposure to BPA and its effects; however, we present the first evidence demonstrating that BPA affects ion channel function directly.

In conclusion, we demonstrate that BPA activates Maxi-K channels in a nongenomic manner. This study focused on immediate effects of BPA on Maxi-K channel activity; however, further investigation will be required to determine any long-term effects of BPA exposure on ion channel function and expression. Our data indicate that the $\beta 1$ subunit increases the BPA-sensitivity of Maxi-K channels; however, the a subunit alone is sufficient for the response of Maxi-K channels to BPA. The toxicology of BPA is not clear, but in cells that express 
Maxi-K channels, activation by BPA would be expected to hyperpolarize the membrane potential. This would decrease excitability in cells that express other voltage-dependent ion channels; however, a more negative membrane potential would also increase the driving force for $\mathrm{Ca}^{2+}$ entry through open $\mathrm{Ca}^{2+}$ channels. Based on the present findings, it would be reasonable to suggest that BPA might act as a vasodilator through the opening of Maxi-K channels. Our findings represent the first known effects of BPA on an ion channel, but other types of ion channels should be studied to increase our understanding of BPA toxicity. 


\section{Acknowledgement}

We are indebted to Dr. Michael J. Davis, University of Missouri School of Medicine for supplying plasmids encoding $K C N M A 1$ and $K C N M B 1$. Our thanks to Drs. Alway, Brock, Frisbee, Hollander, Williamson, Wonderlin, and Yu of the Center for Cardiovascular and Respiratory Sciences for access to equipment and comments on the manuscript. A Research Funds Development Grant from West Virginia University supported this work. 


\section{Figure legends}

Fig. 1 BPA increases Maxi-K current in smooth muscle cells cultured from the canine coronary artery. (Panel A) Representative currents are shown under control conditions, with the application of $10 \mu \mathrm{M} \mathrm{BPA}$, and with $1 \mu \mathrm{M}$ penitrem A. (Panel B) Currents from a representative cell are shown under control conditions, with $1 \mu \mathrm{M}$ penitrem $\mathrm{A}$, and with $10 \mu \mathrm{M}$ BPA in the continued presence of penitrem A. (Panel C) The voltage template used to elicit currents in this and subsequent figures. (Panel D) Group data $(n=5)$ demonstrate the BPA- and penitrem A-sensitivity of currents in cultured coronary artery smooth muscle cells. (Panel E) Penitrem A prevented BPA-induced increase in Maxi-K current $(n=4)$. Asterisks indicate $p<0.05$ vs. control by one-way ANOVA.

Fig. 2 BPA increases Maxi-K channel NP。 in smooth muscle cells freshly isolated from the canine coronary artery. (Panel A) Representative 1 min recordings of Maxi-K channel activity in an inside-out patch before and after exposure to $10 \mu \mathrm{M}$ BPA are shown. Patch potential was $+80 \mathrm{mV}$ and currents were recorded in symmetrical $140 \mathrm{mM} \mathrm{K}^{+}$with $100 \mathrm{nM}$ free $\mathrm{Ca}^{2+}$. BPA increased $N P_{o}$, but had no effect on single channel amplitude. (Panel B) Group data $(n=10$ cells from 4 dogs) demonstrate that $10 \mu \mathrm{M}$ BPA increases $\mathrm{NP}_{\mathrm{o}}$. Asterisk indicates $p<0.05$ by paired $t$ test. (Panel C) Group data $(n=10)$ show that BPA has no effect on single conductance. 
Fig. 3 Maxi-K $\beta 1$ subunit confers sensitivity to $10 \mu \mathrm{M}$ BPA. Currents were measured from AD-293 cells transfected with GFP (Panel A) and Maxi-K channels composed of $\alpha$ (Panel B) or $\alpha+\beta 1$ (Panel C) subunits. Voltage template used is shown in Fig. 1C. Very little whole-cell current was observed in cells expressing GFP only. Cells transfected with the a subunit demonstrate large outward currents with fast activation and little or no inactivation. Cells expressing $\alpha+\beta 1$ subunits demonstrate large outward currents with slower activation. (Panel D) Records from a representative cell transfected with the Maxi-K a subunit show that current is unaffected by $10 \mu \mathrm{M}$ BPA, but blocked by $1 \mu \mathrm{M}$ penitrem A. (Panel E) Current in a cell transfected with $\alpha+\beta 1$ subunits increased with application of $10 \mu \mathrm{M}$ BPA and was blocked by $1 \mu \mathrm{M}$ penitrem A. (Panels F \& G) Group data illustrate the effect of $10 \mu \mathrm{M}$ BPA and $1 \mu \mathrm{M}$ penitrem A on current in cells expressing $\alpha(n=11)$ or $\alpha+\beta 1(n=7)$ subunits. Asterisks indicate $p<$ 0.05 vs. control by two-way repeated measures ANOVA.

\section{Fig. 4 BPA $(10 \mu \mathrm{M})$ increases $\mathrm{NP}_{\circ}$ of Maxi-K channels containing the $\beta 1$} subunit. Representative $1 \mathrm{~s}$ recordings of Maxi-K channel activity in inside-out patches from AD-293 cells expressing Maxi-K $\alpha$ (Panel A) or $\alpha+\beta 1$ (Panel B) subunits before and after exposure to $10 \mu \mathrm{M}$ BPA. Patch potential was $+40 \mathrm{mV}$ in symmetrical $140 \mathrm{mM} \mathrm{K}^{+}$solutions containing $100 \mathrm{nM}$ free $\mathrm{Ca}^{2+}$. (Panels C \& D) contain all-points amplitude histograms from 1 min recordings of patches shown in Panels A \& B. BPA increased the $\mathrm{NP}_{\mathrm{o}}$ of Maxi-K channels containing the $\beta 1$ subunit and no effect on single channel conductance. 


\section{Fig. 5 The activation of Maxi-K channels by BPA is concentration-}

dependent and reversible. (Panel A) Maxi-K currents were measured in the whole-cell configuration after stepping membrane potential from -80 to $+100 \mathrm{mV}$. Cells expressing Maxi-K channels composed of $\alpha$ or $\alpha+\beta 1$ subunits were studied $(n=7-12)$ under control conditions and after exposure to 1,10 , and 100 $\mu \mathrm{M}$ BPA. Current was increased relative to control at all three concentrations in cells expressing $\alpha+\beta 1$ subunits; current was increased only with $100 \mu \mathrm{M}$ BPA in cells expressing the $\alpha$ subunit alone. Asterisks indicate differences between $\alpha$ and $\alpha+\beta 1$ by two-way ANOVA. (Panel B) Maxi-K $(\alpha)$ and Maxi-K $(\alpha+\beta 1)$ currents were elicited by stepping the membrane potential from -80 to $+100 \mathrm{mV}$ for 300 ms every $10 \mathrm{~s}$. BPA (10 $\mu \mathrm{M})$ was applied for $2 \mathrm{~min}$ and washed out. Current increased rapidly with exposure to BPA and returned towards baseline with washout $(n=4)$. (Panel C) Time course for the activation and the reversibility was normalized to the maximal activation of each value.

\section{Fig. 6 BPA, at a concentration of $100 \mu \mathrm{M}$, increases Maxi-K current in} human coronary artery smooth muscle cells. (Panel A) Representative records demonstrate that BPA $(100 \mu \mathrm{M})$ increased whole-cell current in smooth muscle cells cultured from human coronary arteries. (Panel B) contains group data $(n=3-7)$ for effect of three concentrations of BPA on Maxi-K current. (Panel C) RT-PCR revealed the expression of KCNMA1 ( $\alpha$ subunit; 119 bp product) but not KCNMB1 ( $\beta 1$ subunit; 357 bp product) in cultured human smooth muscle 
cells. Human brain cDNA was used as a control and the expression of KCNMA1 and KCNMB1 was detected. $-\mathrm{RT}$ is a reaction without reverse transcriptase; NTC is a no template control. 
Table $31 \beta 1$ subunit determines the response of Maxi-K channels to $10 \mu \mathrm{M}$ BPA

\begin{tabular}{|l|l|l|l|}
\hline Subunit(s) & Condition & NPo & Conductance $(p S)$ \\
\hline$\alpha(n=6)$ & Control & $0.75 \pm 0.27$ & $248 \pm 8$ \\
\hline & BPA & $1.06 \pm 0.42$ & $246 \pm 9$ \\
\hline$\alpha+\beta 1(n=6)$ & Control & $0.96 \pm 0.11$ & $253 \pm 15$ \\
\hline & BPA & $\begin{array}{l}2.97 \pm 0.58(p< \\
0.05)\end{array}$ & $260 \pm 13$ \\
& & & \\
\hline
\end{tabular}


A

cortrol
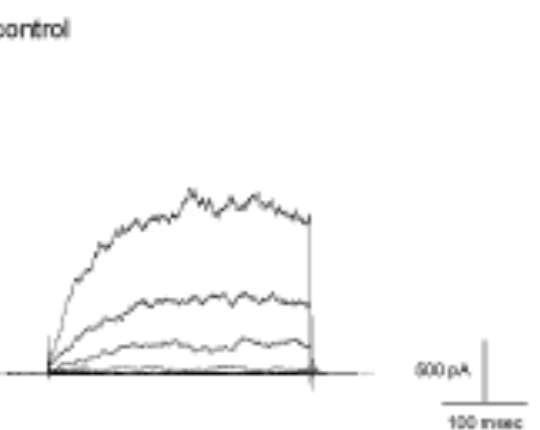

BPA (10,

penitrem $A(1 \mu M)$

B

cortrol

penitrem $A(1 \mu M)$

pentrem $\mathrm{A}(1 \mu \mathrm{M})$

$+\mathrm{BPA}(10 \mu \mathrm{M})$
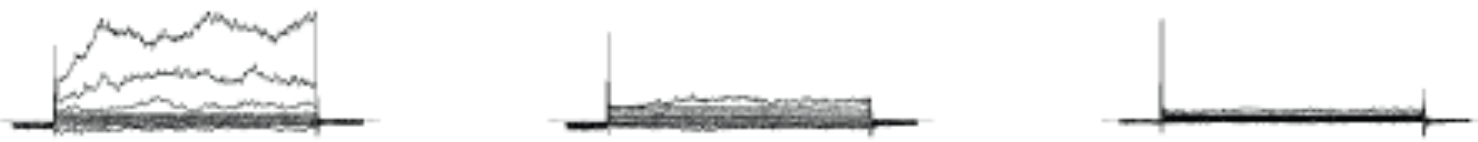

C

D
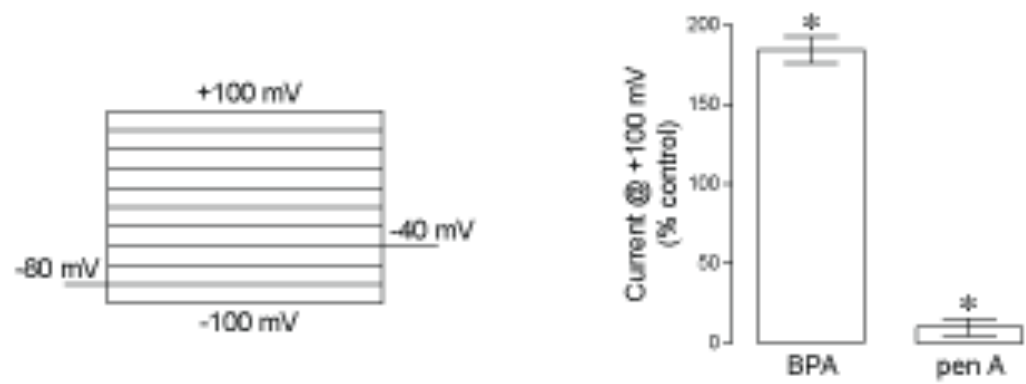

E

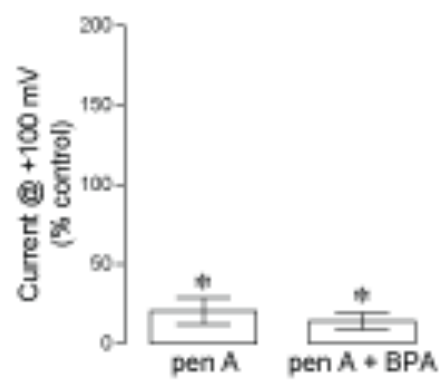

Figure 31 BPA increases Maxi-K current in smooth muscle cells cultured from the canine coronary artery. 
A

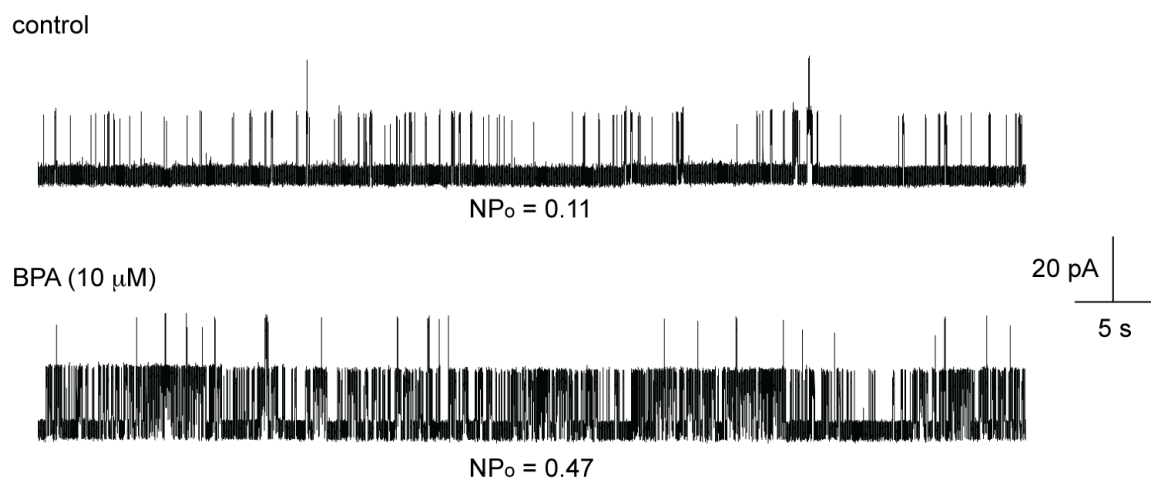

B

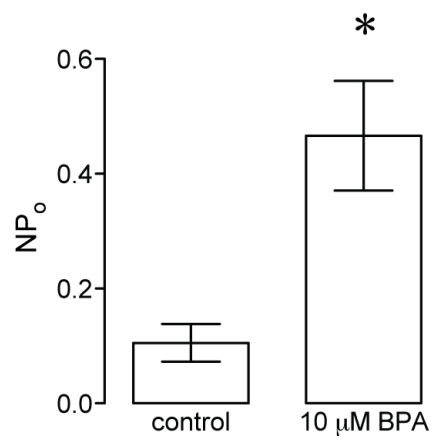

C

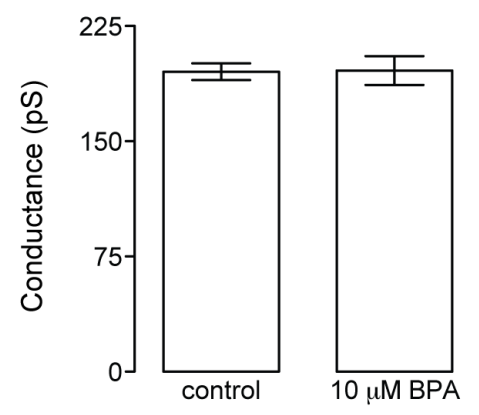

Figure 32 BPA increases Maxi-K channel NPo in smooth muscle cells freshly isolated from the canine coronary artery 

A GFP
$B_{\alpha}$
C $\alpha+\beta 1$
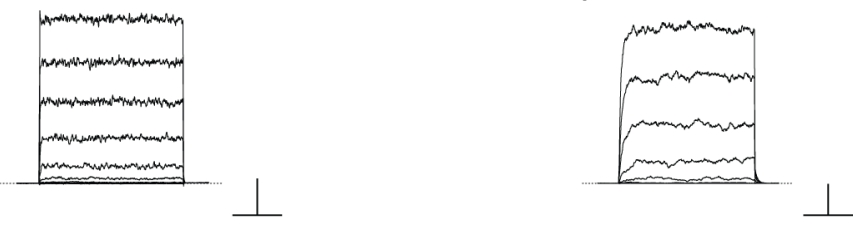
D $\quad \alpha$
control
$10 \mu \mathrm{M} B P A$
$1 \mu \mathrm{M}$ penitrem $\mathrm{A}$
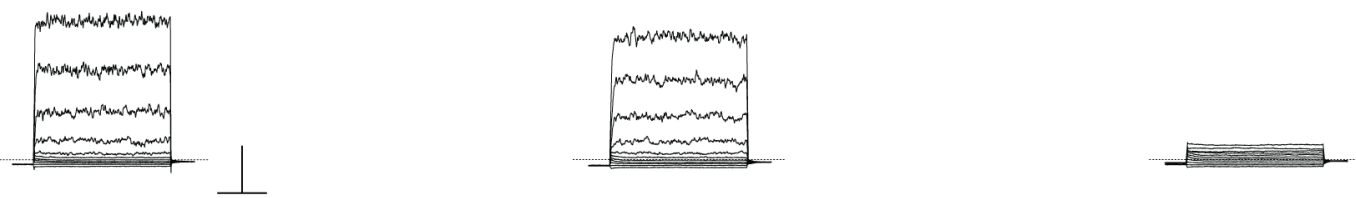
E
$\alpha+\beta 1 \quad$ control
$10 \mu \mathrm{M}$ BPA
$1 \mu \mathrm{M}$ penitrem $\mathrm{A}$
$\mathrm{F}$
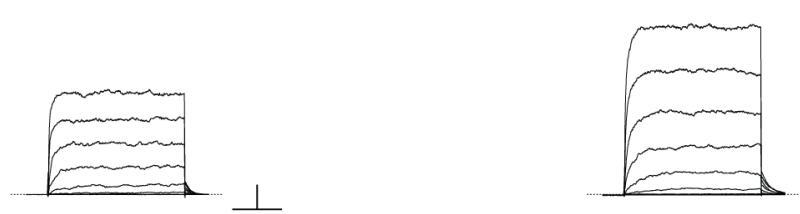
G
$\alpha$

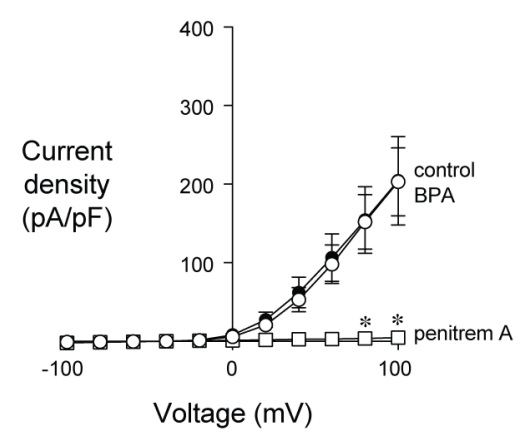
$\alpha+\beta 1$

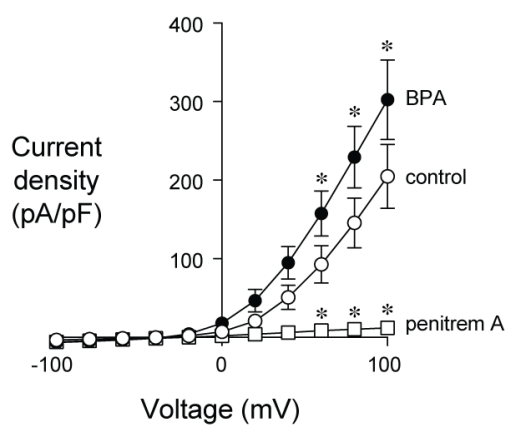

Figure 33 Maxi-K $\beta 1$ subunit confers sensitivity to $10 \mu \mathrm{M}$ BPA 
A $\alpha$

control
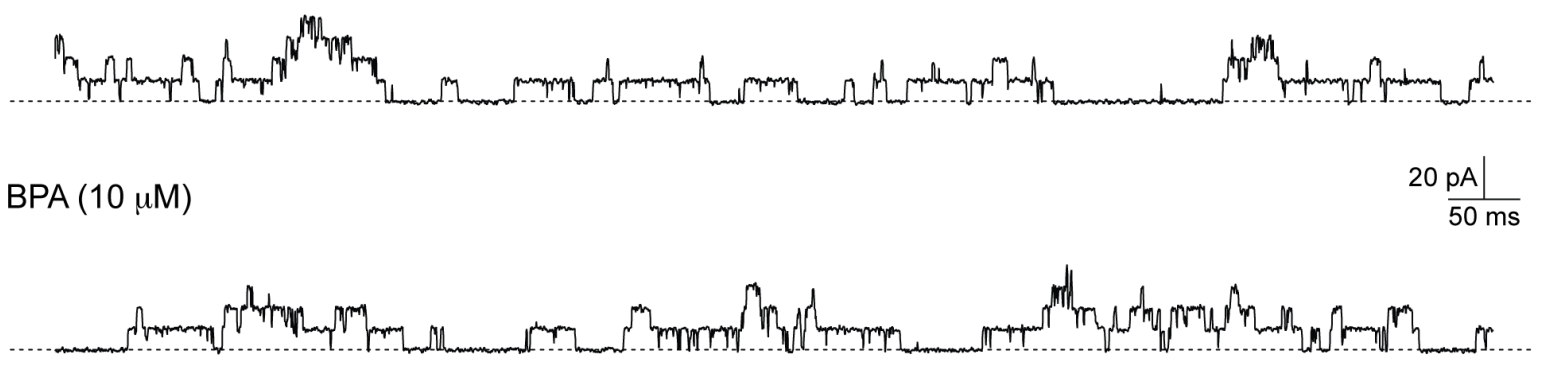

B $\alpha+\beta 1$

control
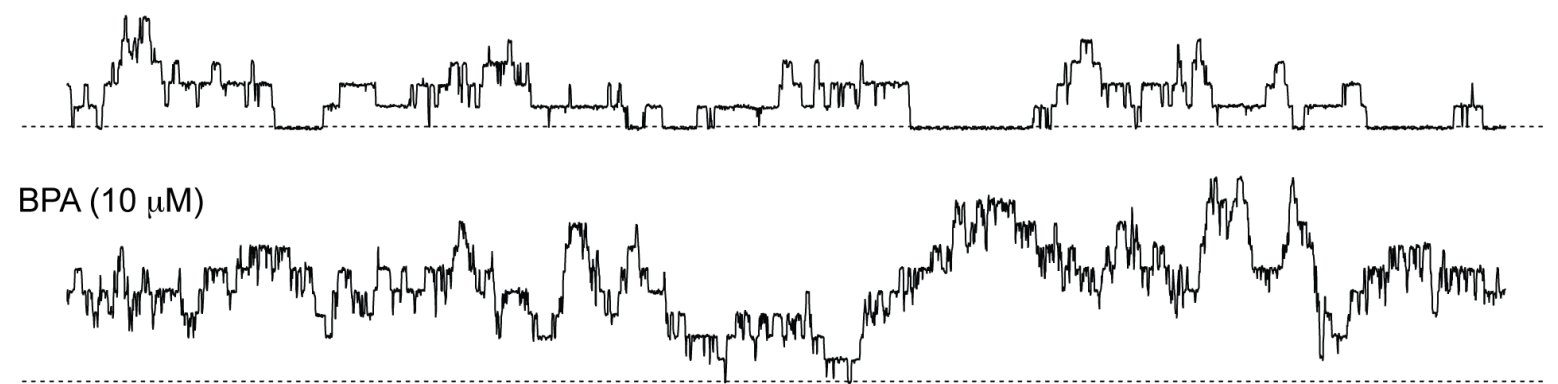

C $\alpha$

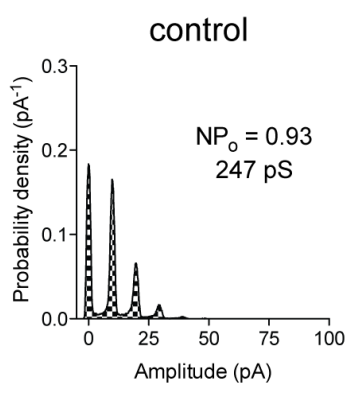

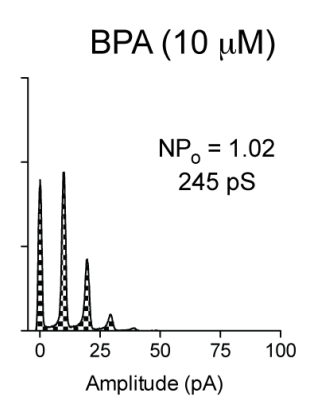

D $\alpha+\beta 1$

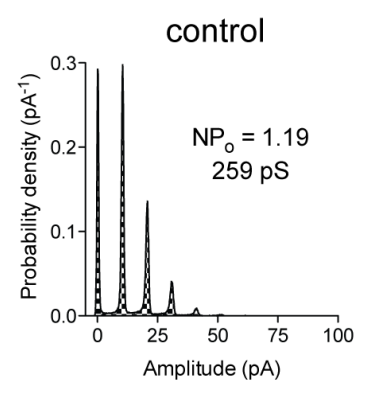

Figure 34 BPA $(10 \mu \mathrm{M})$ increases $\mathrm{NP}_{\circ}$ of Maxi-K channels containing the $\beta 1$ subunit 
A

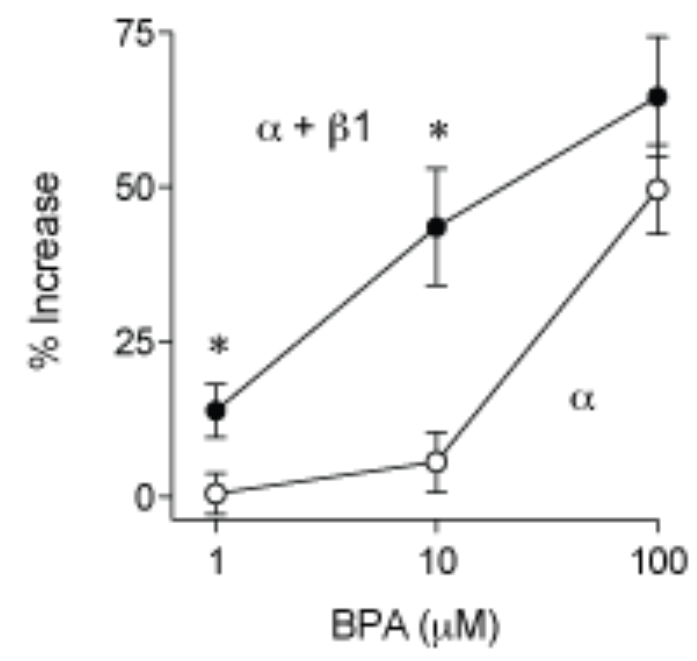

B

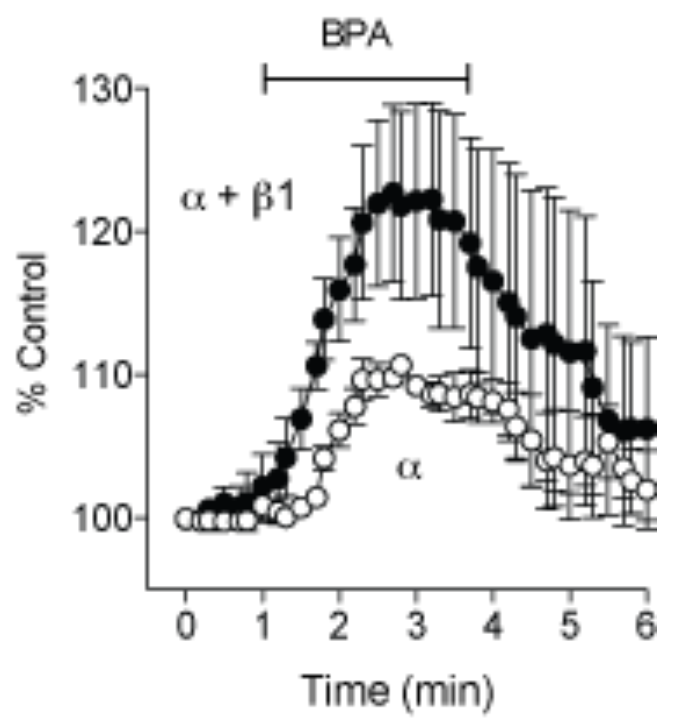

Figure $3 \mathbf{5}$ The activation of Maxi-K channels by BPA is concentrationdependent and reversible. 
A

BPA $(100 \mu \mathrm{M})$
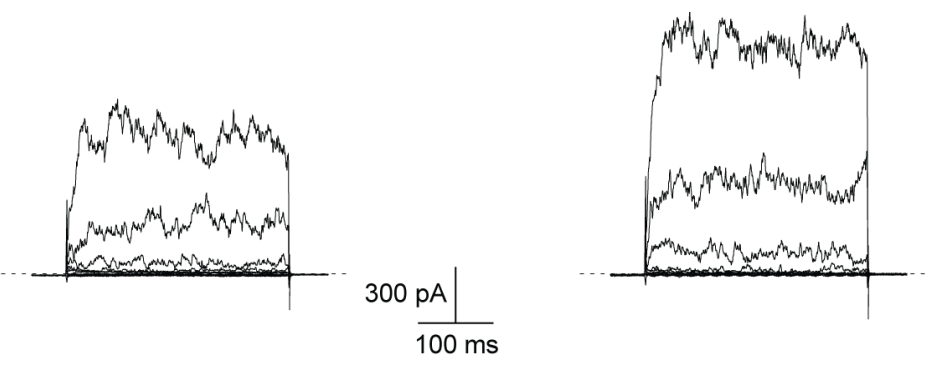

B

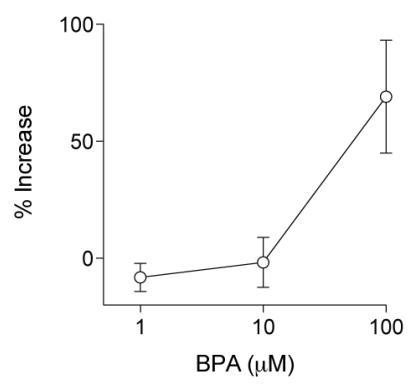

C

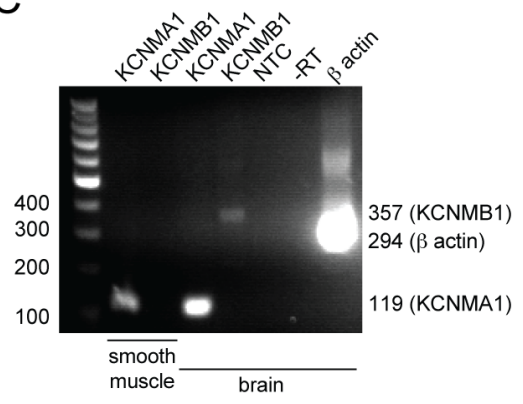

Figure $36 \mathrm{BPA}$, at a concentration of $100 \mu \mathrm{M}$, increases Maxi-K current in human coronary artery smooth muscle cells 


\section{Supplemental information}

Cells from the canine coronary artery were cultured and differentiated into smooth muscle. Cells took $\sim 4-5$ days to start effectively dividing and grew to confluence in $\sim 7$ days. Cells no longer grew after passage $\sim 10$. Confluent cells exhibited a "hill and valley" pattern under phase contrast (Supplemental Fig. 1A). Immunoblots indicated the expression of smooth muscle-specific a actin and myosin heavy chain in differentiated cells (Supplemental Fig. 1B). Phase contrast images and smooth muscle-specific a actin and myosin heavy chain immunoreactivity for cultured human smooth muscle cells are also shown in Supplemental Figs. 1A \& B. Smooth muscle cells were trypsinized and plated on cover glass for patch clamp experiments. These cells retained the smooth muscle phenotype, as shown by immunocytochemistry for smooth musclespecific $\alpha$ actin (Supplemental Fig. 2A). After treatment with differentiation media for 1 or 2 weeks, $75 \pm 4$ and $90 \pm 3 \%$ of the canine cells retained the smooth muscle phenotype ( $n=3$, Supplemental Fig. 2B). Immunocytochemistry and the percent of cells with a smooth muscle phenotype are also shown in Supplemental Figs. 2A \& B. Thus, canine coronary artery smooth muscle cells demonstrated morphology and immunoreactivity consistent with those observed by others in various species (Teng et al., 2006; Christen et al., 199. Taken together, we conclude that the majority of cultured cells possessed a smooth muscle phenotype and were appropriate for study.

\section{METHODS}


Western blots. Cultured cells were washed two times with PBS and harvested in RIPA lysis buffer supplemented with (mM) $2 \mathrm{PMSF}, 1 \mathrm{Na}_{3} \mathrm{VO}_{4}, 1$ DTT and 1x protease inhibitor cocktail solution (Santa Cruz Biotechnology). Samples were sonicated on ice, incubated for $15 \mathrm{~min}$ on ice, and centrifuged at $10,000 \mathrm{~g}$ at $4{ }^{\circ} \mathrm{C}$ for $10 \mathrm{~min}$. The supernatant was removed and stored at $-80^{\circ} \mathrm{C}$ until use. Protein concentrations were determined by BCA method using BSA as a standard (Pierce). Samples were diluted to $1 \mathrm{mg} / \mathrm{ml}$ in Laemmli sample buffer and boiled at $70{ }^{\circ} \mathrm{C}$ for $15 \mathrm{~min}$. Equivalent amounts of protein were separated by SDS-PAGE, followed by electroblotting onto nitrocellulose membranes. Membranes were blocked with 5\% nonfat milk (Bio-Rad) in TBST for $1 \mathrm{~h}$ at room temperature, washed 3 times in TBST, and incubated overnight at $4{ }^{\circ} \mathrm{C}$ in primary antibodies against smooth muscle $\alpha$ actin (1:500; Sigma), smooth muscle myosin heavy chain (1:500; Biomedical Technologies) and b tubulin (1:1000; Santa Cruz Biotechnology). After washing 3 times in TBST, membranes were incubated with anti-species secondary antibody conjugated with HRP and HRP-linked anti-biotin secondary antibodies for a biotinlyated ladder (1:5000; Cell Signaling Technology) for $1 \mathrm{~h}$ at room temperature and then washed again 3 times with TBST. An enhanced chemiluminescence detection system (ECL Advance, Amersham Biosciences) was used to detect the antibodies and the lanes were analyzed using a G:Box system (Syngene).

Immunocytochemistry. Differentiated cells were plated on cover glass and allowed to adhere overnight. Cells were washed with PBS and fixed in $4 \%$ formaldehyde in PBS, $\mathrm{pH} 7.4$ for 30 min at room temperature. After three washes 
in PBS, cells were permeabilized with $0.1 \%$ Triton X-100 in PBS for 2 min. Cells were treated 30 min in blocking solution (2\% goat serum, $3 \%$ BSA in PBS) and then incubated with anti-smooth muscle-specific $\alpha$ actin (1:400; Sigma) for $1 \mathrm{~h}$ at room temperature in a humidified chamber. Following three washes with PBS, cells were incubated with Alexa Fluor 488-conjugated anti-mouse IgG (1:1000; Invitrogen) for $1 \mathrm{~h}$ at room temperature in a humidified chamber. After a final wash with PBS, cover glass was placed on mounting medium (Santa Cruz Biotechnology) on a slide. Images were obtained with an epifluorescence microscope and a SPOT RT camera (Diagnostic Instruments).

\section{REFERENCES}

Teng, B, Ansari, HR, Oldenburg, PJ, Schnermann, J, Mustafa SJ. (2006) Isolation and characterization of coronary endothelial and smooth muscle cells from A1 adenosine receptor knockout mice. Am J Physiol Heart Circ Physiol. 290(4):H1713-1720.

Christen, T, Bochaton-Piallat, ML, Neuville, P, Rensen, S, Redard, M, van Eys, G, Gabbiani, G.

(1999) Cultured porcine coronary artery smooth muscle cells. A new model with advanced differentiation. Circ Res 85: 99-107. 
Supplemental Fig. 1 Cells cultured from the canine LAD coronary artery revealed typical smooth muscle morphology and expressed smooth muscle phenotypic markers. (Panel A) Phase contrast images of cells cultured from the canine coronary artery develop over time into a characteristic "hill and valley" morphology. Human smooth muscle cell cultures are also shown. (Panel B) Immunoblot of smooth muscle-specific myosin heavy chain and a actin in canine and human cells. The expression of these smooth muscle markers increased over time in differentiation media.

\section{Supplemental Fig. 2 Smooth muscle cells plated for patch clamp experiments continue to express phenotypic markers. (Panel A) Immunofluorescence of smooth muscle-specific $\alpha$ actin (green) during differentiation; nuclei are stained blue. Images from canine and human cells are shown. (Panel B) The percentage of cells in culture that express smooth muscle- specific $\alpha$ actin increases over time in differentiation medium $(n=3)$. Asterisks indicate $p<0.05$ vs. day 0 .}


A

Canine cells
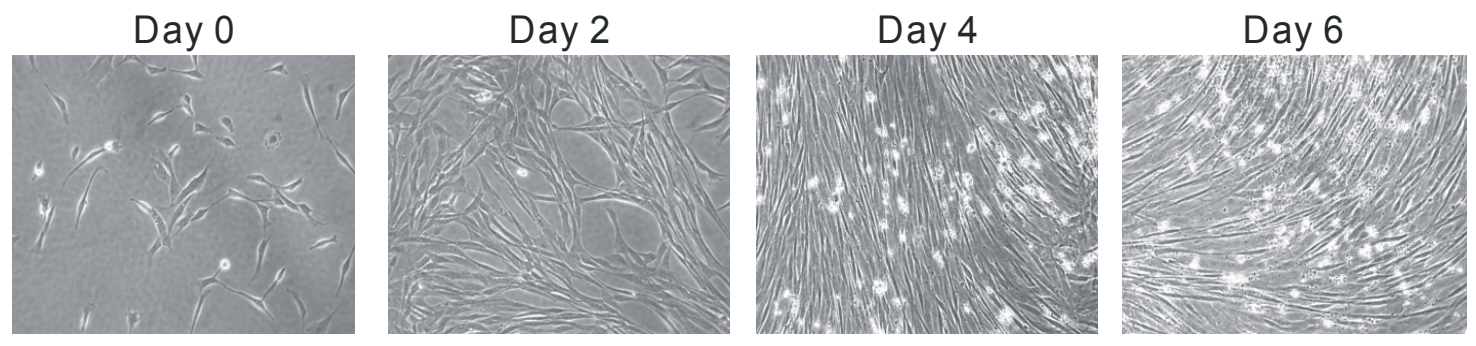

HCASMCs
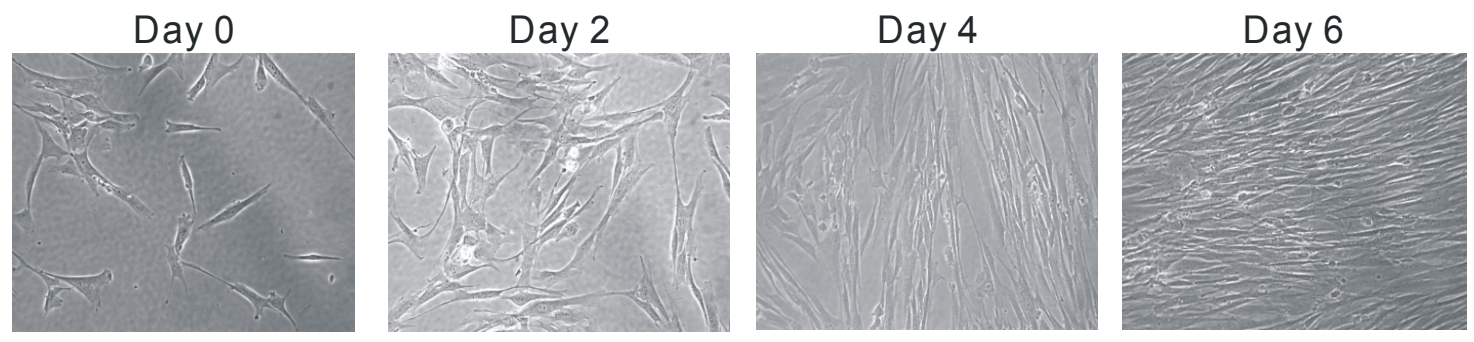

B

HCASMCS

Oday 4days 1 week 2 weeks

SM MHC

SM a actin

$\beta$ tubulin
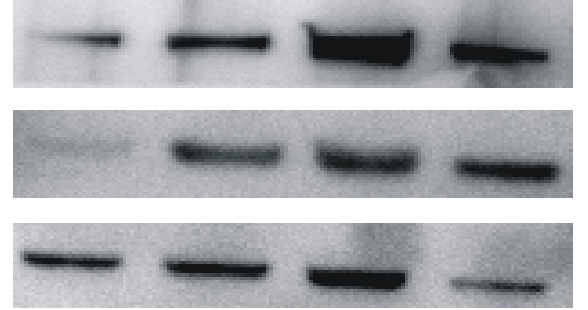

CCASMCs

0 day 4 days 1 week 2 weeks

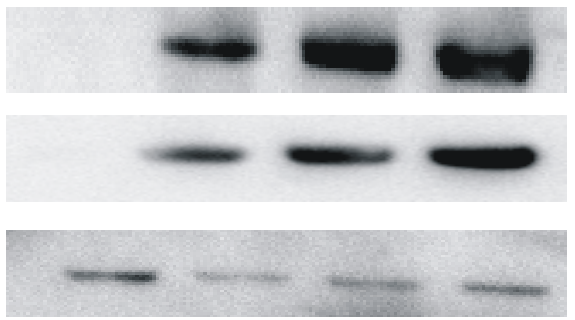

Figure 37 Supplemental Figure 1. Cells cultured from the canine LAD coronary artery revealed typical smooth muscle morphology and expressed smooth muscle phenotypic markers 


\section{A}

Canine cells
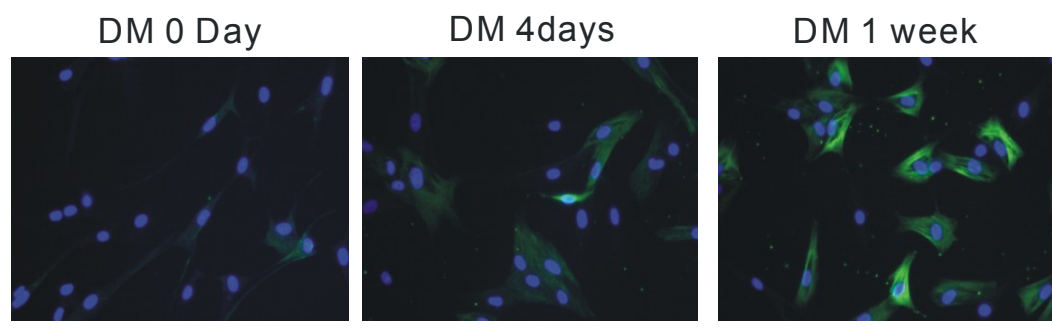

DM 2 weeks

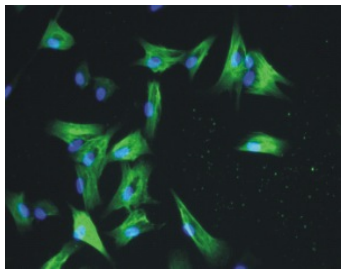

HCASMCs

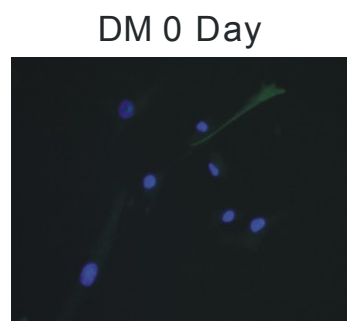

DM 4days

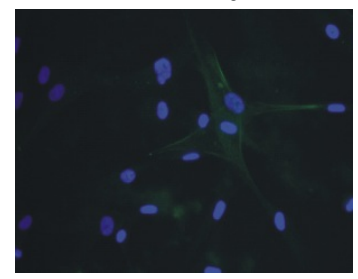

DM 1 week

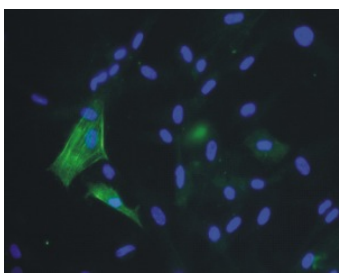

DM 2 weeks

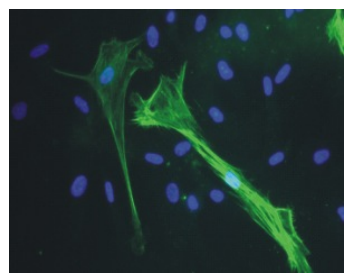

B
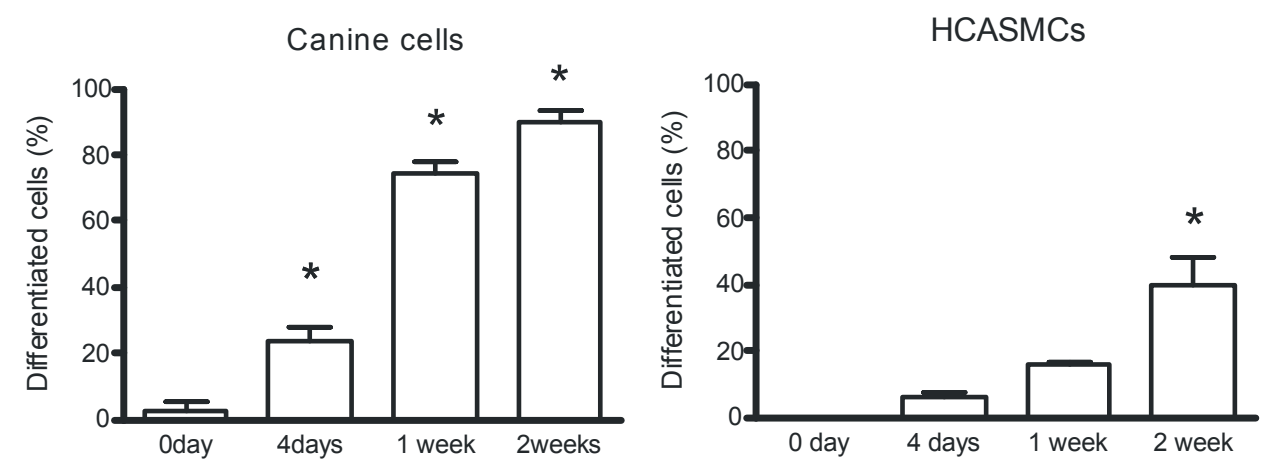

Figure 38 Supplemental Figure 2. Smooth muscle cells plated for patch clamp experiments continue to express phenotypic markers 


\section{References}

Alexander SP, Mathie A \& Peters JA. (2008). Guide to Receptors and Channels (GRAC), 3rd edition. Br J Pharmacol 153 Suppl 2, S1-209.

Alonso-Magdalena P, Laribi O, Ropero AB, Fuentes E, Ripoll C, Soria B \& Nadal A. (2005). Low doses of bisphenol $A$ and diethylstilbestrol impair $\mathrm{Ca} 2+$ signals in pancreatic alpha-cells through a nonclassical membrane estrogen receptor within intact islets of Langerhans. Environ Health Perspect 113, 969-977.

Bouskine A, Nebout M, Brucker-Davis F, Benahmed M \& Fenichel P. (2009). Low doses of bisphenol A promote human seminoma cell proliferation by activating PKA and PKG via a membrane G-protein-coupled estrogen receptor. Environ Health Perspect 117, 1053-1058.

Brenner R, Perez GJ, Bonev AD, Eckman DM, Kosek JC, Wiler SW, Patterson AJ, Nelson MT \& Aldrich RW. (2000). Vasoregulation by the beta1 subunit of the calcium-activated potassium channel. Nature 407, 870-876.

Bukiya AN, Liu J, Toro L \& Dopico AM. (2007). Beta1 (KCNMB1) subunits mediate lithocholate activation of large-conductance $\mathrm{Ca} 2+$-activated $\mathrm{K}+$ channels and dilation in small, resistance-size arteries. Mol Pharmacol 72, 359-369.

Bukiya AN, McMillan J, Parrill AL \& Dopico AM. (2008a). Structural determinants of monohydroxylated bile acids to activate beta 1 subunit-containing BK channels. J Lipid Res 49, 2441-2451.

Bukiya AN, Vaithianathan T, Toro L \& Dopico AM. (2008b). The second transmembrane domain of the large conductance, voltage- and calciumgated potassium channel beta(1) subunit is a lithocholate sensor. FEBS Lett 582, 673-678.

Butler A, Tsunoda S, McCobb DP, Wei A \& Salkoff L. (1993). mSlo, a complex mouse gene encoding "maxi" calcium-activated potassium channels. Science 261, 221-224.

Coiret G, Borowiec AS, Mariot P, Ouadid-Ahidouch H \& Matifat F. (2007). The antiestrogen tamoxifen activates $\mathrm{BK}$ channels and stimulates proliferation of MCF-7 breast cancer cells. Mol Pharmacol 71, 843-851.

Csanady GA, Oberste-Frielinghaus HR, Semder B, Baur C, Schneider KT \& Filser JG. (2002). Distribution and unspecific protein binding of the xenoestrogens bisphenol A and daidzein. Arch Toxicol 76, 299-305. 
Deenadayalu VP, White RE, Stallone JN, Gao X \& Garcia AJ. (2001).

Testosterone relaxes coronary arteries by opening the large-conductance, calcium-activated potassium channel. Am J Physiol Heart Circ Physiol 281, $\mathrm{H} 1720-1727$.

Dick GM. (2002). The pure anti-oestrogen ICI 182,780 (Faslodex) activates large conductance $\mathrm{Ca}(2+)$-activated $\mathrm{K}(+)$ channels in smooth muscle. $\mathrm{Br} \mathrm{J}$ Pharmacol 136, 961-964.

Dick GM, Hunter AC \& Sanders KM. (2002). Ethylbromide tamoxifen, a membrane-impermeant antiestrogen, activates smooth muscle calciumactivated large-conductance potassium channels from the extracellular side. Mol Pharmacol 61, 1105-1113.

Dick GM, Rossow CF, Smirnov S, Horowitz B \& Sanders KM. (2001). Tamoxifen activates smooth muscle BK channels through the regulatory beta 1 subunit. J Biol Chem 276, 34594-34599.

Dick GM \& Sanders KM. (2001). (Xeno)estrogen sensitivity of smooth muscle BK channels conferred by the regulatory beta1 subunit: a study of beta1 knockout mice. J Biol Chem 276, 44835-44840.

Duncan RK. (2005). Tamoxifen alters gating of the BK alpha subunit and mediates enhanced interactions with the avian beta subunit. Biochem Pharmacol 70, 47-58.

Han DH, Chae MR, Jung JH, So I, Park JK \& Lee SW. (2008). Effect of testosterone on potassium channel opening in human corporal smooth muscle cells. J Sex Med 5, 822-832.

Hanaoka T, Kawamura N, Hara K \& Tsugane S. (2002). Urinary bisphenol A and plasma hormone concentrations in male workers exposed to bisphenol $\mathrm{A}$ diglycidyl ether and mixed organic solvents. Occup Environ Med 59, 625628.

Hugo ER, Brandebourg TD, Woo JG, Loftus J, Alexander JW \& Ben-Jonathan N. (2008). Bisphenol A at environmentally relevant doses inhibits adiponectin release from human adipose tissue explants and adipocytes. Environ Health Perspect 116, 1642-1647.

King JT, Lovell PV, Rishniw M, Kotlikoff MI, Zeeman ML \& McCobb DP. (2006). Beta2 and beta4 subunits of BK channels confer differential sensitivity to acute modulation by steroid hormones. J Neurophysiol 95, 2878-2888. 
Knaus HG, McManus OB, Lee SH, Schmalhofer WA, Garcia-Calvo M, Helms LM, Sanchez M, Giangiacomo K, Reuben JP, Smith AB, 3rd \& et al. (1994). Tremorgenic indole alkaloids potently inhibit smooth muscle highconductance calcium-activated potassium channels. Biochemistry 33, 5819-5828.

Korovkina VP, Brainard AM, Ismail P, Schmidt TJ \& England SK. (2004). Estradiol binding to maxi-K channels induces their down-regulation via proteasomal degradation. J Biol Chem 279, 1217-1223.

Krishnan AV, Stathis P, Permuth SF, Tokes L \& Feldman D. (1993). Bisphenol-A: an estrogenic substance is released from polycarbonate flasks during autoclaving. Endocrinology 132, 2279-2286.

Kuiper GG, Carlsson B, Grandien K, Enmark E, Haggblad J, Nilsson S \& Gustafsson JA. (1997). Comparison of the ligand binding specificity and transcript tissue distribution of estrogen receptors alpha and beta. Endocrinology 138, 863-870.

Kume H, Takai A, Tokuno H \& Tomita T. (1989). Regulation of Ca2+-dependent $\mathrm{K}+$-channel activity in tracheal myocytes by phosphorylation. Nature $\mathbf{3 4 1}$, 152-154.

Lang IA, Galloway TS, Scarlett A, Henley WE, Depledge M, Wallace RB \& Melzer D. (2008). Association of urinary bisphenol A concentration with medical disorders and laboratory abnormalities in adults. JAMA 300, 1303-1310.

Lovell PV, King JT \& McCobb DP. (2004). Acute modulation of adrenal chromaffin cell BK channel gating and cell excitability by glucocorticoids. $J$ Neurophysiol 91, 561-570.

McManus OB, Helms LM, Pallanck L, Ganetzky B, Swanson R \& Leonard RJ. (1995). Functional role of the beta subunit of high conductance calciumactivated potassium channels. Neuron 14, 645-650.

Meera P, Wallner M, Jiang Z \& Toro L. (1996). A calcium switch for the functional coupling between alpha (hslo) and beta subunits (KV,Ca beta) of maxi $\mathrm{K}$ channels. FEBS Lett 382, 84-88.

Nadal A, Ropero AB, Laribi O, Maillet M, Fuentes E \& Soria B. (2000). Nongenomic actions of estrogens and xenoestrogens by binding at a plasma membrane receptor unrelated to estrogen receptor alpha and estrogen receptor beta. Proc Natl Acad Sci U S A 97, 11603-11608. 
Nelson MT, Cheng H, Rubart M, Santana LF, Bonev AD, Knot HJ \& Lederer WJ. (1995). Relaxation of arterial smooth muscle by calcium sparks. Science 270, 633-637.

Perez GJ. (2005). Dual effect of tamoxifen on arterial KCa channels does not depend on the presence of the beta1 subunit. J Biol Chem 280, 2173921747.

Robertson BE, Schubert R, Hescheler J \& Nelson MT. (1993). cGMP-dependent protein kinase activates Ca-activated $\mathrm{K}$ channels in cerebral artery smooth muscle cells. Am J Physiol 265, C299-303.

Savabieasfahani M, Kannan K, Astapova O, Evans NP \& Padmanabhan V. (2006). Developmental programming: differential effects of prenatal exposure to bisphenol-A or methoxychlor on reproductive function. Endocrinology 147, 5956-5966.

Tanaka Y, Meera P, Song M, Knaus HG \& Toro L. (1997). Molecular constituents of maxi $\mathrm{KCa}$ channels in human coronary smooth muscle: predominant alpha + beta subunit complexes. J Physiol 502 ( Pt 3), 545-557.

Valverde MA, Rojas P, Amigo J, Cosmelli D, Orio P, Bahamonde MI, Mann GE, Vergara C \& Latorre R. (1999). Acute activation of Maxi-K channels (hSlo) by estradiol binding to the beta subunit. Science 285, 1929-1931.

Vandenberg LN, Maffini MV, Sonnenschein C, Rubin BS \& Soto AM. (2009). Bisphenol-A and the great divide: a review of controversies in the field of endocrine disruption. Endocr Rev 30, 75-95.

Vandenberg LN, Maffini MV, Wadia PR, Sonnenschein C, Rubin BS \& Soto AM. (2007). Exposure to environmentally relevant doses of the xenoestrogen bisphenol-A alters development of the fetal mouse mammary gland. Endocrinology 148, 116-127.

Walsh DE, Dockery P \& Doolan CM. (2005). Estrogen receptor independent rapid non-genomic effects of environmental estrogens on [Ca2+]i in human breast cancer cells. Mol Cell Endocrinol 230, 23-30.

Watson CS, Bulayeva NN, Wozniak AL \& Alyea RA. (2007). Xenoestrogens are potent activators of nongenomic estrogenic responses. Steroids $\mathbf{7 2 , 1 2 4 -}$ 134.

Watson CS, Bulayeva NN, Wozniak AL \& Finnerty CC. (2005). Signaling from the membrane via membrane estrogen receptor-alpha: estrogens, xenoestrogens, and phytoestrogens. Steroids 70, 364-371. 
Wetherill YB, Fisher NL, Staubach A, Danielsen M, de Vere White RW \& Knudsen KE. (2005). Xenoestrogen action in prostate cancer: pleiotropic effects dependent on androgen receptor status. Cancer Res 65, 54-65.

Wetherill YB, Petre CE, Monk KR, Puga A \& Knudsen KE. (2002). The xenoestrogen bisphenol A induces inappropriate androgen receptor activation and mitogenesis in prostatic adenocarcinoma cells. Mol Cancer Ther 1, 515-524.

Wozniak AL, Bulayeva NN \& Watson CS. (2005). Xenoestrogens at picomolar to nanomolar concentrations trigger membrane estrogen receptor-alphamediated $\mathrm{Ca} 2+$ fluxes and prolactin release in $\mathrm{GH} 3 / \mathrm{B} 6$ pituitary tumor cells. Environ Health Perspect 113, 431-439.

Wu X, Yang Y, Gui P, Sohma Y, Meininger GA, Davis GE, Braun AP \& Davis MJ. (2008). Potentiation of large conductance, Ca2+-activated K+ (BK) channels by alpha5beta1 integrin activation in arteriolar smooth muscle. $J$ Physiol 586, 1699-1713.

Yang Y, Murphy TV, Ella SR, Grayson TH, Haddock R, Hwang YT, Braun AP, Peichun G, Korthuis RJ, Davis MJ \& Hill MA. (2009). Heterogeneity in function of small artery smooth muscle BKCa: involvement of the beta1subunit. J Physiol 587, 3025-3044. 
CHAPTER 4 Bisphenol A decreases BK channel expression in rat aortic smooth muscle via estrogen receptor mediated mechanisms

Shinichi Asano and Gregory M. Dick

Division of Exercise Physiology

Center for Cardiovascular \& Respiratory Sciences

West Virginia University School of Medicine

Short title: BPA negatively regulates KCNMA1

Please address correspondence to:

Gregory M. Dick, Ph.D.

West Virginia University School of Medicine

P.O. Box 9105

Morgantown, WV 26506

Phone (304) 293-2542

Fax (304) 293-5513

E-mail gmdick@hsc.wvu.edu 


\section{Abstract}

Background and purpose: Bisphenol A (BPA) is an estrogenic endocrine disruptor implicated in the development cardiovascular disease. We previously demonstrated that BPA activates smooth muscle $\mathrm{BK}\left(\mathrm{K}_{\mathrm{Ca}} 1.1\right)$ channels nongenomically (Asano et al. Br J Pharmacol. 160(1):160-70, 2010). This finding is seemingly inconsistent with BPA-induced cardiovascular disease. Importantly, however, estrogen also activates BK channels, but negatively regulates KCNMA1, the gene encoding BK channels. It is possible that BPA might have a similar effect; therefore, we tested the hypothesis that BPA reduces BK channel expression though a genomic mechanism.

Experimental approach: Rat aortae were placed in tissue culture for a 48-72 hour treatment with BPA (10 $\mu \mathrm{mol} / \mathrm{L})$. BK channel expression was determined by RT-PCR, Western blot, and whole-cell patch clamp. Experiments repeated with BPA in the presence of $\mathrm{ICl} 182,780(1 \mu \mathrm{mol} / \mathrm{L})$, an estrogen receptor antagonist. Key Results: BPA decreased the expression of BK a subunit mRNA and protein. Penitrem A-sensitive BK current was reduced in smooth muscle cells from BPAtreated aortae. ICI 182,780, an estrogen receptor antagonist, blocked the effect of BPA to reduce BK channel mRNA, protein, and current.

Conclusions and implications: These data indicate BPA decreases BK channel expression via activation of nuclear estrogen receptors. Further, our findings represent one potential mechanism by which BPA exposure may possibly be linked to cardiovascular disease. 
Keywords: estrogen; xenoestrogen; KCNMA1; $\mathrm{K}_{\mathrm{Ca}} 1.1$; penitrem A; polycarbonate plastic; cardiovascular disease 


\section{Introduction}

Bisphenol A (BPA) is used to manufacture polycarbonate plastic, resin lining of cans, and dental sealants. Further, BPA is used as a non-polymer additive to other plastics. A number of recent studies support the idea that BPA may be associated with carcinogenesis, altered reproductive function, and developmental issues due to its estrogen mimetic properties (Wetherill et al., 2005; Savabieasfahani et al., 2006; Vandenberg et al., 2007; Hugo et al., 2008). Thus, the FDA has some concerns regarding the effect of BPA, particularly in susceptible populations, such as fetuses, infants, and children. Recent epidemiological studies have revealed a significant relationship between urinary BPA concentration and cardiovascular diseases in the American adult population (Lang et al., 2008; Melzer et al., 2010). Furthermore, there is an association between erectile dysfunction and urinary BPA concentration in BPA-exposed workers (Li et al., 2010a; Li et al., 2010b). These studies suggest BPA-related pathologies may affect a much greater population, and altered vascular function with BPA exposure could be suspected, nonetheless; the mechanism of BPA action in vasculature remains unclear.

We demonstrated that acute BPA exposure could activate large conductance, voltage/ $\mathrm{Ca}^{2+}$-sensitive $\mathrm{K}^{+}\left(\mathrm{BK} ; \mathrm{K}_{\mathrm{Ca}} 1.1\right)$ channels in vascular smooth muscle via a non-genomic mechanism (Asano et al., 2010). This non-genomic effect of BPA on BK channels was similar to that of estrogen and tamoxifen (Valverde et al., 1999; Dick et al., 2001). Estrogen has relevant genomic mechanisms as well, as it alters $\mathrm{K}^{+}$channel expression in variety of tissues (Drici 
et al., 1996; Roepke et al., 2007; Saito et al., 2009). BK channel expression in uterine smooth muscle was decreased in late pregnancy, when estrogen is highest (Song et al., 1999). Furthermore, long-term exposure to estrogen has been shown to directly interact with $\mathrm{BK}$ channels and down regulate BK channel expression in a heterologous expression system and human coronary artery smooth muscle (Korovkina et al., 2004). These studies demonstrate that BK channel is an estrogen-sensitive protein and it may be associated with BPArelated cardiovascular pathologies. However, the effect of continuous exposure to BPA on functional BK channel expression vascular smooth muscle cells is not known. Therefore, this study examined whether BPA modulates BK channel expression in vascular smooth muscle cells and sought to determine the mechanisms. We hypothesized that BPA would alter BK channel expression through a mechanism that is dependent on interaction with classical estrogen receptors. To test this hypothesis, functional BK channel expression was analyzed in A7r5 cell lines and rat aorta. 


\section{Methods}

Cell culture. A7r5 cells were purchased from American Type Cell Culture Collection (ATCC) and were cultured in DMEM supplemented with antibiotic (100 $\mathrm{U} / \mathrm{ml}$ penicillin $\mathrm{G}, 100 \mu \mathrm{g} / \mathrm{ml}$ streptomycin) and $10 \%$ fetal bovine serum. Cells were maintained at $37^{\circ} \mathrm{C}$ and $5 \% \mathrm{CO}_{2}$ in a humidified incubator. The growth medium was replaced with phenol free DMEM (Invitrogen) supplemented antibiotic (100 U/ml penicillin G, $100 \mu \mathrm{g} / \mathrm{ml}$ streptomycin) and $10 \%$ fetal bovine serum

Tissue preparation and culture. The method previously described to culture arteries was utilized (Kleppisch et al., 1996). Briefly, aortae were collected from male Sprague Dawley rats (age 9-12 weeks) euthanized following unrelated experiments. Thoracic aorta was dissected and opened along its longitudinal axis in in low $\mathrm{Ca}^{2+}$ HEPES buffer containing (mM) $135 \mathrm{NaCl}, 5 \mathrm{KCl}, 0.36 \mathrm{CaCl}_{2}, 1$ $\mathrm{MgCl}_{2}, 10$ glucose, $10 \mathrm{HEPES}$, and 5 Tris; $\mathrm{pH}$ 7.4. The aorta was cleaned of adventitia under the dissecting microscope and endothelial cells were removed by rubbing the lumen with cotton swab. After cleaning the tissue, aorta was cut into 3 pieces. These pieces of aortae were randomly placed in $35 \mathrm{~mm}$ dishes filled with phenol-free DMEM supplement with 0.5\% BSA and antibiotics (100 $\mathrm{U} / \mathrm{ml}$ penicillin $\mathrm{G}, 100 \mathrm{ug} / \mathrm{ml}$ streptomycin). Cultured aortae were treated with 0.1\% DMSO, $10 \mu \mathrm{M} \mathrm{BPA}$, and $10 \mu \mathrm{M}$ BPA + $100 \mathrm{nM} \mathrm{ICI} 182780$ for 2 days for mRNA expression assessment and for 3-4 days for protein function/expression. BPA (Sigma-Aldrich), estradiol (MP Biomedicals) and ICI 182,780 (SigmaAldrich) were dissolved in DMSO and diluted 1:1000 for experiments. 
Electrophysiology. Whole-cell patch clamp recordings were performed on single smooth muscle cells isolated from cultured rat aorta as described previously. In brief, solutions used in the recording conditions were a bath solution containing (mM) $135 \mathrm{NaCl}, 5 \mathrm{KCl}, 2 \mathrm{CaCl}_{2}, 1 \mathrm{MgCl}_{2}, 10$ glucose, 10 HEPES, and 5 Tris; pH 7.4. Pipette solution contained (mM) $140 \mathrm{KCl}, 1 \mathrm{MgCl}_{2}, 1$ EGTA, 10 HEPES, 1 ATP, 0.1 GTP and 5 Tris and free $\mathrm{Ca}^{2+} 100 \mathrm{nM}$; $\mathrm{pH} 7.1$. After the successful whole-cell configuration, ramp recordings from -100 to +100 $\mathrm{mV}$ were performed until steady state whole-cell currents were observed.

Immunoblotting, Western blot was performed using anti-ER alpha (1:250; NeoMarker RM-9101), ER beta (1:250; abcam ab3577), and BK channel a subunit (1:500; alomone lab) antibodies. The details of procedures were described previously (Asano et al., 2010). Rat ovary was used for the positive control for ERs in the western blot. For BK $\alpha$ subunits positive control, HEK cells were transfected with a plasmid encoding $h S l o \alpha \beta 1$ (kindly provided by $\mathrm{Dr}$. Lippiat from University Leeds) and these cell lysates were used as positive control.

Reverse transcriptase polymerase chain reaction (RT-PCR). RT-PCR was performed as described previously (Asano et al., 2010). Details of primers and PCR condition are described in Table 1.

Data Analysis. Results are presented as mean \pm SEM. Data were analyzed using Prism software (GraphPad; San Diego, CA). Significant level was set at $p<0.05$. 


\section{Results}

Estrogen receptors in rat aorta. The mRNA and protein expression of ERs have been identified in varied types of vascular smooth muscle cells including different vascular beds, cultured, and species (Orimo et al., 1993; Karas et al., 1994; Freay et al., 1997). However, expression in our models (A7r5 cells and cultured rat aorta) is unknown. We performed RT-PCR to conform ER expression in A7r5 cells and cultured rat aorta (Fig.1 A\&C). Interestingly, different degree of expression of ER $\alpha$ and $\beta$ were observed in A7r5 cell and cultured rat aorta. In order to further confirm the ER expression in our study model, we examined protein expression level by immunoblotting (Fig 1 B\&D). Using rat ovary as a positive control, anti ER $\alpha$ antibody (NeoMarker RM-9101) detected an immunoreactive band around $64 \mathrm{kDa}$ in $\mathrm{A} 7 \mathrm{r} 5$ and cultured rat aorta. Similarly, anti ER $\beta$ antibody (abcam ab3577) detected a prominent band around $52 \mathrm{kDa}$ in these cells. These findings were consistent with other studies utilizing pharmacological approach to identify ERs in vascular smooth muscle cells (Bolego et al., 2005). Our RT-PCR and Western blot data indicated that A7r5 cell and cultured rat aorta express both ER $\alpha$ and $\beta$.

Effect of BPA on BK channel expression. $E_{2}$ has been shown to alter mRNA expression of BK channel $\alpha$ subunits (Song et al., 1999; Benkusky et al., 2000; Eghbali et al., 2003; Jamali et al., 2003). RT-PCR data showed BPA altered BK channel a subunits mRNA levels in A7r5 cells (Fig2 A). To determine whether BPA altered the expression of BK channel a subunit protein content in rat vascular smooth muscle cells, immunoblot using Anti-BK channel $\alpha$ subunit 
was performed. Using HEK cells overexpressed human BK $\alpha \beta 1$ subunit as positive control, a prominent band around $125 \mathrm{kDa}$ was observed in cultured rat aorta (Fig 2 A). Group data $(n=7)$ indicated that $B K$ a subunits content was reduced to $33.3 \pm 7.9 \%$ of control in BPA-treated aortae $(p<0.05)$. We tried several different anti- BK $\beta 1$ subunits antibodies to examine whether $B K \beta 1$ subunit expression was similarly reduced by BPA, however, those commercially available anti BK $\beta 1$ subunits antibodies could not detect endogenous level of BK $\beta 1$ subunits expression (data not shown). Taken together, BPA decreased BK $\alpha$ subunit protein expression in rat aorta.

\section{ER antagonist prevents BPA-induced reduction in BK channel}

expression. In order to further examine the effect of BPA on the functional expression of BK channels, whole cell patch clamp recording were performed on vascular smooth muscle cells. Whole cell recordings from cultured rat aortic smooth muscle cells showed voltage dependent outward rectifying currents (Fig. 3). Compared to aortic SMC treated with vehicle, whole cell current densities at $100 \mathrm{mV}$ were $57.2 \pm 6.5 \%$ lower in aortic SMC treated with $10 \mu \mathrm{M}$ BPA $(n=9$ from 3 different rats, $p<0.05$ ) while whole cell current densities at $100 \mathrm{mV}$ from aortic SMC treated with BPA + ICl were not different. (100.7 $\pm 13.9 \%$ of control, $\mathrm{n}=14$ from 5 different rats). Penitrem $\mathrm{A}(1 \mu \mathrm{M})$, BK channel antagonist, blocked $66.6 \pm 6.0 \%$ of outward currents at $100 \mathrm{mV}$ in vehicle $(0.1 \% \mathrm{DMSO})$ treated aortic SMCs with intracellular $\mathrm{Ca}^{2+} 100 \mathrm{nM}(\mathrm{n}=9$ from 6 different rats, $p<0.05)$. In BPA $(10 \mu \mathrm{M})$ treated aortic SMCs, outward currents were blocked $40.0 \pm 13.7 \%$ by penitrem $A$ ( $n=4$ from 3 different rats, $p<0.05$ ). Outward currents were 
blocked by $68.8 \pm 7.7 \%$ by penitrem $\mathrm{A}$ from $\mathrm{BPA}+\mathrm{ICl}(100 \mathrm{nM})$ treated aortic SMCs ( $n=6$ from 4 different rats, $p<0.05$ ). Although we detected BK channel mRNA (Fig. 2 A) and protein (Fig. 2 B) in A7r5 cells and functional BK channel expression was reported in a previously (Si et al., 2006), we were unable to show any functional BK channel expression in A7r5 cells (thus no patch clamp data are shown). To determine the mechanism by which BPA reduced BK channel expression, we utilized a specific ER antagonist to test our hypothesis that BPA decreases BK channel expression via a genomic mechanism. Patch clamp whole cell recording indicated the mean penitrem A sensitive current density at $80 \mathrm{mV}$ was $30.9 \pm 5.61 \mathrm{pA} / \mathrm{pF}, 22.2 \pm 2.47 \mathrm{pA} / \mathrm{pF}, 45.6 \pm 8.29 \mathrm{pA} / \mathrm{pF}$ in DMSO, $10 \mu \mathrm{M}$ BPA and BPA + $100 \mathrm{nM} \mathrm{ICl}$, respectively $(p<0.05)$. 


\section{Discussion}

The purpose of this study was to examine the effects of long term BPA exposure on functional BK channel expression in vascular smooth muscle cells. Major findings of this study were: 1) BPA significantly decreased BK channel mRNA/protein expression in A7r5 cells and cultured rat aorta; 2) penitrem Asensitive BK channel currents in rat aortic smooth muscle were significantly diminished by BPA treatment; 3) BPA reduces BK channel expression through a mechanism depending up classical ER mediated signaling.

The mechanisms by which BPA is associated with cardiovascular diseases are far beyond our understanding since the association between human BPA exposure and cardiovascular disease is a relatively recent public health concern. However, recent studies are attempting to shed light on some of the potential mechanisms. For instance, BPA in the nanomolar range can promote cardiac arrhythmias due to increased $\mathrm{SR} \mathrm{Ca}^{2+}$ leak via mechanisms depending on different ERs based on gender (Yan et al., 2011; Belcher et al., 2012). Additionally, BPA in the micromolar range can alter atrial contractility via NOcGMP mediated mechanisms (Pant et al., 2011). Similarly, previous works by our laboratory have shown that the acute micromolar range of BPA exposure activates BK channel in canine and human coronary artery via non-genomic mechanisms (Asano et al., 2010). Finding that BPA was a BK channel opener did not readily fit with the idea that BPA is associated with cardiovascular disease; therefore, we decided to investigate longer exposure. In this study, we demonstrated 48-72 hr exposure to BPA decreased BK channel expression in 
vascular smooth muscle via ER-mediated signaling. Taken together, these works may represent some of the possible explanations for the BPA associated altered vascular function seen in epidemiological studies (Lang et al., 2008; Melzer et al., 2010; Melzer et al., 2012).

Estrogen/BPA on BK channel expression. The functions of estrogen are quite complex, in that it is involved not only in classical reproductive function and cell growth, but also in other systems such as the cardiovascular system. Particularly, after the results of a long period of trial and error, the current perspective of hormone replacement therapy (HRT) is that it increases the risk of cardiovascular diseases. Therefore; HRT is no longer recommended for the prevention of cardiovascular diseases (Mosca et al., 2001; Rossouw, 2006). The mechanisms by which HRT increases the risk of cardiovascular diseases are not fully understood. One possibility may be $E_{2}$ induced altered ion channel expression, which has been seen in a number of other studies (Ranki et al., 2002; Kundu et al., 2007; O'Mahony et al., 2007; Kundu et al., 2008). Of those we were particularly interested in the BK channel since it plays a crucial role in vascular function (Nelson et al., 1995).

Currently, there are several possible proposed mechanisms of alteration in BK channel current density via long-term $E_{2}$ treatment (and presumably BPA exposure). One of them is that $E_{2}$ causes alternative splicing to $B K$ transcripts that causes fundamental changes to the BK channel's properties such as $\mathrm{Ca}^{2+}$ and voltage sensitivity. This mechanism is supported by studies from England's group showing that $E_{2}$ and pregnancy induced up-regulation in both mRNA and 
protein expression in mouse uterine smooth muscle cells, but diminished BK channel currents (Benkusky et al., 2000; Holdiman et al., 2002). In contrast to these data, a study by Toro and Stefani's groups demonstrated $E_{2}$ downregulates both BK channel mRNA and protein expression in rat uterine smooth muscle (Song et al., 1999). Furthermore, $\mathrm{E}_{2}$ regulates BK channel expression by different mechanisms depending on the species. Specifically $E_{2}$ regulates BK channel surface expression by transcriptional regulation in rat myomerium, whereas membrane trafficking of BK channel is the major mechanism in regulation of BK channel surface expression in mice myometrium (Eghbali et al., 2003). A final proposed mechanism is that the $B K$ channel itself serves as an $E_{2}$ receptor and that $\mathrm{E}_{2}$ binding to $\mathrm{BK}$ channels triggers proteasomal degradation to decrease BK channel expression in human coronary artery smooth muscle cells (Korovkina et al., 2004). These data typify the complex effects of $E_{2}$ on the regulation of BK channel expression, however, all these studies agree on one point; that long-term treatment of $E_{2}$ decreases functional $B K$ channel expression (Wang et al., 1998; Song et al., 1999; Benkusky et al., 2000; Holdiman et al., 2002; Eghbali et al., 2003; Korovkina et al., 2004). Assuming BPA may regulate BK channel expression in the same way as $E_{2}$ does due to its estrogenic properties, our results agree with these previous reports that demonstrated reduced $B K$ channel current density with $E_{2}$ exposure. Our data showed that the BPA-induced decreases in BK channel currents were most likely due to decreased protein expression in rat aorta. 
It is reasonable to speculate that BPA acts similar to $E_{2}$, as it is estrogenic; nevertheless, it is also possible that BPA uses totally different mechanisms that as of yet, have not been identified. Although our data demonstrate that a pure estrogen receptor antagonist $(\mathrm{ICI} 182,780)$ reversed the BPA-induced decrease in BK channel function (suggesting ER-mediated signaling), we cannot rule out other possibilities such as membrane-initiated estrogen signaling (e.g. GPER activation) may regulate BK channel expression. BPA may also activate GPER mediated cell signaling, and addressing these membrane initiated signaling will require additional experiments. Further studies are needed to determine how other cell signaling pathways are involved in BPA-induced decreased in BK channel expression in vascular smooth muscle.

\section{Estrogen up-regulates BK channel function in uterine artery.}

In contrast to our data, $E_{2}$ has been shown to reduce myogenic tone by mechanisms that depend on the up-regulation of BK $\beta 1$ subunit, but not in $\alpha$ subunits in pregnant sheep uterine artery (Nagar et al., 2005; Hu et al., 2011). A similar study using uterine vascular smooth muscle from ewes showed that $E_{2}$ increased both BK $\alpha$ and $\beta 1$ subunits mRNA/protein (Rosenfeld et al., 2009). We do not have data to explain the controversy, however, expression of BK channels by $E_{2}$ is regulated differently in various species (Eghbali et al., 2003).

Furthermore, some authors have mentioned that different mechanisms of BK channel $\alpha$ or $\beta 1$ subunits up-regulation exist based on factors as seemingly trivial as branch orders of uterine arteries. Again, these results highlight the complex 
effects of $E_{2}$ on $B K$ channel expression. In our experiments, we have tried several BK $\beta 1$ subunit antibodies to analyze the $\beta 1$ subunits expression levels, however, while those commercially available $\beta 1$ subunit antibodies were able to detect overexpressed $h S / o \beta 1$ and $b S / o \beta 1$, they were inadequate for detection of endogenous BK $\beta 1$ subunit expression. Therefore we do not know the effect of BPA on BK channel $\beta 1$ expression in rat aorta. Based on this, it may be possible that several factors such as different vascular beds, sizes and species play a role in $\mathrm{E}_{2} / \mathrm{BPA}$ induced altered $\mathrm{BK}$ channel expression.

\section{A link between BPA exposure and BPA associated pathologies. Many} studies have detected BPA in urine, blood and tissue, but the levels of BPA exposure are controversial. BPA has been shown to accumulate in adipose tissue (Nunez et al., 2001; Fernandez et al., 2007) so that the local BPA concentrations could be higher than the values reported in total blood.

Furthermore, cumulative BPA exposure levels may play a role in BPA associated pathologies. Although these studies make it difficult to assess exact blood BPA levels, the BPA concentration we used $(10 \mu \mathrm{M})$ is likely to be applicable to the occupational BPA exposure studies showing high levels of BPA exposure (Hanaoka et al., 2002; Li et al., 2010a). Interestingly, there was an over 4-fold increase in erectile difficulty that may suggest vascular dysfunction in BPA exposed workers than non-exposed workers (Li et al., 2010a). According to our findings, BPA-induced decreased functional BK channel expression in vascular smooth muscle may be the one of plausible mechanisms. 
Although it is beyond the scope of this study, much attention has been given to the effects of BPA exposure on the development of fetuses, infants and young children. It has been demonstrated that Drosophilia slowpoke (dSlo; homologous to human $K C N M A 1)$ gene expression is precisely regulated based on specific cell types and developmental periods for the normal development (Brenner \& Atkinson, 1996; Chang et al., 2000). Whether BPA alters BK channel expression during development periods is not determined yet. Additional experiments regarding BPA toxicity on ion channels will add to our understanding of the link between BPA exposure and BPA associated pathologies.

In summary, we demonstrate that BPA reduces BK channel expression in vascular smooth muscle. Given that estrogen regulates BK channel expression, this effect of BPA on BK channel expression is likely to be an estrogenic property of BPA. The mechanisms by which BPA reduced BK channel expression involved in classical ERs and nuclear signaling pathways. The findings are novel because they represent the firs known effects of BPA on ion channel expression in any tissue. Additional studies designed to examine in vivo effects of BPA on BK channel expression; as well as to explore other potential ion channel targets will be necessary to increase our understanding of the clear explanation of the association of urinary BPA levels and cardiovascular diseases. 


\section{Acknowledgements}

We thank Dr. JD Lippiat (University of Leeds) for providing the plasmid encoding human BK channel, Dr. RL Goodman (West Virginia University) for donating anti-ER $\alpha$ antibody, Dr. JD Huber (West Virginia Univeristy) for giving anti-ER $\beta$ antibody. We appreciate the labs in the Center for Cardiovascular and Respiratory Research for providing rat aortae. Supported by T32 HL090610. 


\section{Figure legends}

Fig. 1. Cultured rat aorta and A7r5 cells express estrogen receptors. A.B) mRNA expression levels of ERs from A7r5 cells and cultured aortas were analyzed by RT-PCR. C,D) Protein expression levels of ERs were determined by immunoblotting. A rat ovary was used as a positive control for RT-PCR and Western blot.

Fig. 2. BPA reduces $B K$ channel expression. A) A picture of RT-PCR data from different doses of BPA treated A7r5 cells. B) Whole cell lysates obtained from A7r5 cells treated with different doses of BPA were analyzed by immunoblotting with Anti-BK channel $\alpha$ subunit antibody. Group data normalized to SM a-actin showed BPA decreased BK channel expression from A7r5 cells in a concentration-dependent manner $(n=8)$. C). Proteins isolated form cultured rat aortae were analyzed by immunoblotting with Anti-BK channel a subunit antibody. Group data indicated $10 \mu \mathrm{M}$ BPA decreased BK channel expression ( $\mathrm{n}$ $=7$ ). An asterisk $\left({ }^{*}\right)$ indicates significant difference from vehicle treated sample. $P$ $<0.05$.

Fig. 3. BPA decreases functional BK channel expression in cultured rat aorta. Functional BK channel expressions from BPA treated cultured aorta were analyzed by patch clamp whole cell recordings. Currents were elicited by using the voltage template shown. Penitrem A, a selective BK channel antagonist, was utilized to identify BK channel currents. A C) Representative current traces and 
IV relationship from vehicle (0.1\% DMSO), 10uM BPA, and 10uM BPA +100nM $\mathrm{ICI}$ (ERs antagonist) treated rat aorta. An asterisk $\left({ }^{*}\right)$ indicates significant difference from penitrem $\mathrm{A}(P<0.05)$.

Fig. 4. ER antagonist (ICI 182,780) abrogates effect of BPA on BK channel expression A). Representative penitrem A-sensitive currents from each treatment. Group data ( $\mathrm{n}=4$ each group) from penitrem A sensitive currents demonstrated BPA significantly decreased BK channel currents and pretreatment with an ER antagonist prevented BPA induced decreased BK channel expression. $P<0.05$. B). Western blot data indicated BPA decreased BK channel protein contents and that $\mathrm{ICI}$ pretreatment blocked this effect. An asterisk ( $\left.{ }^{*}\right)$ indicates significant difference from vehicle treated sample. $P<0.05$. 
Table 41 Primers used for the RT-PCR analysis mRNA Forward primer $\quad$ Reverse Primer

Size (bp)

Esr1

5'-

5'-

190

NM_012689 CATCGATAAGAACCGGAGGA-3 AAGGTTGGCAGCTCTCATGT-

Exon 4

$3^{\prime}$

Exon 5

Esr2

5'-

5'-

262

NM_012754

TTCCCGGCAGCACCAGTAAC

TCCCTCTTTGCGTTTGGACTA-3'

C-3'

Exon 3

Exon 2

KCNMA1 5'-

5'-

140

(NM_03182

TCGACATGGCTTTCAACGTG3'

GTATACAGACACAAACACGGG G-3'

8)

Exon 13

Exon 14

Actb

5'-

5'-

NM_031144 CCTGAAGTACCCCATTGAACAC GAGTCCATCACAATGCCAGTG 
Some of these primer sets have previously used by others (Zancan et al., 1999; Amberg et al., 2003). 
A

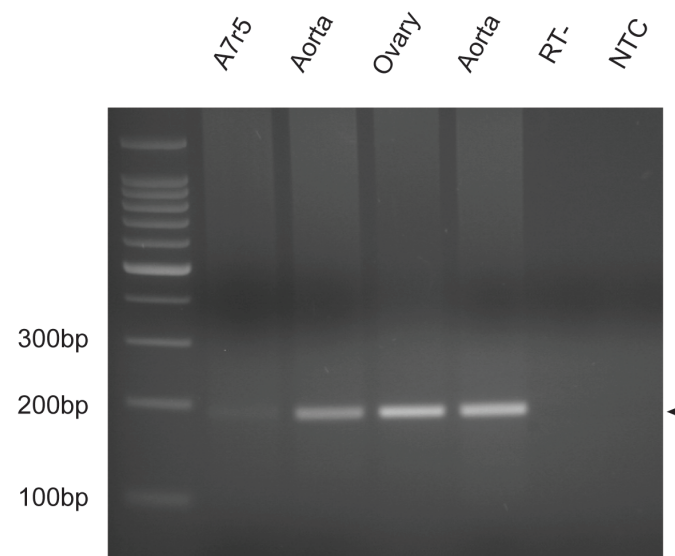

C

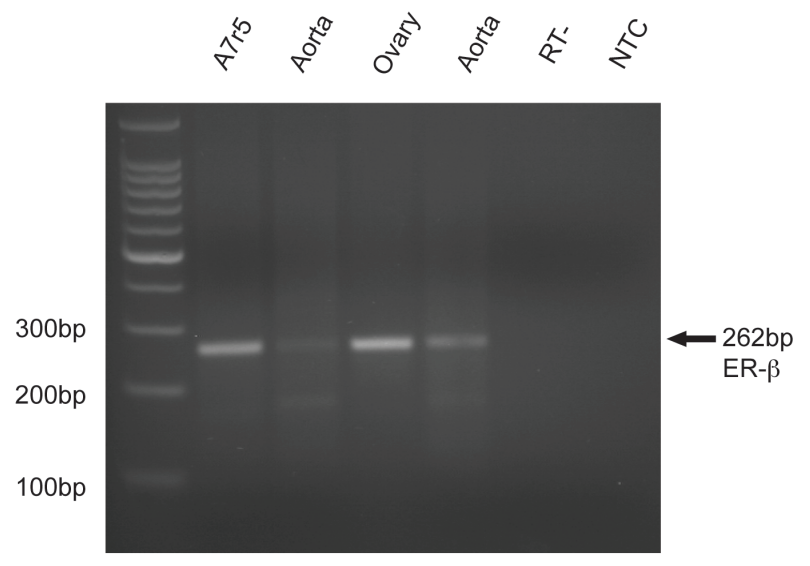

B

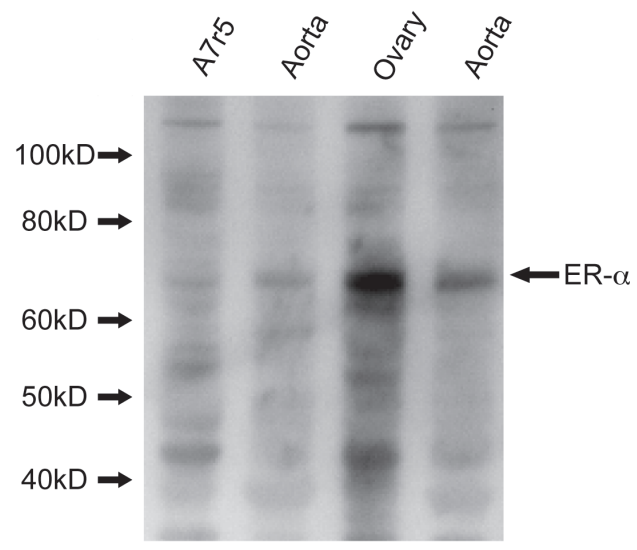

D

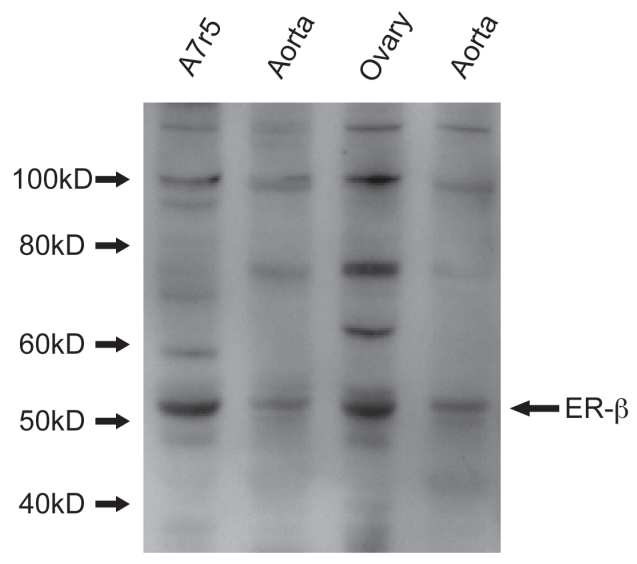

Figure 41 Cultured rat aorta and A7r5 cells express estrogen receptors 
A
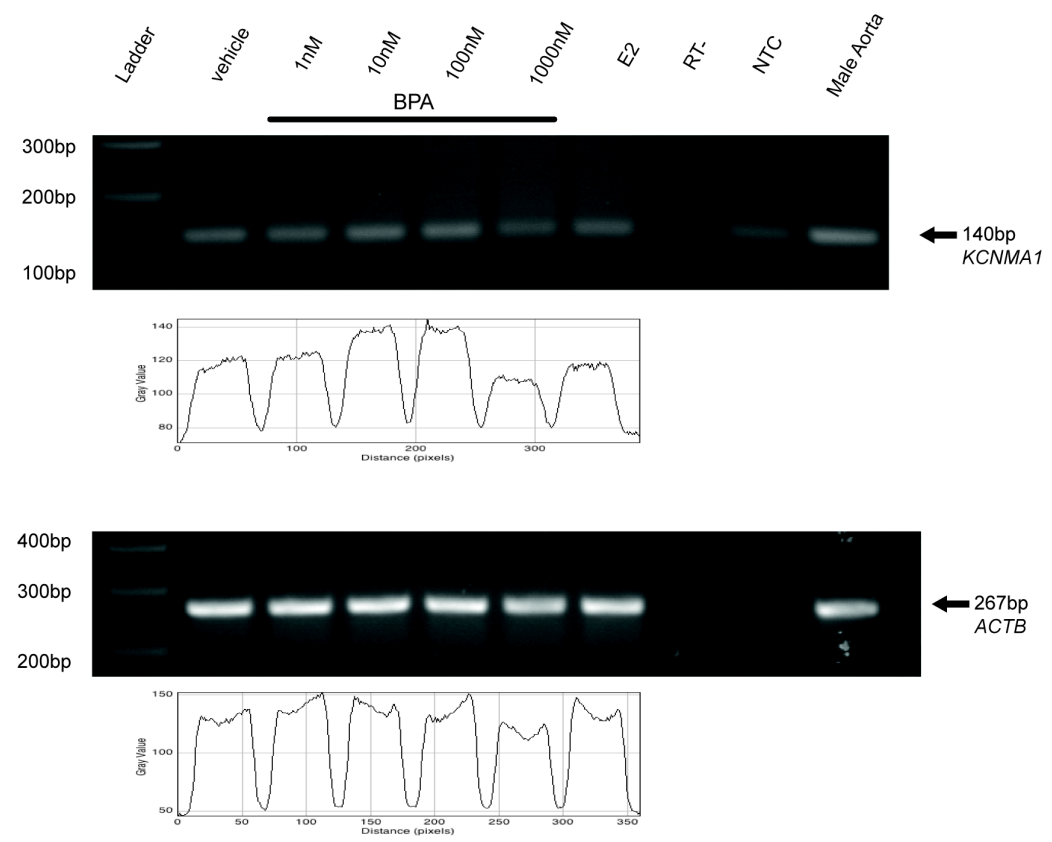

B

A7r5 BK $\alpha$ subunit/SM $\alpha$-actin

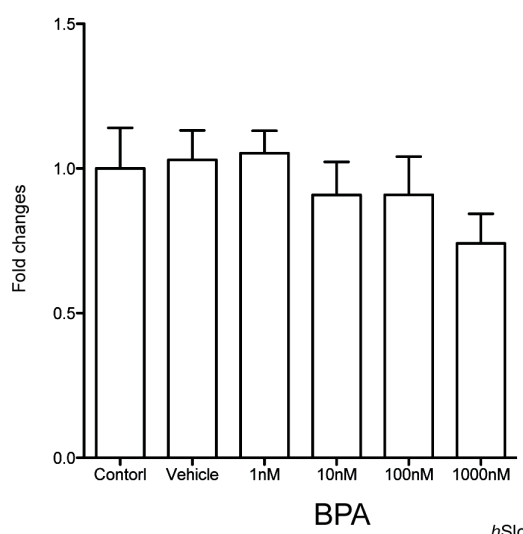

$h$ Sloa bSloa

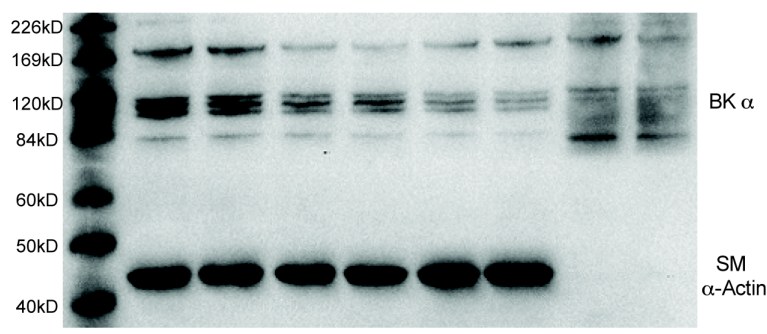

C

Rat Aorta BKa subunit/SM $\alpha$-actin
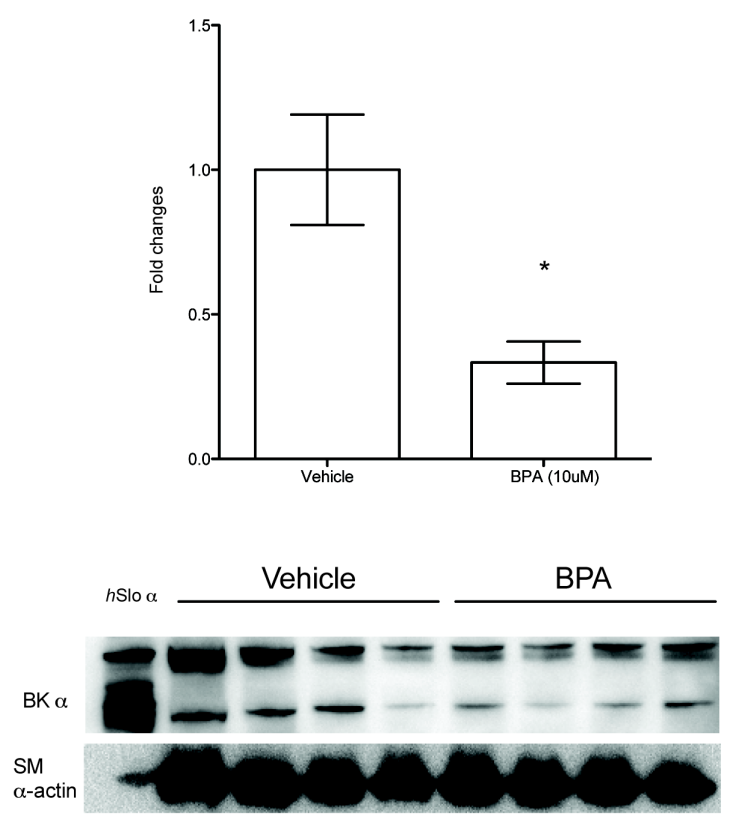

Figure 42 BPA reduces BK channel expression 
A

Vehicle treated aortic SMC

Vehicle (0.1\%DMSO) treated aortic SMC

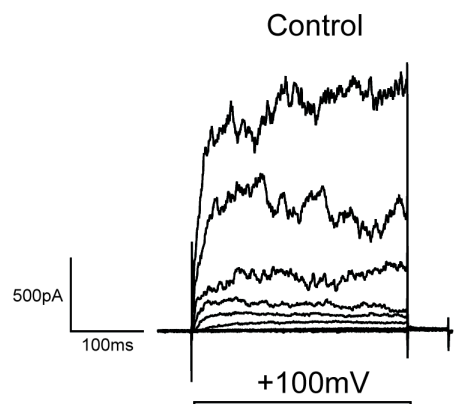

Penitrem A

Control

${ }^{100}$

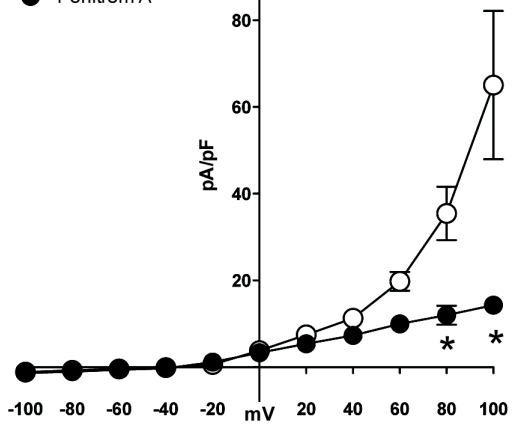

$-80 m V$

$+100 \mathrm{mV}$

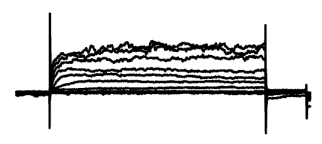

$-100 \mathrm{mV}$

BPA treated aortic SMC

B

BPA treated aortic SMC

Control

Penitrem A
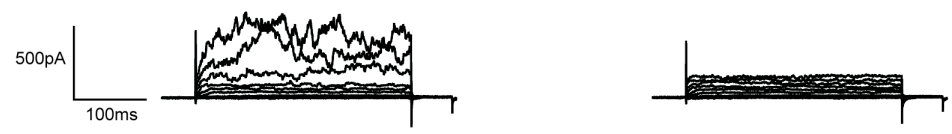

Control
Penitrem

${ }^{100}$

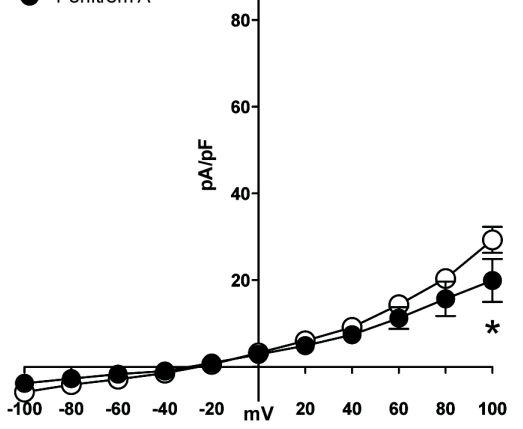

C

$\mathrm{BPA}+\mathrm{ICl}$ treated aortic SMC

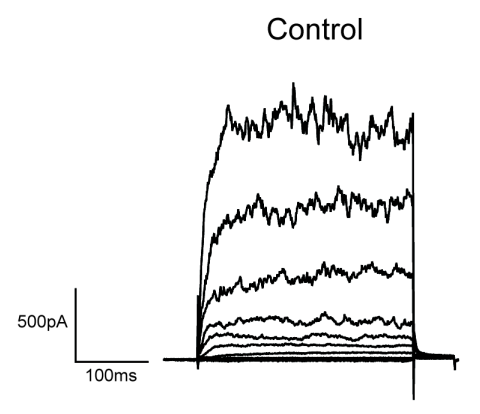

Penitrem A

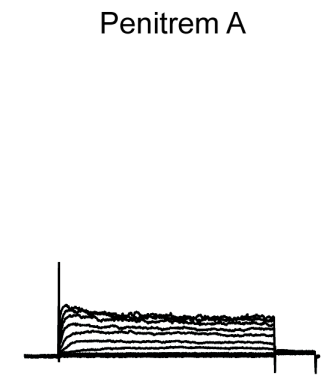

Control

- Penitrem A

BPA + ICI treated aortic SMC

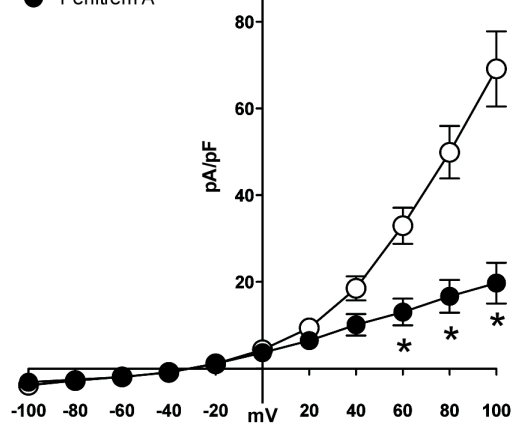

Figure 43 BPA decreases functional BK channel expression in cultured rat aorta 
A

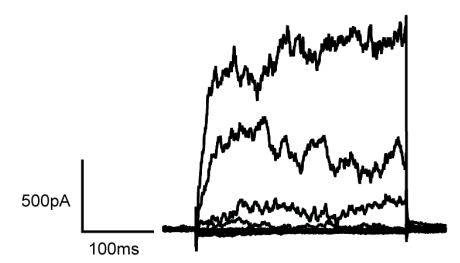

BPA
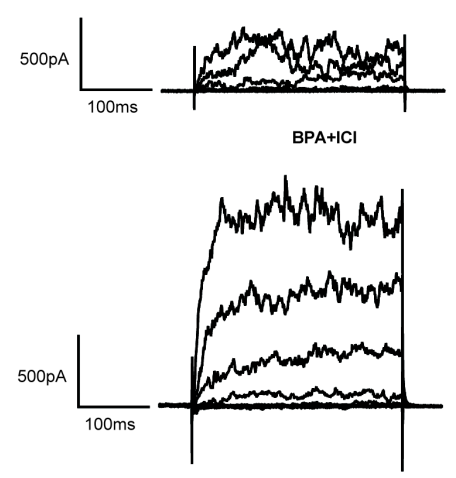

Control

$\triangle \mathrm{BPA}+\mathrm{ICl}$

- BPA

B

$$
\text { Con BPA } \stackrel{\text { BPA }}{\text { ICl }} \text { Con BPA } \underset{\text { ICI }}{\text { BPA }}
$$

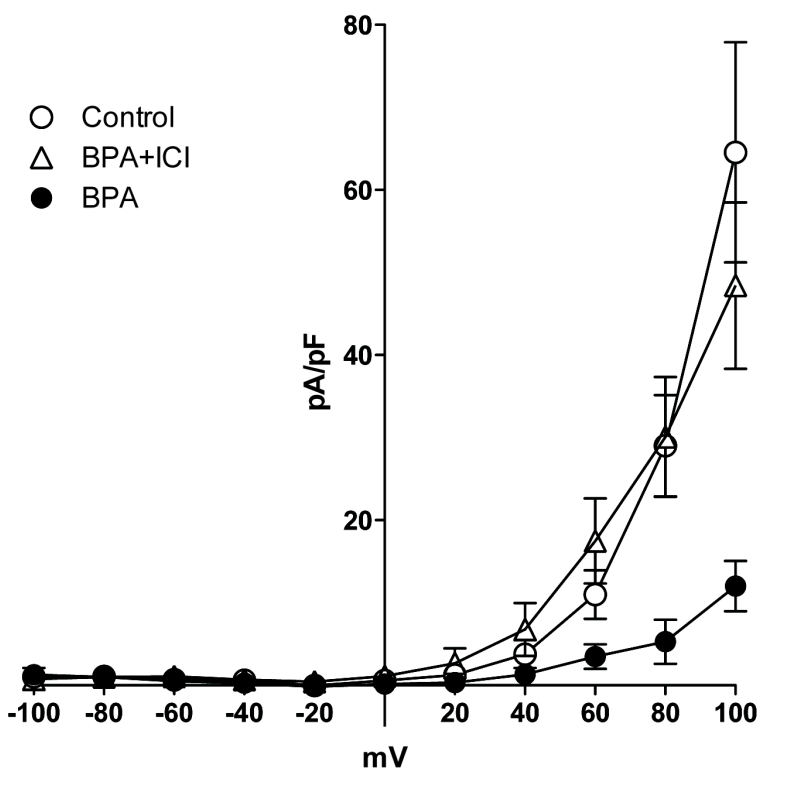

Pen A sensitive currents

$\mathrm{BK} \alpha$

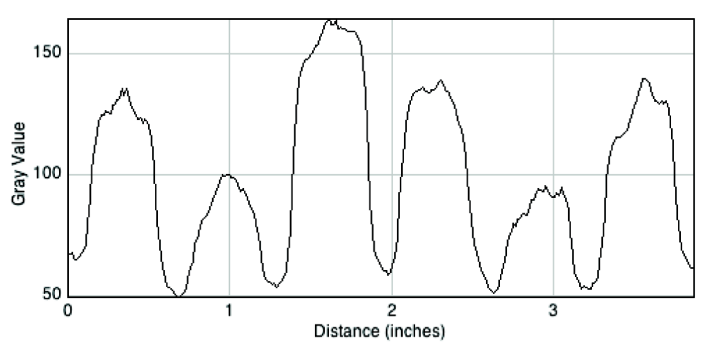

SM $\alpha$-Actin
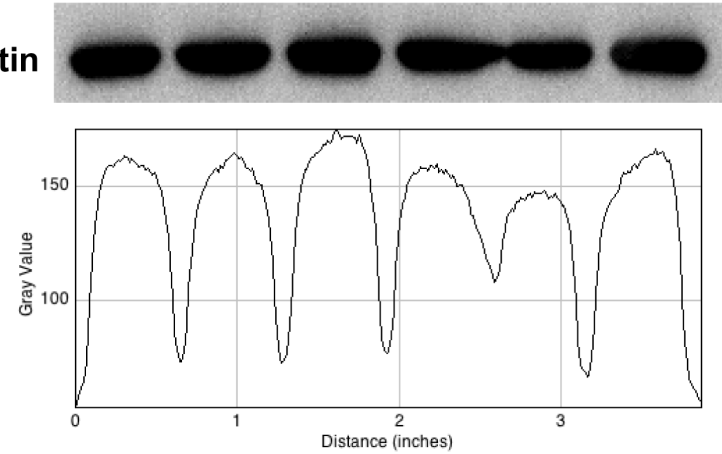

Figure 44 ER antagonist (ICI 182,780) abrogates effect of BPA on BK channel expression 


\section{References}

Amberg GC, Bonev AD, Rossow CF, Nelson MT \& Santana LF. (2003). Modulation of the molecular composition of large conductance, $\mathrm{Ca}(2+)$ activated $\mathrm{K}(+)$ channels in vascular smooth muscle during hypertension. $J$ Clin Invest 112, 717-724.

Asano S, Tune JD \& Dick GM. (2010). Bisphenol A activates Maxi-K (K(Ca)1.1) channels in coronary smooth muscle. British journal of pharmacology 160, 160-170.

Belcher SM, Chen Y, Yan S \& Wang HS. (2012). Rapid estrogen receptormediated mechanisms determine the sexually dimorphic sensitivity of ventricular myocytes to 17 beta-estradiol and the environmental endocrine disruptor bisphenol A. Endocrinology 153, 712-720.

Benkusky NA, Fergus DJ, Zucchero TM \& England SK. (2000). Regulation of the $\mathrm{Ca} 2+-$ sensitive domains of the maxi-K channel in the mouse myometrium during gestation. The Journal of biological chemistry 275, 27712-27719.

Bolego C, Cignarella A, Sanvito P, Pelosi V, Pellegatta F, Puglisi L \& Pinna C. (2005). The acute estrogenic dilation of rat aorta is mediated solely by selective estrogen receptor-alpha agonists and is abolished by estrogen deprivation. The Journal of pharmacology and experimental therapeutics 313, 1203-1208.

Brenner R \& Atkinson N. (1996). Developmental- and eye-specific transcriptional control elements in an intronic region of a $\mathrm{Ca}(2+)$-activated $\mathrm{K}+$ channel gene. Dev Biol 177, 536-543.

Chang WM, Bohm RA, Strauss JC, Kwan T, Thomas T, Cowmeadow RB \& Atkinson NS. (2000). Muscle-specific transcriptional regulation of the slowpoke $\mathrm{Ca}(2+)$-activated $\mathrm{K}(+)$ channel gene. The Journal of biological chemistry 275, 3991-3998.

Dick GM, Rossow CF, Smirnov S, Horowitz B \& Sanders KM. (2001). Tamoxifen activates smooth muscle BK channels through the regulatory beta 1 subunit. The Journal of biological chemistry 276, 34594-34599.

Drici MD, Burklow TR, Haridasse V, Glazer RI \& Woosley RL. (1996). Sex hormones prolong the QT interval and downregulate potassium channel expression in the rabbit heart. Circulation 94, 1471-1474.

Eghbali M, Toro L \& Stefani E. (2003). Diminished surface clustering and increased perinuclear accumulation of large conductance $\mathrm{Ca} 2+-$-activated 
$\mathrm{K}+$ channel in mouse myometrium with pregnancy. The Journal of biological chemistry 278, 45311-45317.

Fernandez MF, Arrebola JP, Taoufiki J, Navalon A, Ballesteros O, Pulgar R, Vilchez JL \& Olea N. (2007). Bisphenol-A and chlorinated derivatives in adipose tissue of women. Reproductive toxicology 24, 259-264.

Freay AD, Curtis SW, Korach KS \& Rubanyi GM. (1997). Mechanism of vascular smooth muscle relaxation by estrogen in depolarized rat and mouse aorta. Role of nuclear estrogen receptor and $\mathrm{Ca} 2+$ uptake. Circulation research 81, 242-248.

Hanaoka T, Kawamura N, Hara K \& Tsugane S. (2002). Urinary bisphenol A and plasma hormone concentrations in male workers exposed to bisphenol $A$ diglycidyl ether and mixed organic solvents. Occup Environ Med 59, 625628.

Holdiman AJ, Fergus DJ \& England SK. (2002). 17beta-Estradiol upregulates distinct maxi-K channel transcripts in mouse uterus. Mol Cell Endocrinol 192, 1-6.

Hu XQ, Xiao D, Zhu R, Huang X, Yang S, Wilson S \& Zhang L. (2011). Pregnancy upregulates large-conductance $\mathrm{Ca}(2+)$-activated $\mathrm{K}(+)$ channel activity and attenuates myogenic tone in uterine arteries. Hypertension 58, 1132-1139.

Hugo ER, Brandebourg TD, Woo JG, Loftus J, Alexander JW \& Ben-Jonathan N. (2008). Bisphenol A at environmentally relevant doses inhibits adiponectin release from human adipose tissue explants and adipocytes. Environ Health Perspect 116, 1642-1647.

Jamali K, Naylor BR, Kelly MJ \& Ronnekleiv OK. (2003). Effect of 17betaestradiol on mRNA expression of large- conductance, voltage-dependent, and calcium-activated potassium channel alpha and beta subunits in guinea pig. Endocrine 20, 227-237.

Karas RH, Patterson BL \& Mendelsohn ME. (1994). Human vascular smooth muscle cells contain functional estrogen receptor. Circulation 89, 19431950.

Kleppisch T, Winter B \& Nelson MT. (1996). ATP-sensitive potassium channels in cultured arterial segments. The American journal of physiology 271, $\mathrm{H} 2462-2468$.

Korovkina VP, Brainard AM, Ismail P, Schmidt TJ \& England SK. (2004). Estradiol binding to maxi-K channels induces their down-regulation via 
proteasomal degradation. The Journal of biological chemistry 279, 12171223.

Kundu P, Alioua A, Stefani E \& Toro L. (2007). Regulation of mouse Slo gene expression: multiple promoters, transcription start sites, and genomic action of estrogen. The Journal of biological chemistry 282, 27478-27492.

Kundu P, Ciobotaru A, Foroughi S, Toro L, Stefani E \& Eghbali M. (2008). Hormonal regulation of cardiac KCNE2 gene expression. Mol Cell Endocrinol 292, 50-62.

Lang IA, Galloway TS, Scarlett A, Henley WE, Depledge M, Wallace RB \& Melzer D. (2008). Association of urinary bisphenol A concentration with medical disorders and laboratory abnormalities in adults. Jama 300, 13031310.

Li D, Zhou Z, Qing D, He Y, Wu T, Miao M, Wang J, Weng X, Ferber JR, Herrinton LJ, Zhu Q, Gao E, Checkoway H \& Yuan W. (2010a). Occupational exposure to bisphenol-A (BPA) and the risk of self-reported male sexual dysfunction. Hum Reprod 25, 519-527.

Li DK, Zhou Z, Miao M, He Y, Qing D, Wu T, Wang J, Weng X, Ferber J, Herrinton LJ, Zhu Q, Gao E \& Yuan W. (2010b). Relationship between urine bisphenol-A level and declining male sexual function. $J$ Androl 31, 500-506.

Melzer D, Osborne NJ, Henley WE, Cipelli R, Young A, Money C, McCormack P, Luben R, Khaw KT, Wareham NJ \& Galloway TS. (2012). Urinary Bisphenol: A Concentration and Risk of Future Coronary Artery Disease in Apparently Healthy Men and Women. Circulation.

Melzer D, Rice NE, Lewis C, Henley WE \& Galloway TS. (2010). Association of urinary bisphenol a concentration with heart disease: evidence from NHANES 2003/06. PLoS One 5, e8673.

Mosca L, Collins P, Herrington DM, Mendelsohn ME, Pasternak RC, Robertson RM, Schenck-Gustafsson K, Smith SC, Jr., Taubert KA \& Wenger NK. (2001). Hormone replacement therapy and cardiovascular disease: a statement for healthcare professionals from the American Heart Association. Circulation 104, 499-503.

Nagar D, Liu XT \& Rosenfeld CR. (2005). Estrogen regulates \{beta\}1-subunit expression in $\mathrm{Ca}(2+)$-activated $\mathrm{K}(+)$ channels in arteries from reproductive tissues. American journal of physiology Heart and circulatory physiology 289, $\mathrm{H} 1417-1427$. 
Nelson MT, Cheng H, Rubart M, Santana LF, Bonev AD, Knot HJ \& Lederer WJ. (1995). Relaxation of arterial smooth muscle by calcium sparks. Science 270, 633-637.

Nunez AA, Kannan K, Giesy JP, Fang J \& Clemens LG. (2001). Effects of bisphenol $A$ on energy balance and accumulation in brown adipose tissue in rats. Chemosphere 42, 917-922.

O'Mahony F, Alzamora R, Betts V, LaPaix F, Carter D, Irnaten M \& Harvey BJ. (2007). Female gender-specific inhibition of KCNQ1 channels and chloride secretion by 17 beta-estradiol in rat distal colonic crypts. The Journal of biological chemistry 282, 24563-24573.

Orimo A, Inoue S, Ikegami A, Hosoi T, Akishita M, Ouchi $\mathrm{Y}$, Muramatsu M \& Orimo H. (1993). Vascular smooth muscle cells as target for estrogen. Biochemical and biophysical research communications 195, 730-736.

Pant J, Ranjan P \& Deshpande SB. (2011). Bisphenol A decreases atrial contractility involving NO-dependent G-cyclase signaling pathway. J Appl Toxicol 31, 698-702.

Ranki HJ, Budas GR, Crawford RM, Davies AM \& Jovanovic A. (2002). 17Betaestradiol regulates expression of K(ATP) channels in heart-derived H9c2 cells. J Am Coll Cardiol 40, 367-374.

Roepke TA, Malyala A, Bosch MA, Kelly MJ \& Ronnekleiv OK. (2007). Estrogen regulation of genes important for $\mathrm{K}+$ channel signaling in the arcuate nucleus. Endocrinology 148, 4937-4951.

Rosenfeld CR, Liu XT \& DeSpain K. (2009). Pregnancy modifies the large conductance $\mathrm{Ca} 2+-$ activated $\mathrm{K}+$ channel and cGMP-dependent signaling pathway in uterine vascular smooth muscle. American journal of physiology Heart and circulatory physiology 296, H1878-1887.

Rossouw JE. (2006). Implications of recent clinical trials of postmenopausal hormone therapy for management of cardiovascular disease. Ann $N Y$ Acad Sci 1089, 444-453.

Saito T, Ciobotaru A, Bopassa JC, Toro L, Stefani E \& Eghbali M. (2009). Estrogen contributes to gender differences in mouse ventricular repolarization. Circulation research 105, 343-352.

Savabieasfahani M, Kannan K, Astapova O, Evans NP \& Padmanabhan V. (2006). Developmental programming: differential effects of prenatal exposure to bisphenol-A or methoxychlor on reproductive function. Endocrinology 147, 5956-5966. 
Si H, Grgic I, Heyken WT, Maier T, Hoyer J, Reusch HP \& Kohler R. (2006). Mitogenic modulation of $\mathrm{Ca} 2+$-activated $\mathrm{K}+$ channels in proliferating $\mathrm{A} 7 \mathrm{r} 5$ vascular smooth muscle cells. British journal of pharmacology 148, 909917.

Song M, Zhu N, Olcese R, Barila B, Toro L \& Stefani E. (1999). Hormonal control of protein expression and mRNA levels of the MaxiK channel alpha subunit in myometrium. FEBS Lett 460, 427-432.

Valverde MA, Rojas P, Amigo J, Cosmelli D, Orio P, Bahamonde MI, Mann GE, Vergara C \& Latorre R. (1999). Acute activation of Maxi-K channels (hSlo) by estradiol binding to the beta subunit. Science 285, 1929-1931.

Vandenberg LN, Maffini MV, Wadia PR, Sonnenschein C, Rubin BS \& Soto AM. (2007). Exposure to environmentally relevant doses of the xenoestrogen bisphenol-A alters development of the fetal mouse mammary gland. Endocrinology 148, 116-127.

Wang SY, Yoshino M, Sui JL, Wakui M, Kao PN \& Kao CY. (1998). Potassium currents in freshly dissociated uterine myocytes from nonpregnant and late-pregnant rats. The Journal of general physiology 112, 737-756.

Wetherill YB, Fisher NL, Staubach A, Danielsen M, de Vere White RW \& Knudsen KE. (2005). Xenoestrogen action in prostate cancer: pleiotropic effects dependent on androgen receptor status. Cancer Res 65, 54-65.

Yan S, Chen Y, Dong M, Song W, Belcher SM \& Wang HS. (2011). Bisphenol A and 17beta-estradiol promote arrhythmia in the female heart via alteration of calcium handling. PLoS One 6, e25455.

Zancan V, Santagati S, Bolego C, Vegeto E, Maggi A \& Puglisi L. (1999). 17Beta-estradiol decreases nitric oxide synthase II synthesis in vascular smooth muscle cells. Endocrinology 140, 2004-2009. 
CHAPTER 5 General Discussion 


\section{Conclusion}

The purpose of this dissertation was to determine whether BPA modulates vascular BK channel function and expression. Furthermore, we wanted to determine the mechanisms of BPA-induced reduction in BK channel function and expression. Our long-range goal was to identify molecular mechanisms by which estrogenic chemicals affect vascular function. Our objective was to determine mechanisms by which BPA modulates BK channel expression and function. The central hypothesis was that BPA alters BK channel expression and function through separate genomic and non-genomic mechanisms. The rationale was that receptors for BPA exist at both the cell membrane and in the nucleus.

Human BPA exposure and cardiovascular disease became public health concerns relatively recently; furthermore, we do not understand whether a cause and effect relationship exists in the association of BPA exposure and cardiovascular diseases seen in epidemiological studies. We chose ion channels for the possible target protein for the effects of BPA. Specifically, we selected BK channels as a target molecule since it is expressed in a variety of tissues and involved in a variety of cellular functions (Ahluwalia et al., 2004; Ruttiger et al., 2004; Meredith et al., 2006; Pyott et al., 2007; Grimm et al., 2009) and plays an important role in vascular tone. Since the gold standard BK channel antagonist, IBTX, has experimental limitations such as cost and membrane impermeability, we reasoned that the characterization of an economical pharmacological alternative would facilitate the study of BK channels. Thus, our initial experiments have systematically characterized the effect of penitrem $A$, a tremorgenic 
mycotoxin, on BK channels and demonstrate the role of BK channels in the vascular function of mice (Chapter 2). Our data demonstrated that whole cell currents from HEK 293 cells transfected with $h$ Slo $\alpha$ or $\alpha+\beta 1$ were effectively blocked by penitrem $\mathrm{A}\left(\mathrm{IC}_{50} 7\right.$ vs. $\left.107 \mathrm{nM} ; p<0.05\right)$. The inhibitory effects of penitrem A $(50.4 \pm 9.38 \%)$ and IBTX $(49.7 \pm 9.44 \%)$ on $\mathrm{K}^{+}$currents were the same degree in coronary artery smooth muscle cells. As for specificity, penitrem A had no effect on Kv1.5 currents and pinacidil-induced vasodilation. Finally, in vivo hemodynamic response indicated that penitrem A significantly augmented phenylephrine induced increases in mean arterial blood pressure by blocking BK channel in mice $(p<0.05)$. Taken together, our data indicated that penitrem $A$ is an excellent tool to study BK channel in vascular function and is not only practical for cell/tissue in vitro studies, but also for whole animal in vivo vascular functional studies.

Next, we wanted to determine the effect of BPA on BK channels using penitrem A. Our data showed that BPA increased BK channel currents and BK channel $\beta 1$ subunits facilitated BK channel's sensitivity to BPA (Chapter 3 ). This was determined by whole cell recording showing greater outward current with acute BPA exposure in cultured CCASMCs and HCASMCs. Single channel recording from freshly isolated canine LAD revealed that BPA increased NPo of BK channel. Based on these findings from cultured cells and freshly isolated cells, we next performed the patch clamp experiments on BK channels exogenously expressed on the cells that do not express BK channels endogenously. In these experiments, cells transected with BK $\alpha$ and $\beta 1$ subunits 
revealed a significant increase in BK channel current and greater NPo when cells were exposed to $10 \mu \mathrm{M}$ BPA. In contrast, cells with BK channel $\alpha$ subunits alone showed no significant increase in BK outward currents or NPo. Given that several steroid hormones activate BK channel via $\beta$ subunits (Valverde et al., 1999; Lovell et al., 2004; King et al., 2006), it is possible that xenoestrogens also may be associated with $\beta$ subunit dependent BK activation. These findings are important as they should serve as additional evidence that the xenoestrogen, BPA, activates BK channels and the role of BK $\beta$ subunits on steroid hormones and xenoestrogens induced BK activations. Non-genomic effect of BPA on BK channel is summarized in Fig. 5-1. 


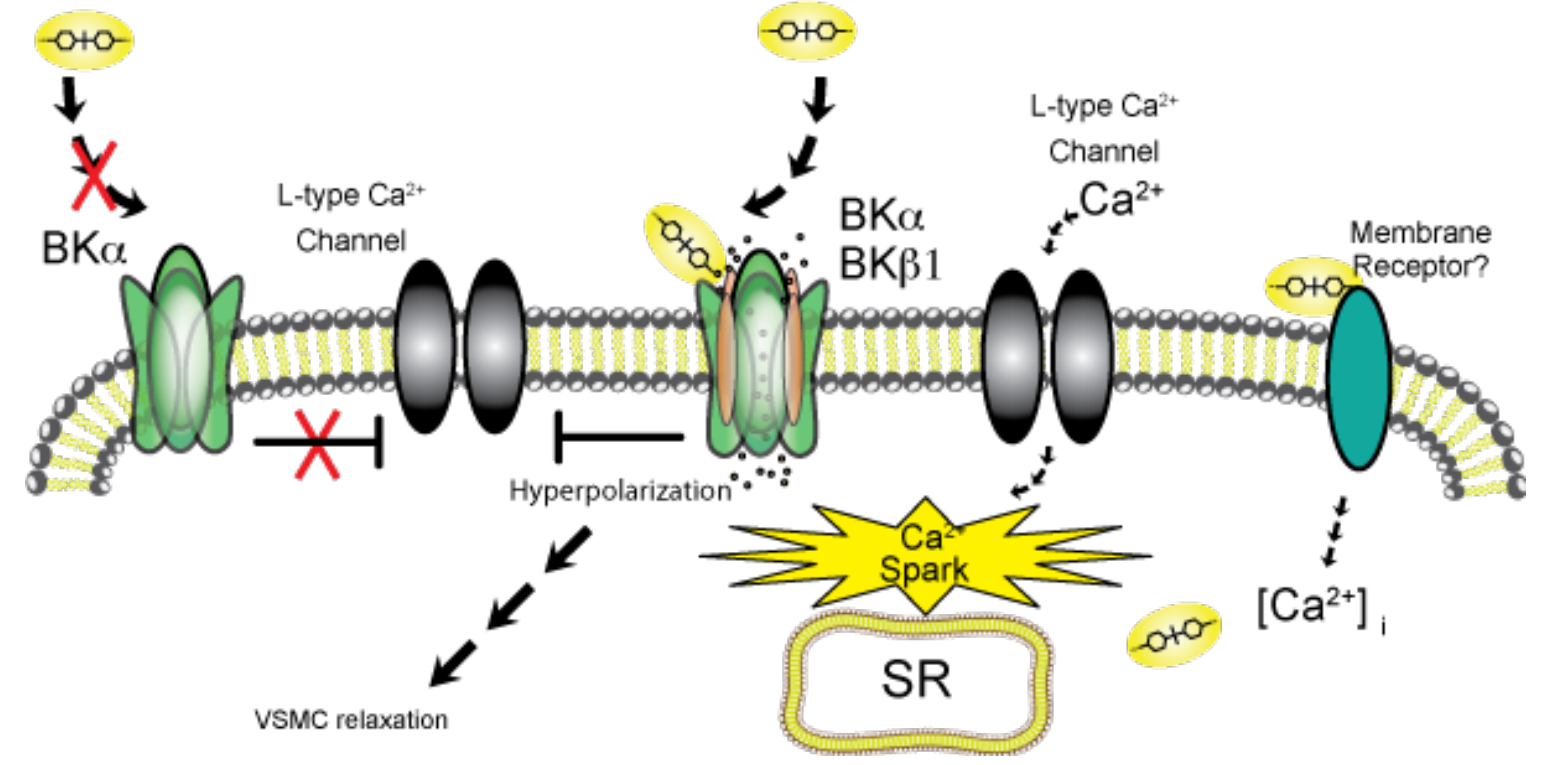

Figure 51 Non-genomic effect of BPA on vascular BK channel.

BPA can activate BK channel independent of changing intracellular $\mathrm{Ca}^{2+}$ levels.

BK $\beta 1$ subunits favors BPA induced BK channel activation. 
The effects of long-term exposure to BPA on BK channel expression were assessed on A7r5, rat aortic cell lines, and cultured rat aorta. In this part of the study (Chapter 4), we hypothesized that BPA would decrease BK channel expression through estrogen receptor dependent signaling. The principle behind this hypothesis was that $\mathrm{BK}$ channel gene expression and functional protein expression from uterine smooth muscle cells are known to be estrogen-sensitive. (Wang et al., 1998; Song et al., 1999; Benkusky et al., 2000; Holdiman et al., 2002; Eghbali et al., 2003; Korovkina et al., 2004). Given that BPA possesses estrogenic properties, we tested whether BPA altered BK channel expression in rat aorta. Our data indicated that BPA altered BK channel transcript from A7r5 cells and decreased protein expression levels in A7r5 cells and cultured rat aorta. The mechanisms of BPA induced decreased BK channel expression depended on classical estrogen receptor signaling, as confirmed by an estrogen receptor antagonist that inhibits BPA's effects on BK channels. Taken together, our data suggested that long term BPA exposure decreased BK channel expression via genomic mechanisms. The genomic effect of BPA on vascular BK channel expression is summarized in Fig. 5-2. 


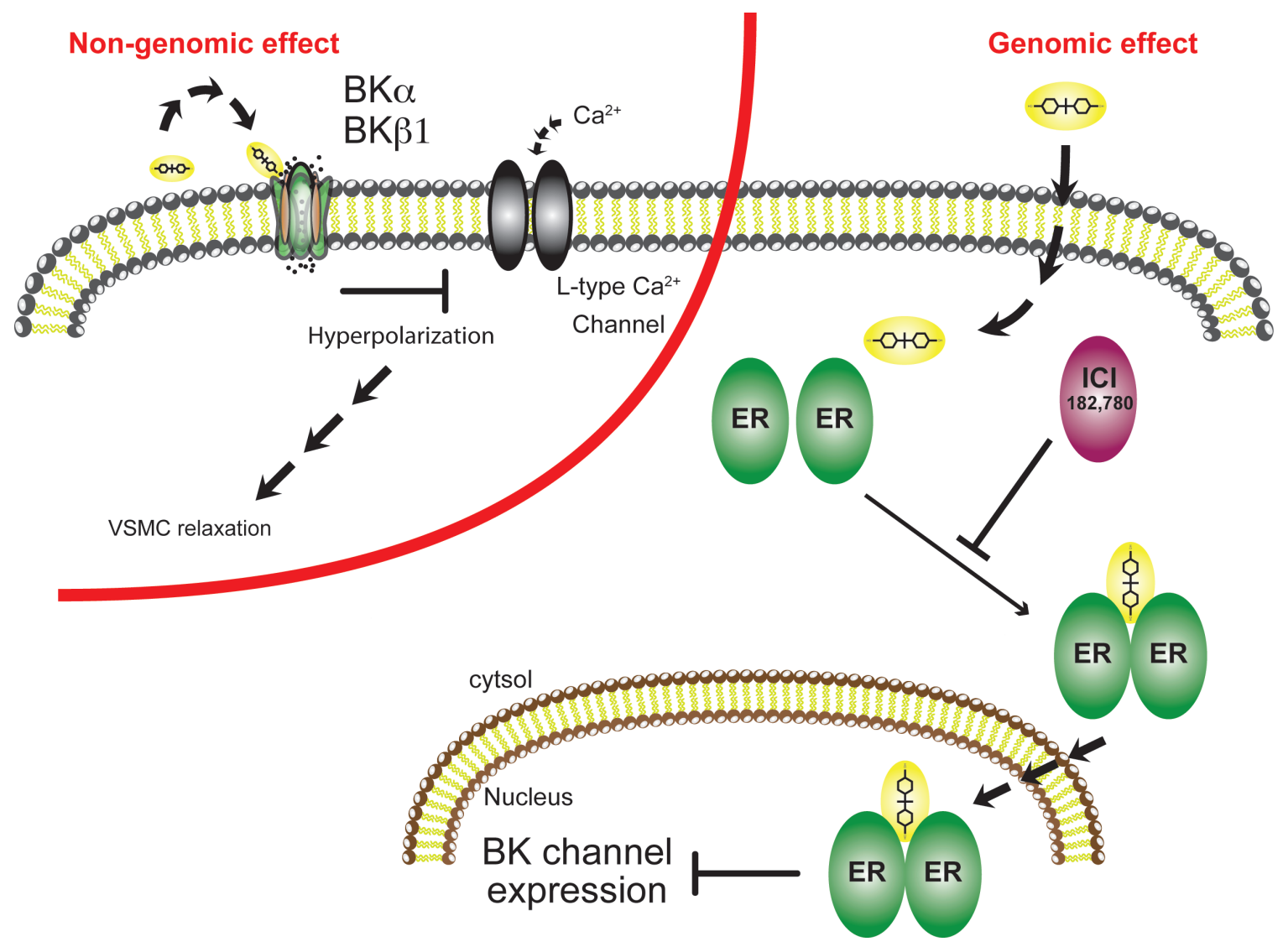

Figure 52 Genomic effect of BPA on vascular BK channel.

BPA can activate BK $\alpha \beta 1$ channels at the plasma membrane. Additionally, BPA can interact with ERs to regulate BK channel a subunit expression. ER antagonist, ICI 182, 780 can prevent the effect of BPA to reduce BK channel $\alpha$ subunit expression. 
It is important to mention some limitations of this study. In order to assess the genomic and nongenomic effects of BPA on the BK channel, multiple model cells were utilized. Specifically, nongenomic pharmacological properties of BPA were elucidated using cultured and native vascular smooth muscle cells, as well as cloned BK channels, including: cultured canine coronary smooth muscle cells, cultured human coronary artery smooth muscle cells, cloned bovine BK channels expressed in HEK 293 cells, and native canine coronary artery smooth muscle cells. The reason we used so many different cell types over time was basically due to comments from grant and manuscript reviewers (e.g., previous results were in canine cells, so reviewers asked us to establish a canine cell culture model). Further, we chose human coronary cells for relevance, but abandoned the model due to cost. We realize that having this number of model cells can be distracting; however, similar results from multiple cell types strengthened our conclusion that BPA activated BK channels through a non-genomic mechanism depending on the $\beta 1$ subunit. The genomic effects of BPA on BK channels were tested in A7r5 cells (a neonatal rat aortic cell line) and smooth muscle from tissue cultured rat aorta. Given that the expression of BK channel by estrogen is regulated in different ways based on species, we limited our model system to rats for the genomic studies. It is possible that the effect of BPA on BK channel expression may be different in other species. Although our study demonstrate that BPA decreased BK channel expression via ERs, it is possible that BPA may utilize other mechanisms in reducing BK channel expression (e.g., proteosomal degradation). Since the genomic and nongenomic mechanisms of BPA's effects 
on BK channel were elucidated in different models, a criticism could be that each mechanism is model-specific. Importantly, however, we demonstrated both genomic and non-genomic mechanisms of BPA in rat aorta, suggesting that the results can be generalized to other smooth muscle. Whether both genomic and non-genomic effects are relevant to human BPA exposure needs to be examined in future studies.

Given that BPA is detected in over $95 \%$ of the US population and similar findings have been reported world wide, there is little doubt that some level of BPA is in virtually everyone's system. One important question that needs to be addressed is whether the levels of BPA exposure to the general population are significant for cardiovascular disease. Table 1 was derived from a review study by Vandenberg LN et al (Vandenberg et al., 2007). The majority of epidemiological studies indicated geometric mean urinary BPA ranges from $1.12 \sim 27.3 \mathrm{ng} / \mathrm{ml}$. Based on these studies, the current consensus regarding human BPA exposure levels is in the parts per billion levels (vom Saal et al., 2007). Recent data of urinary BPA levels from US NHANES (2003/2004 and 2005/2006) are also within these ranges (2.6 ug/L (Calafat et al., 2008), 2.49 $\mathrm{ng} / \mathrm{ml}$, (Melzer et al., 2010)) and data from the European Prospective Investigation of Cancer (EPIC) were median urinary BPA $1.3 \mathrm{ng} / \mathrm{ml}$ (Melzer et al., 2012).

Interestingly, there is a BPA pharmacokinetic study on human subjects that directly measured both blood and urinary BPA levels (Volkel et al., 2002). The study demonstrated that peak blood $\mathrm{d}_{16}$-BPA-glucuronide was approximately 
6-fold higher than urinary $d_{16}$-BPA-glucuronide after consuming radiolabeled BPA (5 mg/person). Furthermore, local BPA concentration could also be higher because BPA can be stored in adipose tissue and it has been suggested that it leaches from adipose tissue (Nunez et al., 2001; Fernandez et al., 2007b). Thus, it is difficult to assess how accurately these urinary BPA levels reflected blood BPA levels. On the other hand, in factory workers who are exposed BPA because of their occupation, median urinary BPA concentrations were $84.6 \mu \mathrm{g} / \mathrm{g}$ $\mathrm{Cr}$ (He et al., 2009), $57.9 \mu \mathrm{g} / \mathrm{g} \mathrm{Cr}$ (Li et al., 2010) and this population had over 20-30 times more exposure compared to the general population $(2.6 \mu \mathrm{g} / \mathrm{g} \mathrm{Cr}$, US NHANES) (Calafat et al., 2008) 


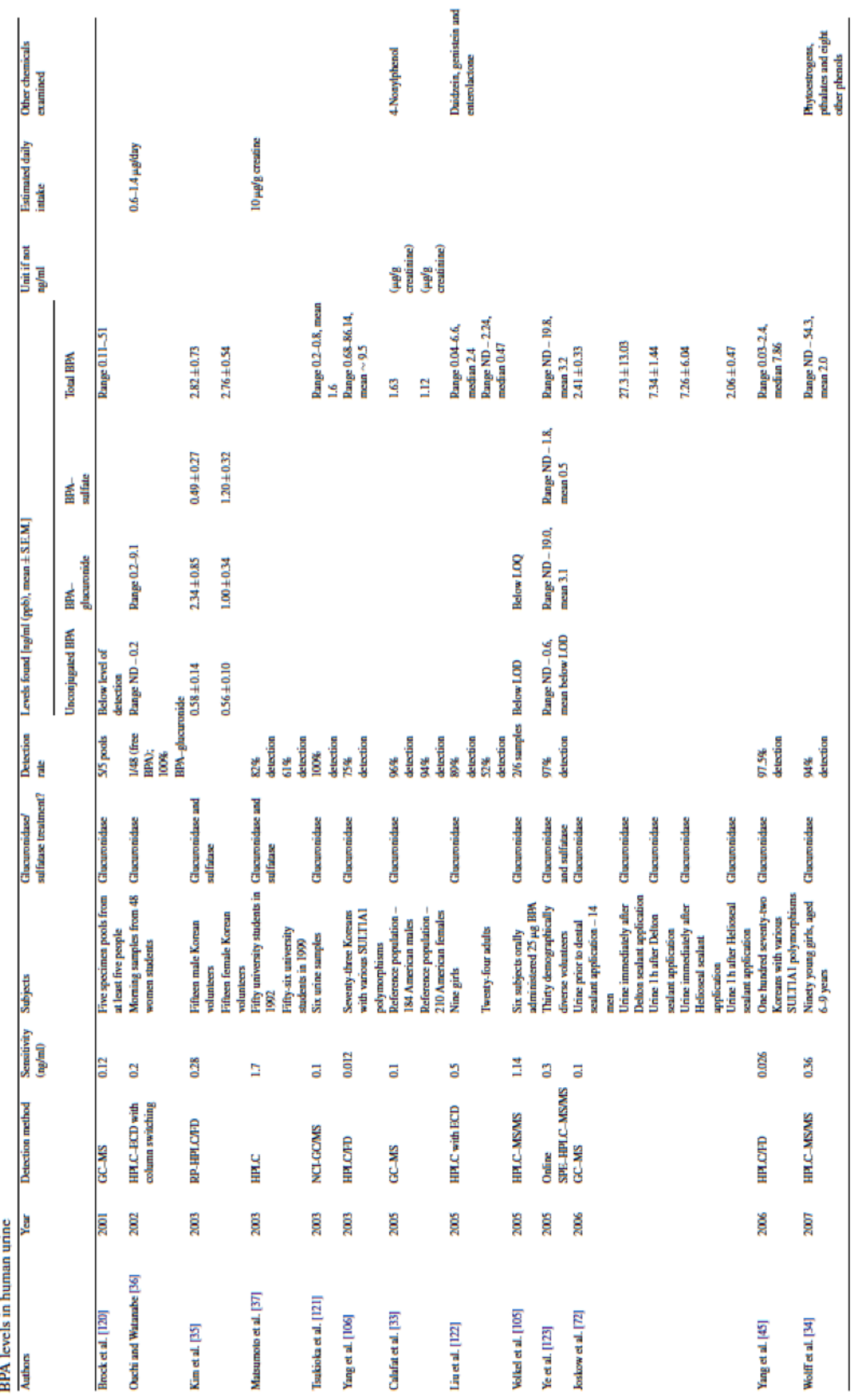

Table 51 Studies measured urinary BPA 
Based on these studies regarding the level of human BPA exposure, our studies using a micro molar range of concentration were applicable to the occupationally exposed populations, but probably not to the general population. Similar to our study, the micro molar range of BPA exposures has been shown to decrease atrial contractility in rat heart due to the alteration of NO-cGMP signaling (Pant et al., 2011). Our studies examined only BK channels based on the estrogen sensitive properties of BK channels, however, it is possible that other proteins may be particularly susceptible to BPA, and may alter cardiovascular function. Indeed, recent studies indicated that exposure levels relevant to the general population, in the nano molar range of BPA, have been shown to alter $\mathrm{Ca}^{2+}$ handling in cardiac myocytes, promoting arrhythmic events in rodent hearts (Yan et al., 2011; Belcher et al., 2012). In order to address the link between BPA exposure and cardiovascular events, further investigation is required to answer the molecular mechanisms of BPA's effect.

Whether these BPA-induced changes in vascular BK channel function and expression directly link to the association of BPA exposure and cardiovascular diseases are currently unclear, our data are the first evidence to describe that BPA modulates vascular BK channel function and expression via genomic and non-genomic mechanisms. Further studies are needed to determine if BPA affects other ion channels that have roles in regulating vascular function.

\section{Future directions:}


Multiple aspects regarding the mechanism of action for BPA toxicology will be opened to scientists in this field. First, it would be interesting to determine whether there is a critical time or point of exposure that is associated with the development of cardiovascular disease. Does prenatal exposure eventually lead to cardiovascular disease in later life? How much exposure and over what time period is required to see the development of cardiovascular disease? Does in vivo exposure to BPA reduce BK channel expression in VSMC and alter vascular reactivity? Second, is it possible that BPA modulates the function and expression of other ion channels? Since steroid hormones alter $\mathrm{Ca}^{2+}$ channel expression and function (Er et al., 2007; Ullrich et al., 2007; Sarkar et al., 2008) it will be interesting to determine whether BPA possesses similar properties. Lastly, are there population-specific effects of BPA? Are females more susceptible to BPAassociated disease due to the importance of estrogen signaling? Do endogenous estrogen levels influence the toxicological effects of BPA? Additionally, since BPA is lipophilic and accumulated in adipose tissue, (Fernandez et al., 2007a), is the obese population affected by a higher level of BPA? These interesting studies will require an initial characterization and a certain level of understanding of BPA's interaction with other molecules. Our study provided novel evidence that BPA modulates vascular BK channel via a non-genomic and genomic mechanisms. 


\section{References}

Ahluwalia J, Tinker A, Clapp LH, Duchen MR, Abramov AY, Pope S, Nobles M \& Segal AW. (2004). The large-conductance Ca2+-activated $\mathrm{K}+$ channel is essential for innate immunity. Nature 427, 853-858.

Belcher SM, Chen Y, Yan S \& Wang HS. (2012). Rapid estrogen receptormediated mechanisms determine the sexually dimorphic sensitivity of ventricular myocytes to 17 beta-estradiol and the environmental endocrine disruptor bisphenol A. Endocrinology 153, 712-720.

Benkusky NA, Fergus DJ, Zucchero TM \& England SK. (2000). Regulation of the $\mathrm{Ca} 2+-$ sensitive domains of the maxi-K channel in the mouse myometrium during gestation. The Journal of biological chemistry 275, 27712-27719.

Calafat AM, Ye X, Wong LY, Reidy JA \& Needham LL. (2008). Exposure of the U.S. population to bisphenol A and 4-tertiary-octylphenol: 2003-2004. Environmental health perspectives 116, 39-44.

Eghbali M, Toro L \& Stefani E. (2003). Diminished surface clustering and increased perinuclear accumulation of large conductance $\mathrm{Ca} 2+$-activated $\mathrm{K}+$ channel in mouse myometrium with pregnancy. The Journal of biological chemistry 278, 45311-45317.

Er F, Michels G, Brandt MC, Khan I, Haase H, Eicks M, Lindner M \& Hoppe UC. (2007). Impact of testosterone on cardiac L-type calcium channels and $\mathrm{Ca2+}$ sparks: acute actions antagonize chronic effects. Cell Calcium 41, 467-477.

Fernandez MF, Arrebola JP, Taoufiki J, Navalon A, Ballesteros O, Pulgar R, Vilchez JL \& Olea N. (2007a). Bisphenol-A and chlorinated derivatives in adipose tissue of women. Reprod Toxicol 24, 259-264.

Fernandez MF, Arrebola JP, Taoufiki J, Navalon A, Ballesteros O, Pulgar R, Vilchez JL \& Olea N. (2007b). Bisphenol-A and chlorinated derivatives in adipose tissue of women. Reproductive toxicology 24, 259-264.

Grimm PR, Irsik DL, Settles DC, Holtzclaw JD \& Sansom SC. (2009). Hypertension of Kcnmb1-/- is linked to deficient $\mathrm{K}$ secretion and aldosteronism. Proc Natl Acad Sci U S A 106, 11800-11805.

He Y, Miao M, Wu C, Yuan W, Gao E, Zhou Z \& Li DK. (2009). Occupational exposure levels of bisphenol A among Chinese workers. J Occup Health $51,432-436$. 
Holdiman AJ, Fergus DJ \& England SK. (2002). 17beta-Estradiol upregulates distinct maxi-K channel transcripts in mouse uterus. Mol Cell Endocrinol 192, 1-6.

King JT, Lovell PV, Rishniw M, Kotlikoff MI, Zeeman ML \& McCobb DP. (2006). Beta2 and beta4 subunits of BK channels confer differential sensitivity to acute modulation by steroid hormones. J Neurophysio/ 95, 2878-2888.

Korovkina VP, Brainard AM, Ismail P, Schmidt TJ \& England SK. (2004). Estradiol binding to maxi-K channels induces their down-regulation via proteasomal degradation. The Journal of biological chemistry 279, $1217-$ 1223.

Li D, Zhou Z, Qing D, He Y, Wu T, Miao M, Wang J, Weng X, Ferber JR, Herrinton LJ, Zhu Q, Gao E, Checkoway H \& Yuan W. (2010). Occupational exposure to bisphenol-A (BPA) and the risk of self-reported male sexual dysfunction. Hum Reprod 25, 519-527.

Lovell PV, King JT \& McCobb DP. (2004). Acute modulation of adrenal chromaffin cell BK channel gating and cell excitability by glucocorticoids. $J$ Neurophysiol 91, 561-570.

Melzer D, Osborne NJ, Henley WE, Cipelli R, Young A, Money C, McCormack P, Luben R, Khaw KT, Wareham NJ \& Galloway TS. (2012). Urinary Bisphenol: A Concentration and Risk of Future Coronary Artery Disease in Apparently Healthy Men and Women. Circulation.

Melzer D, Rice NE, Lewis C, Henley WE \& Galloway TS. (2010). Association of urinary bisphenol a concentration with heart disease: evidence from NHANES 2003/06. PLoS One 5, e8673.

Meredith AL, Wiler SW, Miller BH, Takahashi JS, Fodor AA, Ruby NF \& Aldrich RW. (2006). BK calcium-activated potassium channels regulate circadian behavioral rhythms and pacemaker output. Nat Neurosci 9, 1041-1049.

Nunez AA, Kannan K, Giesy JP, Fang J \& Clemens LG. (2001). Effects of bisphenol $A$ on energy balance and accumulation in brown adipose tissue in rats. Chemosphere 42, 917-922.

Pant J, Ranjan P \& Deshpande SB. (2011). Bisphenol A decreases atrial contractility involving NO-dependent G-cyclase signaling pathway. J Appl Toxicol 31, 698-702.

Pyott SJ, Meredith AL, Fodor AA, Vazquez AE, Yamoah EN \& Aldrich RW. (2007). Cochlear function in mice lacking the BK channel alpha, beta1, or beta4 subunits. J Biol Chem 282, 3312-3324. 
Ruttiger L, Sausbier M, Zimmermann U, Winter H, Braig C, Engel J, Knirsch M, Arntz C, Langer P, Hirt B, Muller M, Kopschall I, Pfister M, Munkner S, Rohbock K, Pfaff I, Rusch A, Ruth P \& Knipper M. (2004). Deletion of the $\mathrm{Ca} 2+$-activated potassium (BK) alpha-subunit but not the BKbeta1-subunit leads to progressive hearing loss. Proc Natl Acad Sci U S A 101, 1292212927.

Sarkar SN, Huang RQ, Logan SM, Yi KD, Dillon GH \& Simpkins JW. (2008). Estrogens directly potentiate neuronal L-type $\mathrm{Ca} 2+$ channels. Proc Natl Acad Sci U S A 105, 15148-15153.

Song M, Zhu N, Olcese R, Barila B, Toro L \& Stefani E. (1999). Hormonal control of protein expression and mRNA levels of the MaxiK channel alpha subunit in myometrium. FEBS Lett 460, 427-432.

Ullrich ND, Koschak A \& MacLeod KT. (2007). Oestrogen directly inhibits the cardiovascular L-type Ca2+ channel Cav1.2. Biochem Biophys Res Commun 361, 522-527.

Valverde MA, Rojas P, Amigo J, Cosmelli D, Orio P, Bahamonde MI, Mann GE, Vergara C \& Latorre R. (1999). Acute activation of Maxi-K channels (hSlo) by estradiol binding to the beta subunit. Science 285, 1929-1931.

Vandenberg LN, Hauser R, Marcus M, Olea N \& Welshons WV. (2007). Human exposure to bisphenol A (BPA). Reproductive toxicology 24, 139-177.

Volkel W, Colnot T, Csanady GA, Filser JG \& Dekant W. (2002). Metabolism and kinetics of bisphenol a in humans at low doses following oral administration. Chem Res Toxicol 15, 1281-1287.

vom Saal FS, Akingbemi BT, Belcher SM, Birnbaum LS, Crain DA, Eriksen M, Farabollini F, Guillette LJ, Jr., Hauser R, Heindel JJ, Ho SM, Hunt PA, Iguchi T, Jobling S, Kanno J, Keri RA, Knudsen KE, Laufer H, LeBlanc GA, Marcus M, McLachlan JA, Myers JP, Nadal A, Newbold RR, Olea N, Prins GS, Richter CA, Rubin BS, Sonnenschein C, Soto AM, Talsness CE, Vandenbergh JG, Vandenberg LN, Walser-Kuntz DR, Watson CS, Welshons WV, Wetherill Y \& Zoeller RT. (2007). Chapel Hill bisphenol A expert panel consensus statement: integration of mechanisms, effects in animals and potential to impact human health at current levels of exposure. Reproductive toxicology 24, 131-138.

Wang SY, Yoshino M, Sui JL, Wakui M, Kao PN \& Kao CY. (1998). Potassium currents in freshly dissociated uterine myocytes from nonpregnant and late-pregnant rats. The Journal of general physiology 112, 737-756. 
Yan S, Chen Y, Dong M, Song W, Belcher SM \& Wang HS. (2011). Bisphenol A and 17 beta-estradiol promote arrhythmia in the female heart via alteration of calcium handling. PLoS One 6, e25455. 